\title{
Meeresalgen von Helgoland: Ergänzung
}

\author{
P. Kornmann \& P.-H. Sahling \\ Biologische Anstalt Helgoland (Meeresstation); D-2192 Helgoland, \\ Bundesrepublik Deutschland
}

\begin{abstract}
Marine algae of Helgoland: Supplementation. Complementary to a previous publication (Kornmann \& Sahling, 1977), this investigation deals mainly with microscopic algae occurring in the rocky littoral of Helgoland island (North Sea). Based on the results obtained from cultivation experiments, the heterogeneous Ulvella-complex of Dangeard has been rearranged and partly included in a new genus Stromatella, and Planophila respectively. The life history of Chlorocystis cohnii proved to be heteromorphic, the zygotes developing into a Codiolum-sporophyte. Also in Halochlorococcum marinum, some of the biflagellate swarmers give rise to Codiolum-like cells. Chlorocystis and Halochlorococcum, up to now members of the Chlorococcales, are incorporated into the new Codiolophycean order, Chlorocystidales. Three new Halochlorococcum species are described, the epiphytic "Chlorochytrium" moorei also being combined with this genus. Supplementary observations on some crustose red algae from transparent substrates are included in this study, as well as findings of some species not previously reported for the Helgoland area.
\end{abstract}

\section{EINLEITUNG}

Die vorliegende Ergänzung der "Meeresalgen von Helgoland" ist anderer Art als der 1977 erschienene Teil, in dem hauptsächlich die makroskopischen Algen dargestellt sind. Das Buch sollte in erster Linie den Teilnehmern an meeresbiologischen Kursen als Orientierungshilfe dienen, die Ergänzung wendet sich hauptsächlich an den fachlich interessierten Leser. Die meisten der hier behandelten Formen sind epi- oder endophytisch lebende sowie aus Kulturen mit bewachsenem Substrat - Steinen, Muschelschalen oder Glasscherben - isolierte Grünalgen. Dabei wurden mehrere Arten wiedergefunden, die Dangeard (1965a-d) mit ähnlicher Methodik entdeckt und beschrieben hatte. Wahrscheinlich sind diese bisher nur von den französischen Küsten bekanntgewordenen Kleinalgen in europäischen Gewässern weit verbreitet.

Nach Form und Inhalt können auch drei Arbeiten als Ergänzungen zur Algenflora von Helgoland gelten, die inzwischen erschienen sind. Die. Gattung Blidingia wurde ausführlich bearbeitet (Kornmann \& Sahling, 1978). Scinaia und Helminthocladia, seit vielen Jahrzehnten nicht mehr am Standort gefunden, sind als kalkbohrende Mikrothalli vorhanden und wurden aus diesen kultiviert (Kornmann \& Sahling, 1980a). Ostreobium quekettii, eine kalkbohrende Grünalge, vermehrt sich mit ungeschlechtlichen Zoosporen zu gleichartigen Generationen (Kornmann \& Sahling, 1980b). 
Besonderes Interesse verdienen die an ihrem Standort auf durchsichtigem Substrat gesammelten krustenförmigen Algen; sie konnten in ihrer natürlichen Erscheinungsform untersucht und mit der im Laboratorium erzielten Nachkommenschaft verglichen werden. Erfahrungsgemäß entspricht ihr Habitus nur in gut wachsenden Kulturen bis zur Fertilisierung dem Naturmaterial; ältere Kulturen sind nicht mehr vergleichbar. Alle Kulturen wurden einheitlich unter den als zweckmäßig erkannten Bedingungen gehalten. Als Medium diente Nährlösung nach Provasoli mit einem Zusatz von Erdabkochung, die Temperatur betrug $15^{\circ} \mathrm{C}$, die tägliche Beleuchtungsdauer 14 Stunden, die Lichtstärke schwankte je nach der Entfernung von der Leuchtstoffröhre zwischen 1100 und 1900 Lux. Solche Schwankungen fallen bei den morphologisch-entwicklungsgeschichtlich ausgerichteten Versuchen überhaupt nicht ins Gewicht. Die meisten der in dieser Studie untersuchten Formen konnten in allen Stadien ihrer Entwicklung beobachtet und gekennzeichnet werden; in vielen Fällen lassen Serienaufnahmen den Leser gleichsam an den Beobachtungen teilnehmen.

\section{SYSTEMATISCHE ÜBERSICHT}

Die in dieser Arbeit gewonnenen Ergebnisse haben zu einigen taxonomischen und systematischen Änderungen geführt. Die neue Gattung Stromatella nimmt zwei der von Dangeard (1965b) zu Ulvella gestellten Arten auf, eine weitere wurde der Gattung Planophila zugeteilt. Chlorocystis Reinh. und Halochlorococcum Dangeard haben einen Entwicklungszyklus mit einem Codiolum-Stadium. Auf diesen heteromorphen Generationswechsel gründet sich die neue Ordnung Chlorocystidales der Codiolophyceae.

Die Chlorophyta werden nach dem von Ettl (1981) vorgeschlagenen System in sieben Klassen gegliedert; neu ist die Klasse Chlamydophyceae. Durch die Eliminierung von Chlorocystis und Halochlorococcum erhalten die Chlorococcales ein einheitliches Gepräge, so daß sich diese Ordnung den Chlamydophyceae ohne Einschränkung einfügt.

\section{Chrysophyta}

CHRYSOPHYCEAE

SARCINOCHRYSIDALES Chrysomeridaceae Giraudyopsis stellifer

\section{Chlorophyta}

\section{CHLAMYDOPHYCEAE}

CHLAMYDOMONADALES Chlamydomonadaceae

Chlamydomonas spec.

\section{CHLOROPHYCEAE}


CHAETOPHORALES

CHLOROCYSTIDALES

SIPHONOCLADALES

ECTOCARPALES

CRYPTONEMIALES

CERAMIALES
(Die Familiensystematik ist noch zu wenig geklärt.)

Stromatella monostromatica 10

Stromatella papillosa

Ulvella lens

Pringsheimiella scutata

19

Syncoryne reinkei

\section{CODIOLOPHYCEAE}

Chlorocystidaceae

Chlorocystis cohnii

24

Halochlorococcum marinum $\quad 30$

Halochlorococcum tenuis $\quad 37$

Halochlorococcum operculatum 39

Halochlorococcum dilatatum 40

Halochlorococcum moorei $\quad 42$

\section{BRYOPSIDOPHYCEAE}

Cladophoraceae "Characium hagmeierianum"

46

\section{Phaeophyta}

PHAEOPHYCEAE

Myrionemataceae

Myrionema strangulans

46

Microspongium globosum

\section{Rhodophyta}

\section{FLORIDEOPHYCEAE}

Corallinaceae
Peyssonneliaceae
Ceramiaceae

Melobesia membranacea

50

Lithophyllum orbiculatum

56

Rhodophysema elegans

56

Callithamnion byssoides

\section{CHRYSOPHYCEAE}

\section{Giraudyopsis stellifer Dangeard}

Helgoland ist ein neuer Fundort dieser bisher selten registrierten, aus Rohkulturen von verschiedenen Algen isolierten fädigen Chrysophycee. Dangeard (1965a, d) fand sie in Colpomenia-Kulturen von Guéthary (Basses-Pyrénées); er hielt sie für eine Braunalge von unsicherer systematischer Stellung. Etwa gleichzeitig wurde Giraudyopsis von 

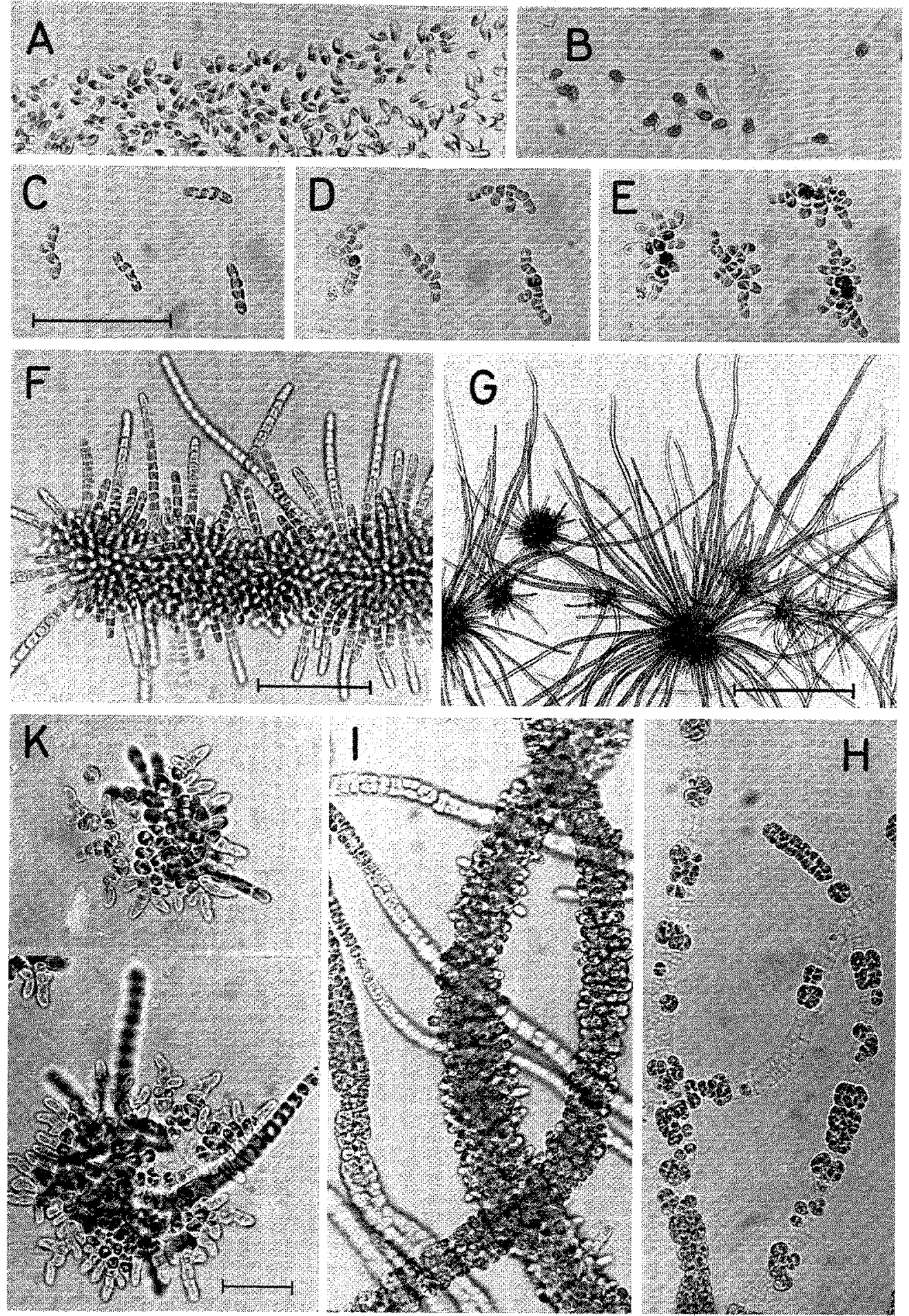

Abb. 1. Giraudyopsis stellifer. A, B Schwärmersaum, über Osmiumdampf fixiert und mit Hämatoxylin nach Ehrich gefärbt. C-E Dieselbe Gruppe von Keimlingen im Alter von 2, 3 und 4 Tagen. $F$, $G$ Aus einer 6 bzw. 11 Tage alten Kultur. H Weitgehend ausgeschwärmte Fäden. I Aus nicht entleerten Sporangien auswachsende Keimlinge. $\mathrm{K}$ Zwei fertile Basalscheiben mit entleerten Sporangien. Maßstrecken: $A, B, K=20 \mu \mathrm{m} ; C-E=50 \mu \mathrm{m} ; \mathrm{F}, \mathrm{H}, \mathrm{I}=50 \mu \mathrm{m} ; \mathrm{G}=200 \mu \mathrm{m}$ 
Loiseaux (1967) in Material von Roscoff gefunden und eingehend untersucht. Die Feinstruktur und der Bau der Schwärmer wiesen sie als Chrysophycee aus. Pedersen (1980) berichtete über das Vorkommen von Giraudyopsis stellifer bei der Isle of Man.

Gayral \& Billard (1977) vereinigen in der Ordnung Sarcinochrysidales alle Chrysophyceen, deren Schwärmer zwei seitliche ungleiche Geißeln tragen, also den Schwärmern der meisten Phaeophyceen ähnlich sind. Die Familie Chrysomeridaceae umfaßt die fädigen Formen.

Wahrscheinlich ist Giraudyopsis weiter verbreitet, als die drei jetzt bekannten Fundorte vermuten lassen. Bei Helgoland wurde sie von 1978 bis 1982 in mehreren Rohkulturen gefunden, von Steinen oder Muschelschalen aus Gezeitentümpeln und aus dem Sublitoral, ebenso aus einer von einem Ponton entnommenen Algenprobe.

Aus den negativ phototaktischen Schwärmern (Abb. 1 A, B) entsteht zunächst ein fädig verzweigter kriechender Thallus, dessen mittlere Zellen sich zu einer Scheibe zusammenschließen. Schon nach vier Tagen beginnt die Bildung aufrechter Fäden, die sich zwei Tage später zahlreich auf den Scheiben erheben (Abb. 1 C-F). Sie sind zunächst monosiphon, werden aber schon bald in kleine Zellen aufgeteilt, in denen jeweils ein Schwärmer entsteht. Abbildung $1 \mathrm{G}$ zeigt 11 Tage alte büschelige Pflanzen, ihre längsten Fäden sind mehrreihig und fertil. Fertile und teilweise ausgeschwärmte Fäden erinnern an plurilokuläre Sporangien $(\mathrm{H}, \mathrm{I})$. Nur in lockeren, mit wenigen Schwärmern angelegten Kulturen erhält man schöne Büschel mit über $1 \mathrm{~mm}$ langen Fäden. Die Pflanzen werden ohne Erneuerung der Nährlösung schnell überständig und entleeren keine Schwärmer mehr; die Fäden sind dann dicht mit den aus den Sporangien wachsenden Keimlingen besetzt (I).

Auch die Zellen der Basalscheiben können fertil werden. Darauf ließ die Beobachtung schließen, daß zuweilen schon in Kulturen ohne fertile aufrechte Fäden zahlreiche Keimlinge vorhanden sind. Fertile Scheiben mit reifen und entleerten Sporangien zeigt unsere Abbildung bei $\mathrm{K}$.

\section{CHLAMYDOPHYCEAE}

\section{Chlamydomonas spec.}

Eine Chlamydomonas-Art ist bisher nur einmal in unseren Kulturen aufgetreten. Ausgangsmaterial war eine am 23. Juli 1981 in Seewasser ausgelegte alte Austernschale. Eine nach einer Stunde entnommene Probe phototaktisch angesammelter Schwärmer wurde in einen "schwimmenden Tropfen" gebracht, ein auf der Oberfläche der Kulturflüssigkeit schwimmendes Deckglas mit einem Tropfen Nährlösung. Neben Algenkeimlingen entwickelten sich einige Exemplare einer Chlamydomonas-Art. Sie vermehrten sich rasch, und ihre Schwärmer konnten leicht von den Keimlingen getrennt werden.

Im "schwimmenden Tropfen" mit wenigen Schwärmern angelegte Kulturen zeigten schon sehr bald das ungewöhnliche Verhalten dieses Organismus: die negativ phototaktischen Schwärmer setzten sich auf dem Deckglas fest. Im allgemeinen haften sie bis zur Fertilisierung, sie können sich aber auch vorübergehend vom Substrat lösen. Die Zellen sitzen so fest auf ihrer Unterlage, daß sie auch durch starkes Schütteln in einem Röhrenglas nicht abgespült werden. 

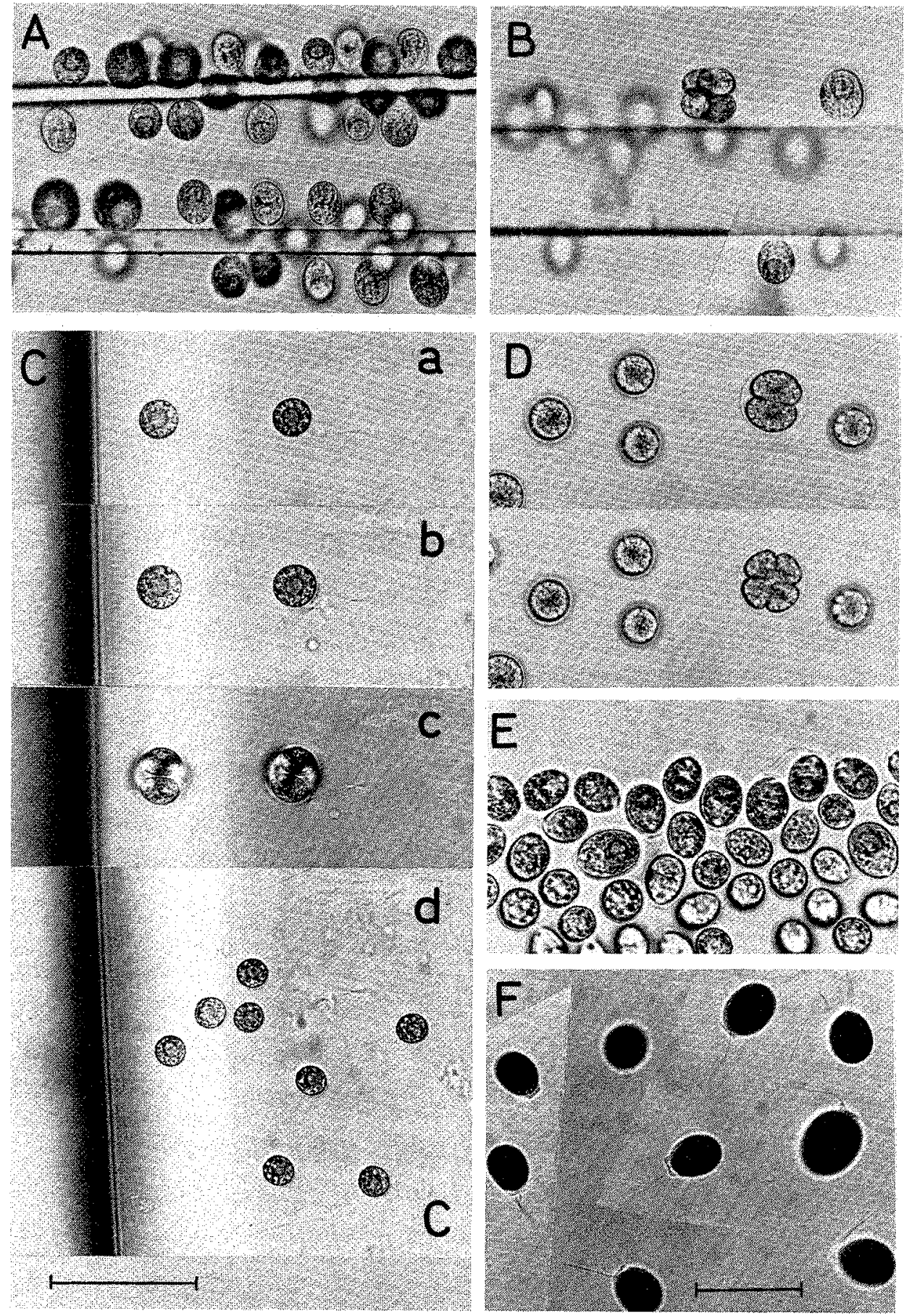

Abb. 2. Chlamydomonas spec. A, B auf Glaswolle bzw. einem Glasfaden festsitzende Zellen. C Stadien aus dem zweitägigen Entwicklungszyklus, weitere Erläuterung im Text. D Schwärmerbildung, im Abstand von $1^{1 / 3}$ Stunden aufgenommen. E Am Tropfenrand angesammelte Schwärmer, über Osmiumdampf fixiert. F Schwärmer nach Jodfärbung. Maßstrecken: $A-D=50 \mu m ; E-F$

$$
=30 \mu \mathrm{m}
$$


In Glas- oder Plastikschalen kultiviert, besiedeln die rasch sich vermehrenden Zellen die hintere Schalenwand. Mit zunehmender Dichte finden die meisten Schwärmer keine Ansatzfläche mehr und bleiben zwangsläufig beweglich. Dreht man eine solche Kultur um $180^{\circ}$, so bewegt sich eine grüne Wolke dicht über dem Boden zur gegenüberliegenden Wandung. Viele setzen sich auf diesem Wege auf dem Schalenboden fest, sehr gerne auch an den Kanten von Deckglassplittern oder an Fäden aus Glaswolle (Abb. 2 A, B).

Wegen mangelnder Vertrautheit mit der Gattung und fehlenden technischen Voraussetzungen sehen wir von einer taxonomischen Beschreibung dieser vielleicht neuen Chlamydomonas-Art ab. Die Zellen sitzen mit einer breiten flachen Papille auf dem Substrat (Abb. 2 A, E, F); sie sind gedrungen ellipsoidisch und im Querschnitt drehrund; die beiden etwas mehr als körperlangen Geißeln sind noch bei Beginn der Schwärmerbildung in langsam schlagender Bewegung. Die Zellen sind je nach Alter 14-20 $\mu \mathrm{m}$ lang, die entsprechenden Breiten liegen zwischen 10-16 $\mu \mathrm{m}$. Der Protoplast liegt der zarten Zellwand eng an. Über die Struktur des Chromatophors war keine völlige Klarheit zu gewinnen; wahrscheinlich hat er acht Rippen, in die Stromastärke eingelagert ist. Etwa in der Mitte der Zelle befindet sich der leuchtend rote elliptische Augenfleck. Ein großes Pyrenoid liegt median im verdickten Boden des Chromatophors. An stark gepreßten Zellen erkennt man zwei kleine Vakuolen am Vorderende. Vor der Fertilisierung werden die Zellen fast kugelig; der Protoplast hebt sich von der Zellmembran $\mathrm{ab}$, und in zweimaligem Teilungsschritt entstehen vier Zoosporen. Das reife Sporangium ist nahezu kugelig und 20-22 $\mu \mathrm{m}$ dick.

Die festsitzende Lebensweise ermöglicht es, Wachstum und Generationsdauer dieser Chlamydomonas-Art messend zu verfolgen (Abb. $2 \mathrm{C}$ ). Die beiden für eine Photoserie ausgewählten Zellen waren bei Beginn der Beobachtung um 10.00 Uhr (a) etwa einen Tag alt und $12 \mu \mathrm{m}$ dick. Sie vergrößerten ihren Durchmesser bis $16.10 \mathrm{Uhr}$ (b) auf $15 \mu \mathrm{m}$. Während der Dunkelperiode von 21.00 bis $7.00 \mathrm{Uhr}$ erfolgte die Schwärmerbildung: die Aufnahme um 8.45 Uhr (c) zeigt zwei reife Sporangien. Die Schwärmer traten noch am Vormittag aus und setzten sich ganz in der Nähe der Sporangien fest (d). Gerade zur Ruhe gekommen, waren sie $10 \mu \mathrm{m}$ dick. Dieser Entwicklungsablauf wurde mehrfach auch in Versuchen mit Einzelschwärmern im "schwimmenden Tropfen" bestätigt. Mit großer Regelmäßigkeit folgten die Generationen bei den gegebenen Versuchsbedingungen $-15^{\circ} \mathrm{C}, 14$ Stunden Lichtgenuß von etwa $1200 \mathrm{Lux}$ - einander im Rhythmus von zwei Tagen. In älteren Kulturen findet die Schwärmerbildung auch unabhängig von der Lichtperiode statt (D).

Die hier dargestellte marine Chlamydomonas-Art gleicht in der Lebensweise Chl. olifani Korshikov (1932), einer im Süßwasser epizootisch auf dem Panzer eines Rädertiers, Brachionus angularis (Loricata), lebenden Art.

\section{CHLOROPHYCEAE}

\section{Planophila microcystis (Dangeard) comb. nov.}

Basionym: Ulvella microcystis Dangeard, 1965b, p. 47, pl. I, 1-7, pl. III, 2

Diese von Dangeard (1965b) als Ulvella microcystis beschriebene Grünalge trat in einer Rohkultur mit einer alten Austernschale aus einem Gezeitentümpel im Bereich der Niedrigwasserlinie auf. Die Entstehungsgeschichte des scheibenförmigen Thallus und 




Abb. 3. Planophila microcystis, A Entstehung des scheibenformigen Thallus während sieben Tagen. B Fertile Scheiben. C Zoosporen vom Rand eines Tropfens, über Osmiumdampf fixiert. D G Gruppenweise zur Ruhe gekommene Zoosporen schließen sich während 3 Tagen zu einer polygonalen Zellfläche zusammen. Mabstrecken: $\mathrm{A}, \mathrm{D}-\mathrm{G}=50 \mu \mathrm{m} ; \mathrm{B}, \mathrm{C}=50 \mu \mathrm{m}$ 
seine kleinen eckigen Zellen unterscheiden die Alge klar von Ulvella und weisen ihr den Platz bei den Chlorosarcinales zu. Die einzige Gattung der Chlorosarcinaceen mit viergeißeligen Zoosporen ist Planophila Gemeck (1907), alle anderen haben zweigeißelige Schwärmer. Aus der ursprünglichen Beschreibung läßt sich keine rechte Vorstellung von dieser Gattung gewinnen, sie wurde aber von Bourrelly (1966, p. 267) gut gekennzeichnet. Die bisher bekanntgewordenen Arten stammen aus Erdproben.

Dangeard hebt die Kleinheit der Zellen sowie ihre sehr regelmäßige Teilung und Anordnung in den jungen einschichtigen Scheiben als besonders charakteristisch hervor; durch diese Merkmale unterscheidet sie sich klar von den frühen Entwicklungsstadien seiner anderen "Ulvella"-Arten. Die Lebensgeschichte von Planophila microcystis ist in einer täglichen Folge von Aufnahmen während sieben Tagen dargestellt (Abb. 3 A). Der Thallus besteht aus gleichartigen Zellen, die nach jeder Teilung durch ihre gemeinsame Wand miteinander in Verbindung bleiben und sich zu einem pseudoparenchymatischen Lager zusammenschließen. Die zentralen Zellen platten sich polygonal gegeneinander $\mathrm{ab}$, und nur die Randzellen sind peripher abgerundet. Bis zum 5. Tage vermehrt sich die Zahl der Zellen in Zweierpotenzen. In der sechs Tage alten Kultur ist eine Differenzierung eingetreten: Die zentralen Zellen können sich nach der Teilung nicht mehr in der Fläche einordnen, sie weichen nach oben aus, werden kugelig und einzelne schon fertil. In der sieben Tage alten Kultur sind die Keimlinge aus den zuerst entleerten Schwärmern schon zweizellig.

Fertile Scheiben aus einer Rohkultur zeigt Abbildung 3 B. Alle Zellen können zu Sporangien mit zwei oder vier Schwärmern werden. Offenbar entsteht schon auf dem Chromatophor der sich umwandelnden Zelle ein Pigmentfleck, der bei der Durchschnürung halbiert wird: die Augenflecke der beiden Schwärmer eines Sporangiums liegen nämlich unmittelbar nebeneinander. Die positiv phototaktischen Schwärmer sind kreiselförmig (C). Aus einer flachen Vertiefung ihres breiten Vorderendes entspringen vier Geißeln von etwa $1 / 2$ facher Körperlänge. Der Chromatophor mit Pyrenoid und rundem, etwas über die Oberfläche vorgewölbtem Augenfleck nimmt mehr als die hintere Hälfte ihres Körpers ein. Länge und Breite der Schwärmer schwanken zwischen 5-6 und 3-4,5 $\mu \mathrm{m}$. Von der unterschiedlichen Größe der festgesetzten Schwärmer hängt der Zeitpunkt ihrer ersten Teilung ab, wie ein Vergleich der Aufnahmen bei D und E deutlich erkennen läßt.

Auf eine recht ungewöhnliche Weise ist die polygonale Zellfläche in Abbildung $3 \mathrm{G}$ entstanden. Wenn reichlich Schwärmer in einer Kultur vorhanden sind, so kommen sie gerne gruppenweise auf dem Schalenboden zur Ruhe; die Gruppen können $1 \mathrm{~mm}$ Durchmesser erreichen. Abbildung $3 \mathrm{D}$ zeigt eine solche 6 Stunden alte Kolonie. Die festsitzenden Schwärmer haben noch deutlich sichtbare Augenflecke, sie sind unterschiedlich groß und halten einen ziemlich weiten Abstand voneinander ein. In der 18 Stunden alten Kultur (E) haben sich die größeren Zellen schon geteilt; die übrigen sind gewachsen, haben aber noch ihren Augenfleck. Am nächsten Tage sind alle Zellen geteilt, zwischen den Zellpaaren sind nur noch wenige Lücken (F). Nach weiteren 24 Stunden ist eine Fläche aus dicht zusammengepreßten polygonalen Zellen entstanden, nur die Randzellen sind außen abgerundet (G). Die weitere Entwicklung führt zu flachen Polstern, indem die sich teilenden Zellen nach oben ausweichen. Solche dichten Lager gehen bald in einen Ruhezustand über, und erst nach Erneuerung der Nährlösung werden die Zellen wieder zur Teilung oder Fertilisierung angeregt. 
Stromatella gen. nov.

Stromatella monostromatica (Dangeard) comb. nov.

Basionym: Ulvella monostromatica Dangeard, 1965b, p. 45, pl. I, 8-13, pl. III, 1

Als Ulvella monostromatica beschrieb Dangeard (1965b) eine Alge, die er mehrfach aus Kulturen mit Material von der Mittelmeer- und Atlantikküste isolierte. Solche einschichtigen Scheibchen sind auch bei Helgoland häufig anzutreffen. Ein Vergleich mit Dangeards Abbildungen schließt jeden Zweifel an ihrer Übereinstimmung aus.

Auf Muschelschalen oder Steinen zusammen mit anderen Kleinalgen wachsend, entziehen sich die scheibenförmigen Thalli einer direkten Beobachtung, sie treten aber häufig in Kulturen mit solchem Ausgangsmaterial auf. Durch einen günstigen Umstand konnten wir die Alge in nahezu reinem Bestand aus der Natur erhalten. Am 10. August 1977 wurde am Strand der Düne eine leicht grün gefärbte, teilweise eingesandete und im Wasser flutende Plastikfolie gefunden. Der grüne Belag bestand überwiegend aus fertilen Scheiben (Abb. 4 A). Die kleinen viergeißeligen Schwärmer (B) sammelten sich positiv phototaktisch zu einem dichten Saum an. Im Juli 1978 wurde die Alge nochmals auf einer im Jachthafen treibenden Plastikfolie gefunden.

Durch ihre Entstehungsgeschichte schließen sich die monostromatica-Scheiben aus der Gattung Ulvella aus (vgl. Abb. 9). Zwei Tage alte Keimlinge sind noch ungeteilt, nach vier Tagen sind es vierzellige, gerade oder hakenförmig abgewinkelte Fädchen (Abb. 4 C). Die beiden Endzellen sind wachstumsfähig, sie strecken und teilen sich, während aus den unteren Zellen Zweige entspringen. 5 Tage alte Thalli zeigen einen bilateral symmetrischen Aufbau; jede Hälfte ist ein akropetal verzweigtes, in einer Ebene ausgebreitetes System. Die inneren Zellen schließen sich zu einem zentralen polygonalen Komplex zusammen, von dem freie, sich verzweigende Fäden ausstrahlen. Bei den 5 und 6 Tage alten Stadien ist die Symmetrieachse eingezeichnet. Eine der sechs Tage alten Scheiben beginnt in der Mitte fertil zu werden und hat zwei Tage später schon leere Sporangien. Einen weitgehend ausgeschwärmten, am Rande noch wachsenden Thallus zeigt Abbildung $4 \mathrm{E}$.

Monostromatische Scheiben entstehen nur bei einem guten Kontakt mit dem Substrat; bei einer schlechten Haftung an der Unterlage runden sich die Zellen schon nach geringer Verzweigung der Fäden ab und werden fertil (D, untere Pflanze). Ebenso kommt es zu einer frühzeitigen Fertilisierung, wenn sich die Keimlinge in einer allzu dichten Kultur gegenseitig in ihrer Ausbreitung behindern. In den kugeligen, etwa $9 \mu \mathrm{m}$ großen Sporangien werden jeweils 8 Zoosporen gebildet.

Stromatella und Ulvella repräsentieren zwei verschiedenartige Organisationstypen scheibenförmiger Algen: den nachträglichen Zusammenschluß von akropetal verzweigten Fäden bei Stromatella gegenüber der unmittelbar nach den ersten Teilungen gebildeten Scheibe mit einem Randmeristem bei Ulvella (Abb. 9). Nachfolgend die Diagnose der neuen Gattung:

\section{Stromatella gen. nov.}

Der scheibenförmige, monostromatische Thallus, der mit seiner ganzen Fläche am Substrat haftet, besteht aus bilateral-symmetrischen Hälften. Die aus der geteilten Zoospore entstandenen Zellen entwickeln sich zu akropetal verzweigten Fadensystemen. In der Mitte des Thallus verschmelzen die Fäden seitlich miteinander, am Rand 

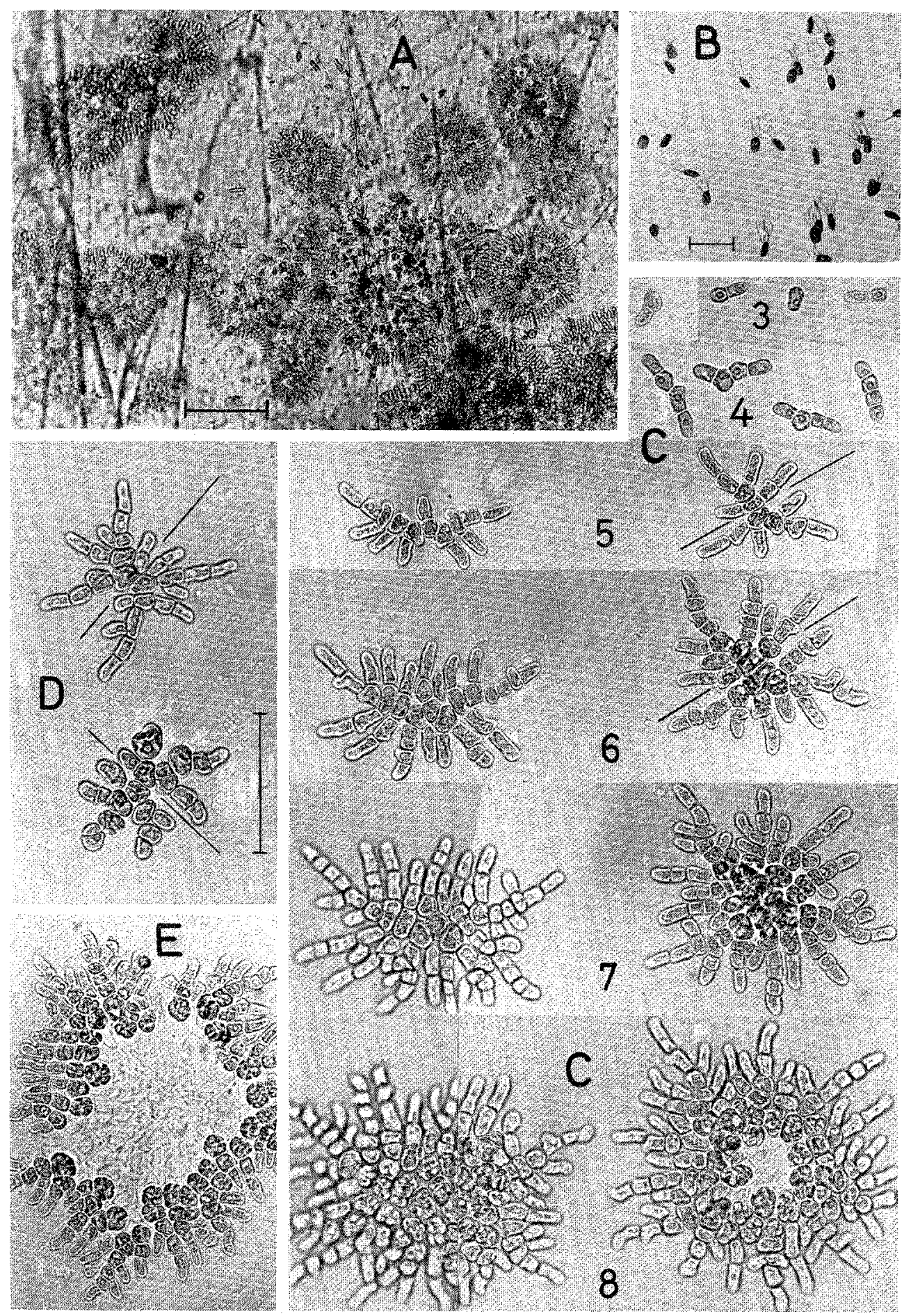

Abb, 4. Stromatella monostromatica. A Thalli auf einer flutenden Plastikfolie, 10. 8. 1977. B Schwärmer. C Entwicklung der Scheiben vom 3. bis zum 8. Tage. D Zwei Thalli aus derselben Kultur, der untere haftet nicht am Substrat. $\mathrm{E}$ Älterer, in der Mitte ausgeschwärmter Thallus. Maßstrecken: $A=100 \mu \mathrm{m} ; B=20 \mu \mathrm{m} ; \mathrm{C}-\mathrm{E}=50 \mu \mathrm{m}$ 
sind sie frei. Jede vegetative Zelle enthält einen wandständigen Chromatophor mit einem Pyrenoid. Die Umwandlung der Zellen in Sporangien schreitet von der Mitte zum Rand fort.

\section{Stromatella gen. nov.}

Thallus discoidalis, monostromaticus, substrato tota area affixus, compositus est ex duabus partibus similibus. Cellulae bipartitione zoosporarum enatae evolvunt in systemas filorum acropetaliter ramosorum. Fila in media parte thalli inter se a latere adjuncta, in margine thalli soluta. Quaeque cellula vegetativa habet chromatophorum ad parietem applicatum et pyrenoideo unico praeditum. Transformatio cellularum in sporangia de media parte thalli ad marginem procedens.

Stromatella papillosa (Dangeard) comb. nov.

Basionym: Ulvella papillosa Dangeard, 1965b, p. 50, pl. II 1-6, pl. IV 2. 1969, p. 42, pl. VI und $\mathrm{X}$

Diese von Dangeard (1965b) als Ulvella papillosa beschriebene Alge ist leicht zu erkennen, besonders nach der 1969 veröffentlichten zusätzlichen Darstellung ihrer "Form mit großen Zellen". Sein Ausgangsmaterial waren verschiedene, in einer Petrischale ausgelegte Algen von Hendaye (Basses Pyrénées), auf deren Boden sich die grüngelben, unregelmäßigen Scheiben entwickelten.

Bei Helgoland ist diese Alge in 6 bis $8 \mathrm{~m}$ Tiefe sehr verbreitet; sie stellt sich in vielen Rohkulturen mit Steinen oder Muschelschalen ein. Auf Glasscherben wachsend, konnte sie mehrfach in ihrer natürlichen Erscheinungsform beobachtet werden (Abb. 5 A-D). Die bis $1 \mathrm{~mm}$ großen Scheiben mit unregelmäßigem Umriß fallen durch ihre 25-30 $\mu \mathrm{m}$ langen und $6-7 \mu \mathrm{m}$ breiten Randzellen auf, die sich häufig radial gebündelt in einer Schicht zusammenschlieBen (D). Díe Scheiben sind auch in der Mitte im allgemeinen einschichtig; dort sind die isodiametrischen Zellen oft als reife oder entleerte Sporangien anzutreffen (B).

Die in Abbildung 5 bei $E$ und $F$ dargestellte Form wuchs 10 Wochen lang in einer Rohkultur mit $\mathrm{GeO}_{2}$ haltiger Nährlösung auf einer Glasscherbe aus dem Sublitoral. Sie gleicht der "im Wirbel" wachsenden Form Dangeards (1969); in den gekrümmten Strahlen des rosettenartigen Thallus schmiegen sich die kurzen Zweige eng an ihre Hauptachse an (F). Die bei E abgebildete Pflanze war reichlich fertil; mit einer Rasierklinge vom Glas abgehobene Teile aus der Thallusmitte zeigen die Sporangien mit ihren langen Papillen im Profil (Abb. 6 A). In frischer Nährlösung wurden zahlreiche Schwärmer entleert. Die positiv phototaktischen Zoosporen haben vier Geißeln und einen deutlichen Augenfleck; sie sind durchschnittlich $6-7 \mu \mathrm{m}$ lang und $5 \mu \mathrm{m}$ breit (Abb. 6 B).

Aus den Zoosporen entsteht eine gleichartige Generation nach dem bei Stromatella monostromatica ausführlich dargestellten Muster (Abb. $6 \mathrm{C}$, die Ziffern geben das Alter der Kultur an). Die Entwicklung erfolgt in den ersten fünf Tagen nur sehr langsam, schreitet dann aber besonders rasch fort. Bei der Keimung tritt der Inhalt der Zoospore meistens in einen Keimschlauch über, die leere Membran ist an vielen 4 bis 5 Tage alten Keimlingen noch zu sehen. Bei fehlendem Kontakt zum Substrat kann der Keimschlauch recht lang werden, was die Entwicklung der Scheibe verzögert (vgl. die verschieden großen, 7 Tage alten Pflanzen). 4 und 5 Tage alte Keimlinge sind gedrungen die Zellen 
Meeresalgen von Helgoland
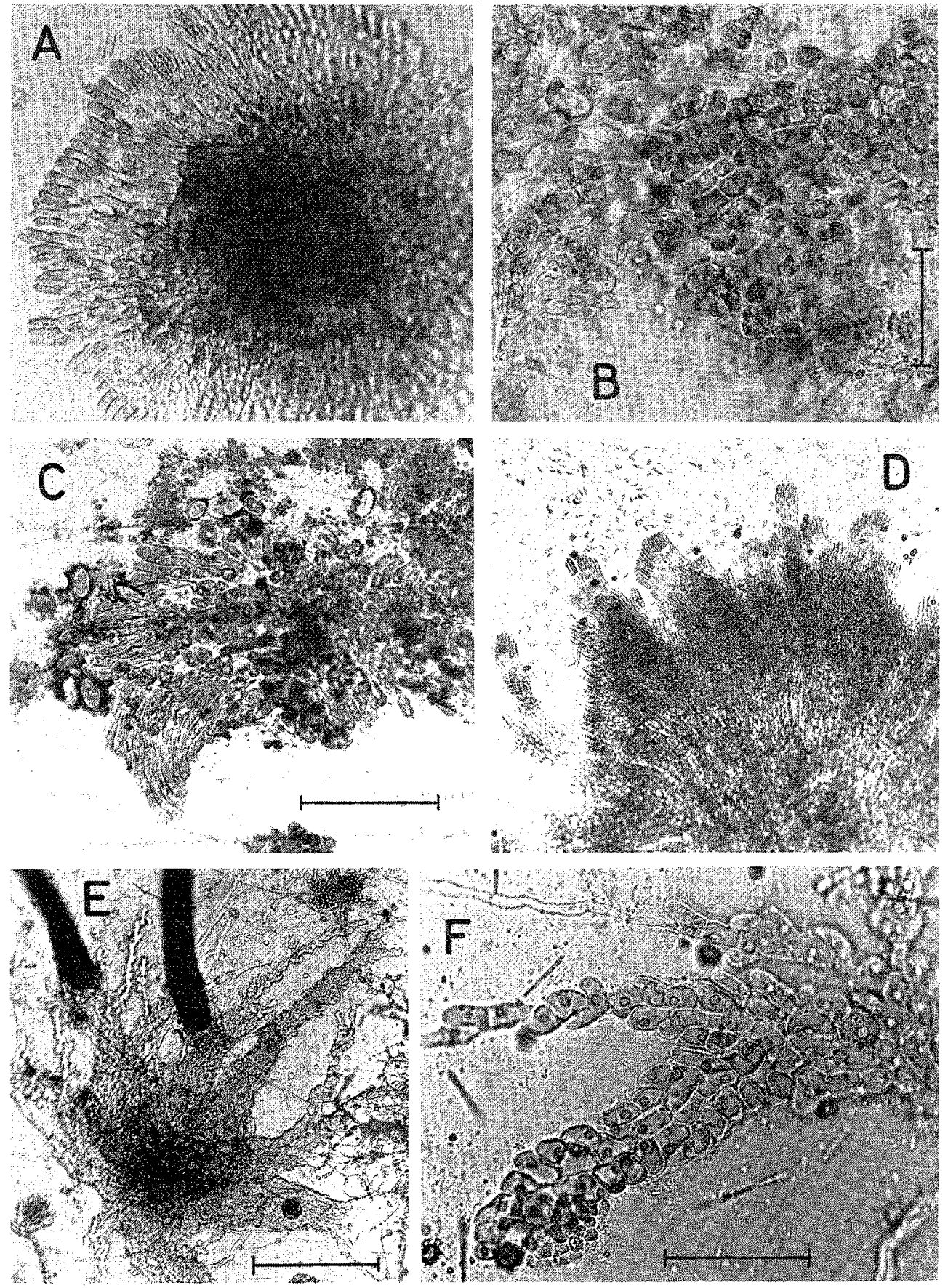

Abb. 5. Stromatella papillosa, A-D Naturmaterial auf Glasscheiben aus dem Sublitoral, A, B, Fertile Scheibe und Ausschnitt mit reifen sowie leeren Sporangien, 18. 5, 1977, C, D Aus Material vom 29. 8. und 30. 6. 1977. E, F Naturmaterial, 10 Wochen lang in $\mathrm{GeO}_{2}$ haltiger Nährlösung kultiviert. Maßstrecken: $\mathrm{A}, \mathrm{C}=100 \mu \mathrm{m} ; \mathrm{B}=50 \mu \mathrm{m} ; \mathrm{D}, \mathrm{E}=200 \mu \mathrm{m} ; \mathrm{F}=50 \mu$ 

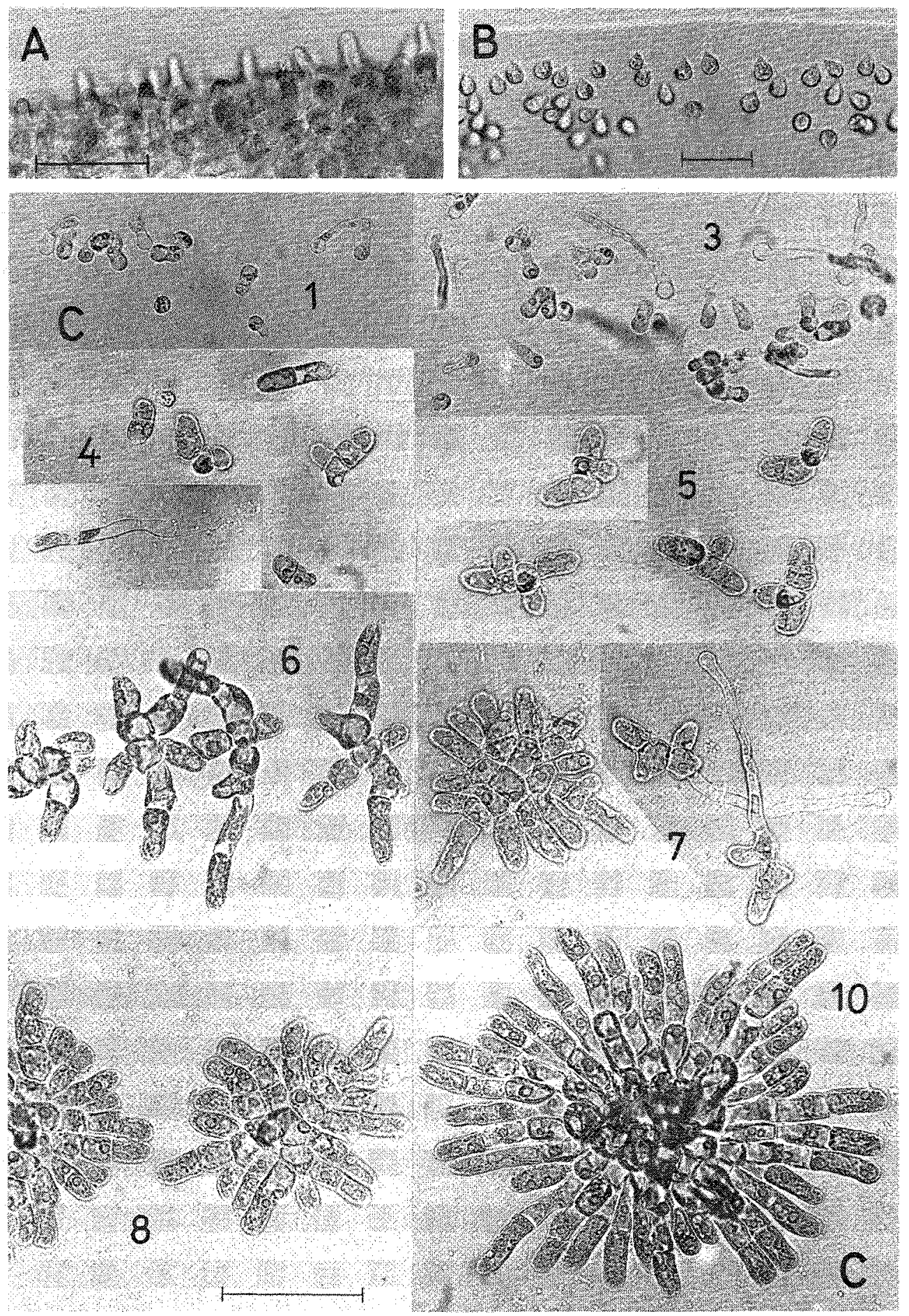

Abb. 6. Stromatella papillosa. A Aus der Mitte der Scheibe von Abb. 5 E, die in der Rohkultur fertil geworden ist; Sporangien mit langen Papillen. B Zoosporen. C Keimung und Entwicklung bis zu 10 Tagen, die Ziffern geben das jeweilige Alter der Kultur an. Maßstrecken: $A=50 \mu m_{i} B=20 \mu m_{i} C$ 

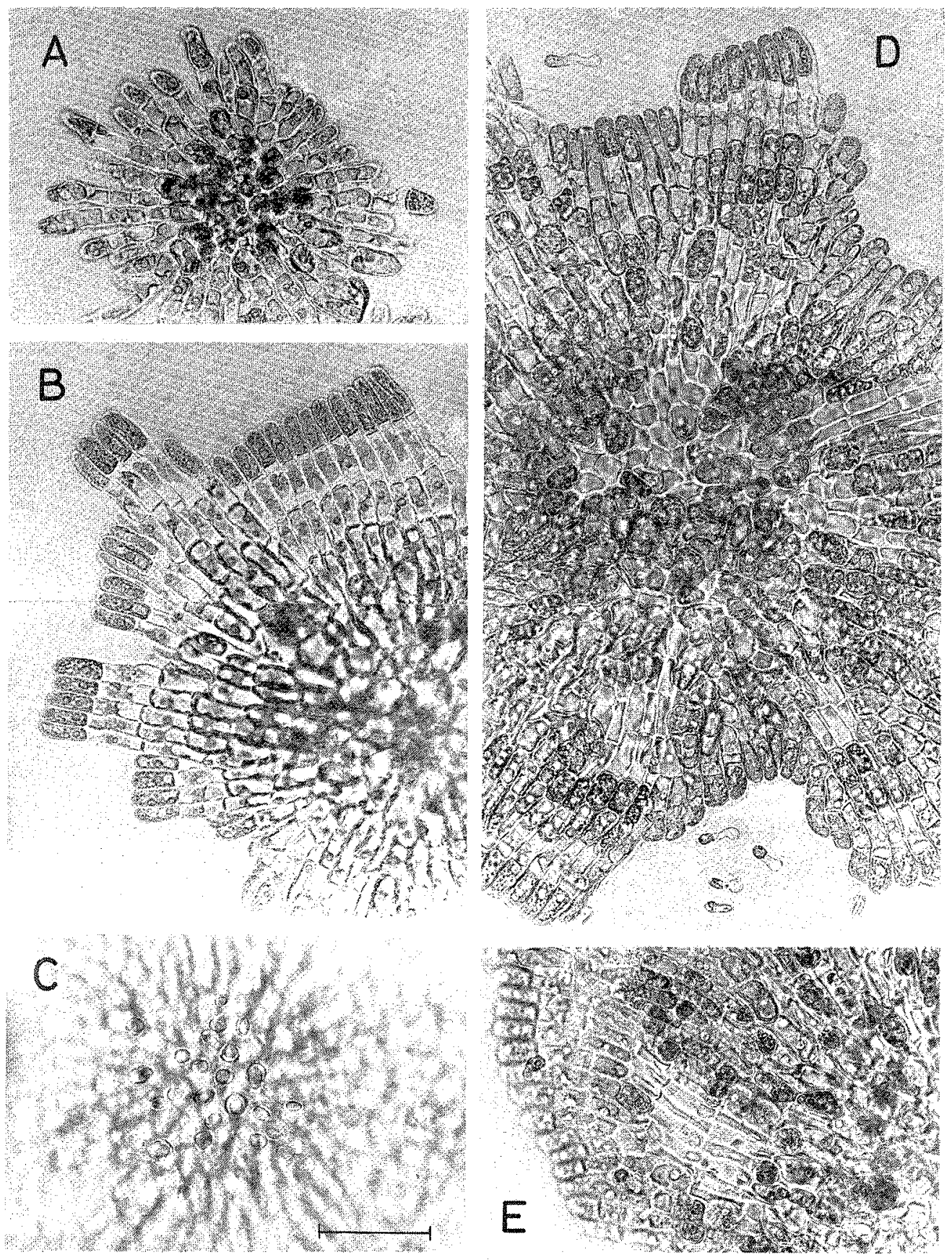

Abb. 7. Stromatella papillosa. A 12 Tage alter fertiler Thallus. B, C 16 Tage alte Pflanzen, entleerte Sporangien bei hoher Einstellung des Objektivs. D, E 20 Tage alte Kultur, die Fertilisierung schreitet randwärts fort; bei D Keimlinge der neuen Generation. Maßstrecke: $A-E=50 \mu \mathrm{m}$ 
sind auffallend kurz und breit. Vom 6. Tage an beginnen die äußeren Zellen des fädig verzweigten Keimlings sich stark zu verlängern, und nach 7 Tagen ist eine sternförmige Scheibe mit isodiametrischen zentralen und gestreckten Randzellen entstanden. Diese beginnen sich schon bei den 10 Tage alten Thalli paarweise aneinanderzulegen; den daraus resultierenden typischen bündelartigen Zusammenschluß der Randzellen zeigt der 16 Tage alten Thallus (Abb. 7 B). Die meisten Scheiben sind schon nach 12 Tagen fertil (Abb. $7 \mathrm{~A})$, vergrößern aber ihre Fläche weiterhin sehr schnell. Ausschnitte aus 16 Tage alten Pflanzen sind bei $B$ und $C$ dargestellt. Die subapikalen Randzellen zeigen deutlich den plattenförmigen Chromatophor mit Pyrenoid. In der Scheibenmitte sieht man bei hoher Einstellung des Objektivs die Offnungen der entleerten, papillenartig vorgewölbten Sporangien (C). Die Fertilisierung schreitet randwärts fort (D, Unterseite einer Scheibe). Auch die auBerhalb der Mitte gelegenen Zellen werden fertil, diese Sporangien öffnen sich an ihrem distalen Ende (E).

\section{UIvella lens Crouan frat.}

Ulvella lens ist im Sublitoral in etwa $6 \mathrm{~m}$ Tiefe sehr verbreitet; sie tritt in vielen Rohkulturen auf, in denen Steine oder Muschelschalen 3 bis 4 Tage lang ausgelegt waren. Schon nach 10 bis 14 Tagen sind dann die Scheibchen mit ihren langgestreckten und gabelig septierten Randzellen nicht zu übersehen (Abb. 8 G). Benachbarte Scheiben schließen sich zu einem einheitlichen Thallus zusammen. Die Scheibenmitte wird durch die nach oben wachsenden Zellen mehrschichtig. Im allgemeinen werden die Thalli nicht spontan fertil; in älteren Kulturen erfolgt die Sporangienbildung erst nach Erneuerung der Nährlösung. Die viergeißeligen Zoosporen sind positiv phototaktisch, was auch Nielsen (1977) feststellte.

Die Abbildungen 8 A-E zeigen die Thalli auf Glasplatten vom natürlichen Standort in allen Stadien ihrer Entwicklung. Ganz junge Scheiben (B) entsprechen denen in Kultur (Abb. 9). Fertile Pflanzen (Abb. 8 A, C) haben einen schmalen einschichtigen Saum um die undurchsichtige Mitte. Weitgehend ausgeschwärmte Thalli (D, E) sind durchscheinend, was darauf schließen läBt, daß ihre fertile Mitte nicht immer mehrschichtig ist. Unter Kulturbedingungen bleiben die Scheiben lange vegetativ und werden dabei in der Mitte mehrschichtig. Nicht auf dem Substrat haftende Thalli wachsen zu pseudoparenchymatischen Klumpen heran,

Nielsens (1977) Beobachtungen an Ulvella lens von Roscoff stimmen ganz mit unseren überein. Nur die fest auf dem Substrat haftenden Keimlinge entwickeln sich zu Scheiben, lockersitzende oder an der Oberfläche der Flüssigkeit sich entwickelnde Pflanzen sind zunächst fädig und wachsen dann zu kugeligen oder unregelmäßigen Zellkomplexen heran. An ihnen treten schon bald zahlreiche dünne Haare auf, während die Scheiben keine Haare tragen. Setzen sich die Zoosporen auf einem Watte- oder Nylonfaden fest, so wird er von dem sich entwickelnden Thallus mantelförmig umhüllt. An solchen in der Flüssigkeit untergetauchten Thalli entstehen schon bald zahlreiche Haare aus den Zellen der erhöhten Mitte (F).

Nielsen vertritt die Ansicht, daß Ochlochaete lentiformis Huber keine wesentlichen Unterschiede gegenüber UTvella lens aufweist. Wenn auch Huber (1893) diese Art in den mit Ulvella lens überschriebenen Abschnitt eingliedert, so betont er doch ausdrücklich ihre morphologischen Unterschiede. Die Synonymie der beiden Arten erscheint 

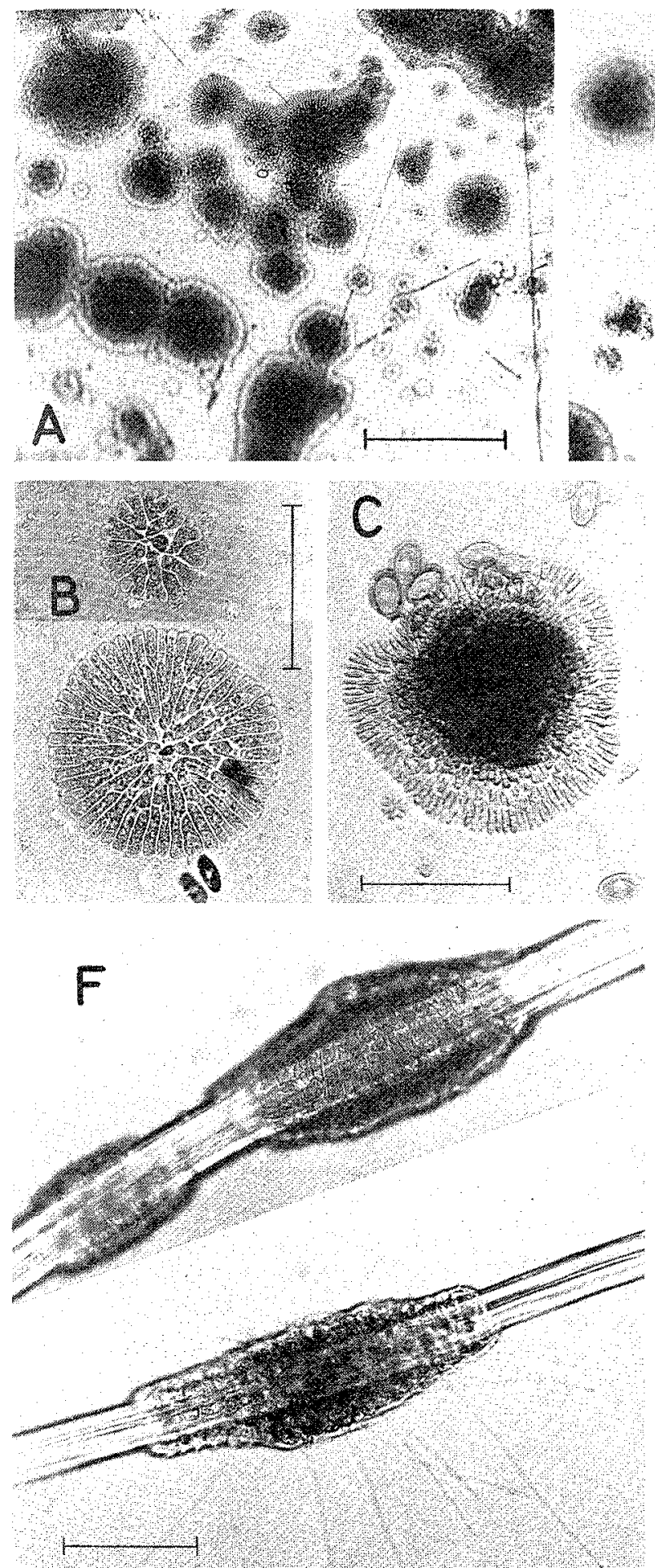
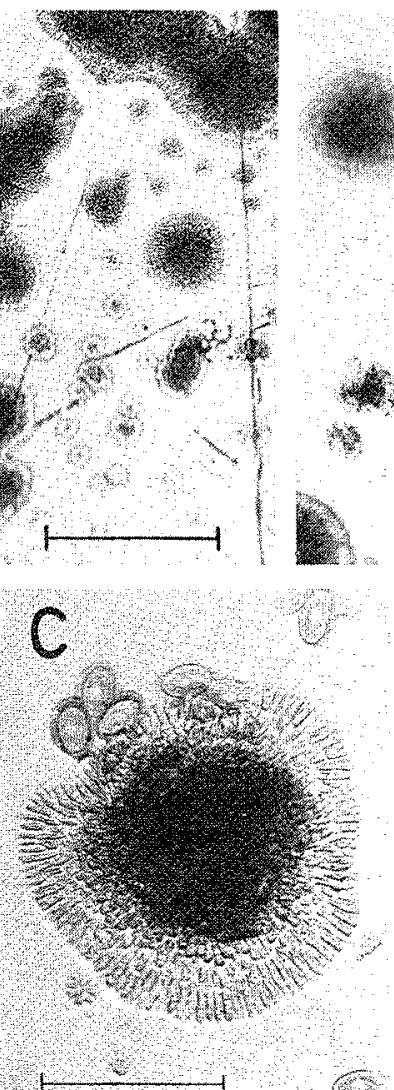

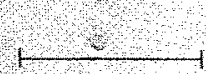

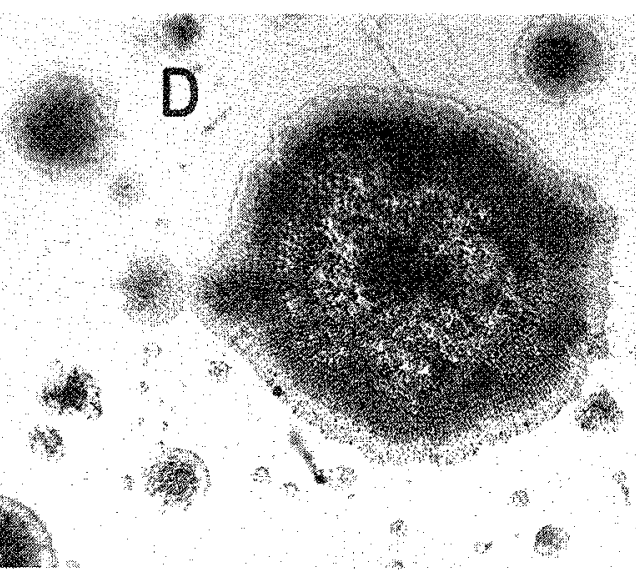

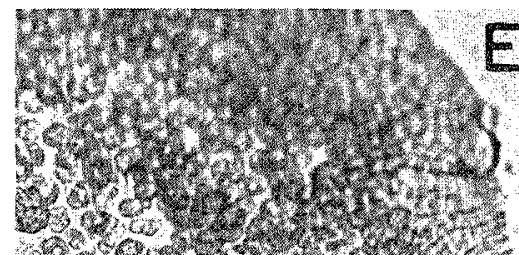

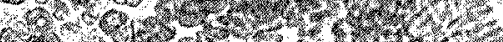

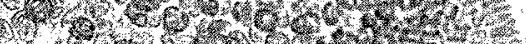

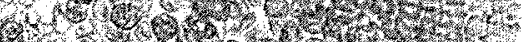

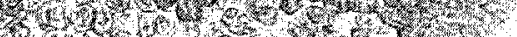

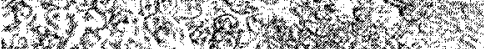

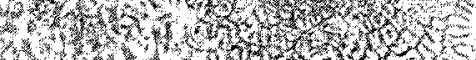

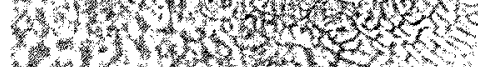

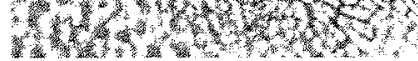
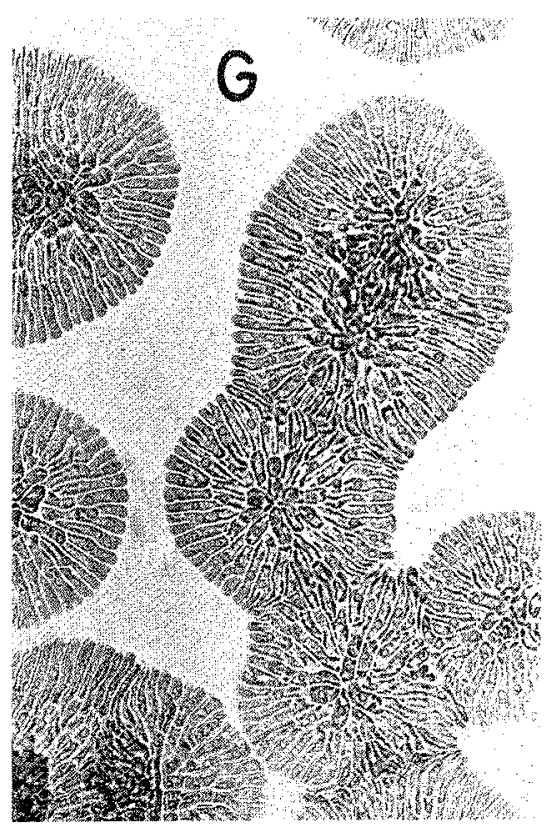

Abb. 8. Ulvella lens. A-E Naturmaterial auf Glasplatten aus etwa $6 \mathrm{~m}$ Tiefe. A Besonders dicht besiedelte Flaschenscherbe. B Junge Scheiben. C Fertiler Thallus. D, E Teilweise ausgeschwärmte Thalli. F Pflanzen auf Nylonfäden, eine mit Haaren. G 15 Tage alte Scheiben aus einer Rohkultur. Maßstrecken: $A, D=200 \mu \mathrm{m} ; B, G=50 \mu \mathrm{m} ; C=100 \mu \mathrm{m} ; E, F=50 \mu \mathrm{m}$ 

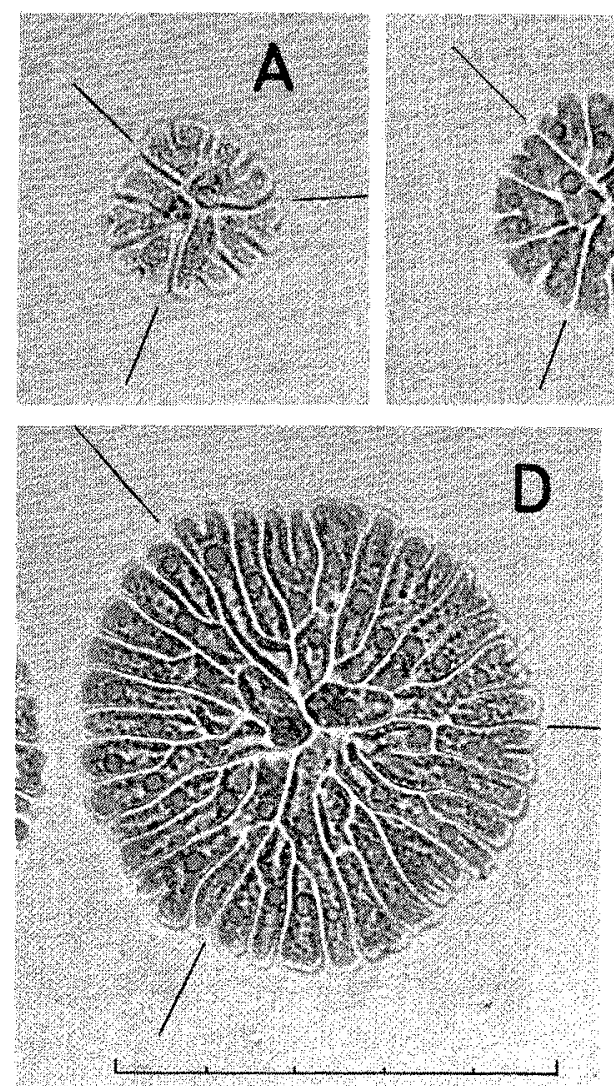
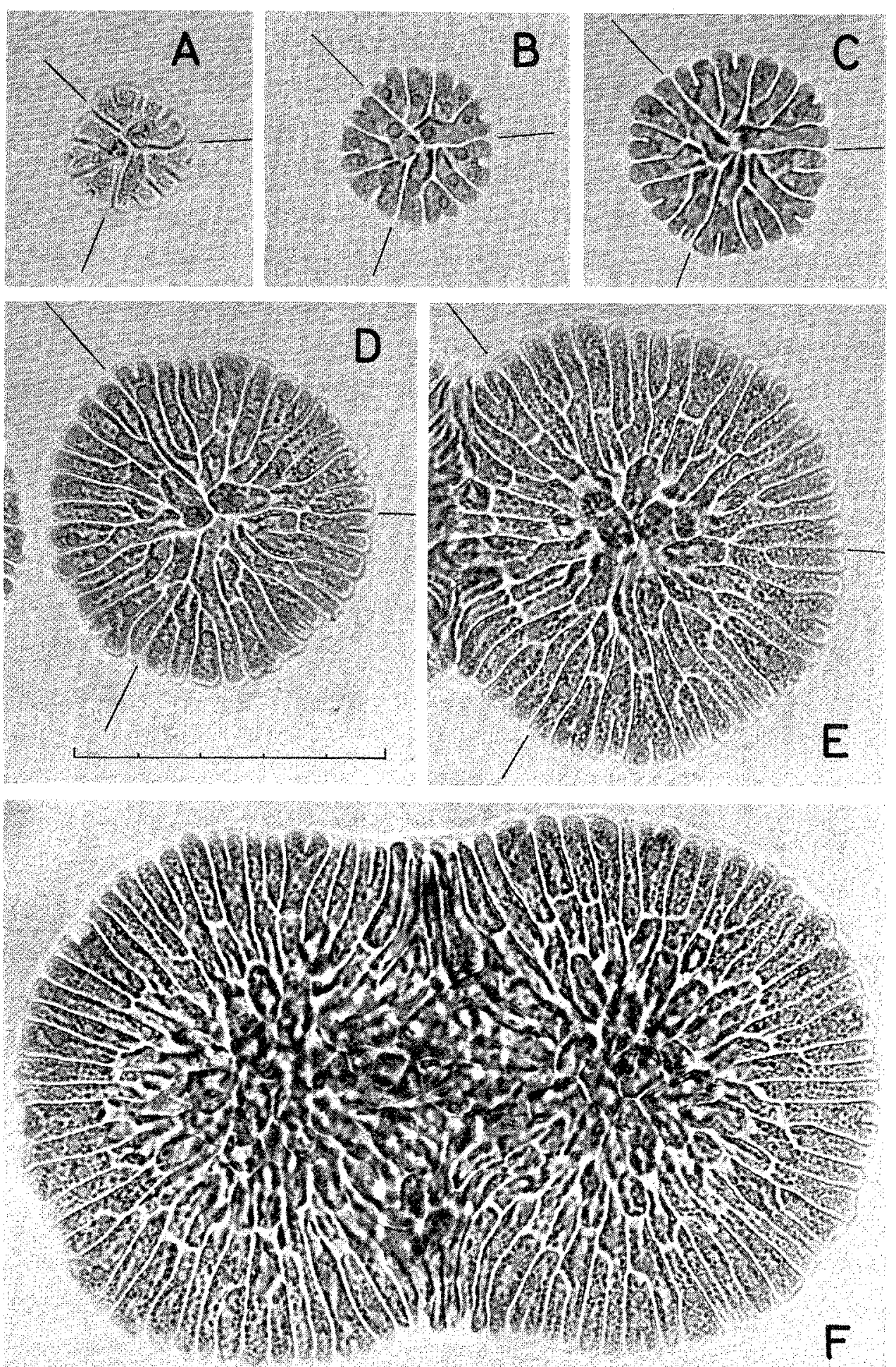

Abb. 9. Ulvella lens. Wachstum einer Scheibe während 6 Tagen, zwischen C und D liegen 2 Tage. Ausführliche Enläuterung im Text. Maßstrecke $=50$ um 
daher nicht genügend erwiesen; eine sichere Beurteilung sollte sich auf die entwicklungsgeschichtliche Untersuchung von Ochlochaete gründen.

Pflanzen mit den Merkmalen von Ulvella setchellii Dangeard wurden in den vielen bisher untersuchten Proben nicht gefunden.

Für die taxonomische Kennzeichnung der Gattung ist die Entstehungsgeschichte des Thallus der typischen Art, Ulvella lens, von grundlegender Bedeutung (Abb. 9). Der Gattung ist eine ganze Reihe ähnlich aussehender Formen zugeführt worden, deren ontogenetische Entwicklung aber völlig andersartig ist. Beispiele sind die drei in der vorliegenden Studie den Gattungen Planophila (p. 7) und Stromatella (p. 10) zugeteilten "Ulvella"-Arten.

Der Keimling bei A - das Alter ist nicht bekannt - besteht aus drei zu einer Scheibe zusammengeschlossenen Sektoren, von denen der untere rechts schon zweizellig ist. Die vier Zellen sind an der Peripherie ausgebuchtet oder durch radiale Septen tief eingeschnitten. Am Tage danach haben sich in jedem Sektor zwei oder drei kurze Randzellen von einer langen, bis ins Zentrum reichenden Zelle abgetrennt (B). Am nächsten Tag ist das Bild wenig verändert: alle Zellen haben sich radial verlängert, und die bei B am tiefsten gespaltenen Randzellen haben sich durch eine schräg abwärts verlaufende Wand geteilt (C). Das Ergebnis dieser inäqualen Teilung ist jeweils eine längere Zelle, der eine kürzere seitlich aufsitzt. Zwischen den Bildern C und D liegen zwei Tage. Noch immer lassen sich die drei primären Sektoren mit Hilfe der angedeuteten Radien gut erkennen. In dem rechten unteren Sektor erstreckt sich noch eine lange Zelle (aber schon mit 2 Pyrenoiden!) vom Rand bis zur Mitte; die entsprechenden Zellen in den beiden anderen Sektoren haben an ihrer Basis eine breitere Zelle abgegliedert. Damit wird die Differenzierung der Scheibe in große, zentrale, später sich nach oben aufwölbende Zellen und einen monostromatischen Rand eingeleitet. Die Bilder D bis F folgen einander in Tagesabständen. Zwei benachbarte Scheiben verwachsen miteinander; in dieser Zone weichen die Zellen wie in der Scheibenmitte nach oben aus. Viele der tief gespaltenen Randzellen teilen sich wie beschrieben durch schräg verlaufende Wände, doch treten in zunehmendem Maße auch tangentiale Wände auf.

Die in Kultur entstandene $70 \mu \mathrm{m}$ breite Scheibe (E) stimmt morphologisch mit der ebenso großen aus der Natur überein (Abb. 8 B), jedoch ist die Scheibenmitte bei der kultivierten Pflanze schon weiter differenziert. Ulvella lens ist in der Natur weniger aufgewölbt als in den Kulturen, worauf eingangs schon hingewiesen wurde.

\section{Pringsheimiella scutata (Reinke) Marshewianka}

Nielsen \& Pedersen (1977) haben die von Reinke 1888 beschriebenen und $1889 \mathrm{im}$ Atlas deutscher Meeresalgen abgebildeten, als geschlechtlich und ungeschlechtlich angesehenen Generationen von Pringsheimia scutata als zwei verschiedene Arten erkannt. Reinkes "ungeschlechtliche Pflanze" (Tafel 25, Fig. 1-6, bei Oltmanns 1922, I, Fig. 201, 1 und 4) entspricht Pringsheimiella scutata, auf der "Geschlechtspflanze" (Tafel 25, Fig. 7-10, bei Oltmanns Fig. 201, 2 und 3) wurde die Gattung Syncoryne begründet. Während Syncoryne reinkei bei Helgoland häufig vorkommt (p. 22), ist Pringsheimiella scutata recht selten und konnte trotz intensiver Suche in den letzten Jahren nicht gefunden werden. Die folgende Darstellung geht daher auf Funde im Juli 1959 zurück. Zweimal konnten die Epiphyten auf Sphacelaria in Wasserlöchern der 
Betonblöcke vor der Westmole gesammelt werden. Sie hüllten die Stämmchen ihrer Wirtspflanze flach mantelförmig ein (Abb. $10 \mathrm{~A})$. Die langgestreckten Randzellen schmiegen sich dem Substrat an, während sich die abgerundeten Zellen in der Mitte der einschichtigen Scheibe nach oben wölben. Die hier abgebildeten, in Kultur aus Zoosporen nach 19 Tagen entstandenen Pflanzen gleichen ganz dem Naturmaterial.

Auf Objektträgern entwickeln sich sowohl Gametophyten als auch Sporophyten zu gleichartigen Scheiben (Abb. 10 B). Eine 24 Tage alte Kultur enthielt neben den

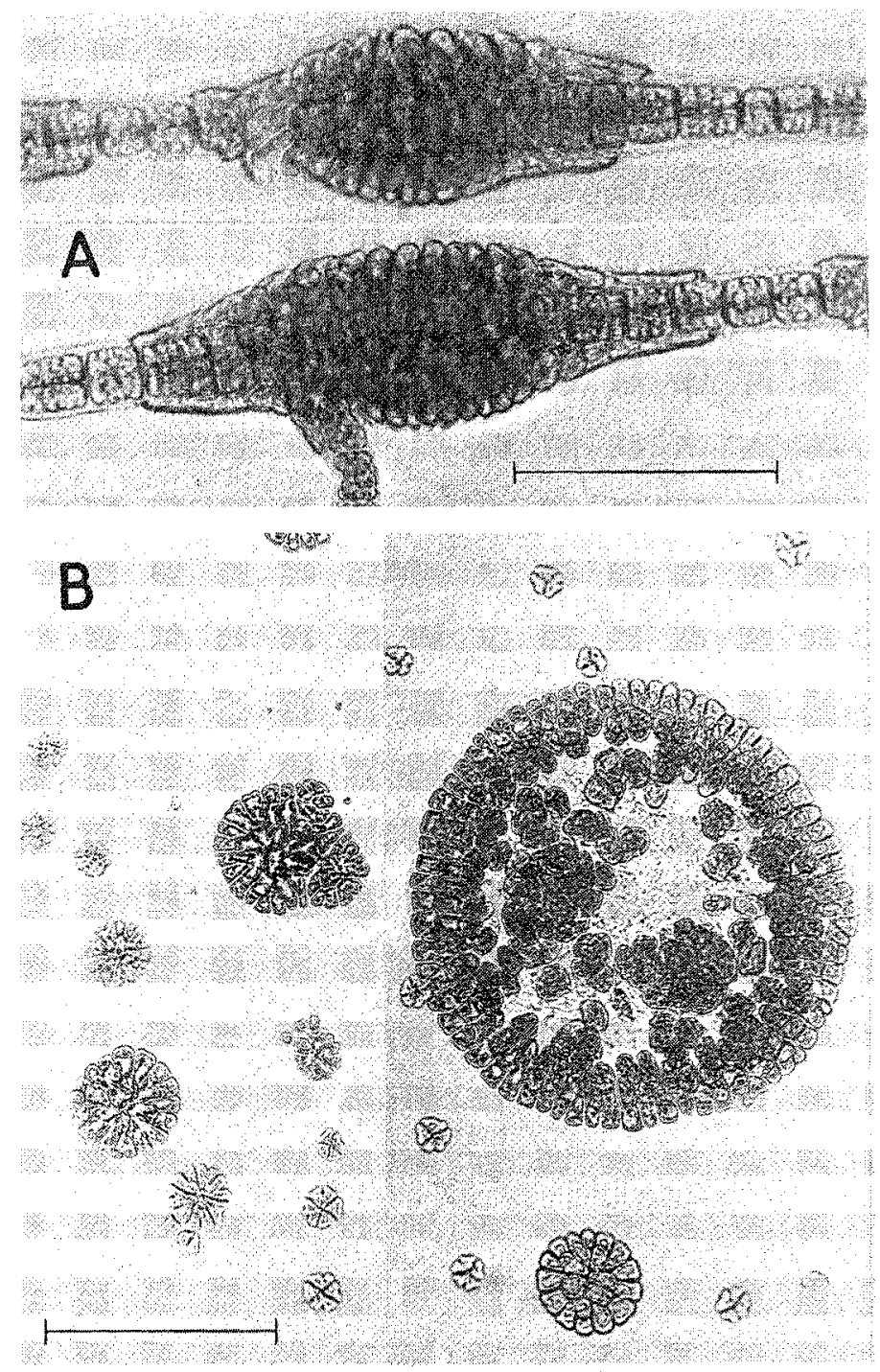

Abb. 10. Pringsheimiella scutata, aus Dauerpräparaten von kultivierten Pflanzen. A Sphacelaria mantelförmig umhüllend, 19 Tage alt. B 24 Tage alter fertiler Gametophyt und junge Sporophytenscheiben in freier Kultur. Maßstrecken: A, B jeweils $100 \mu \mathrm{m}$ 

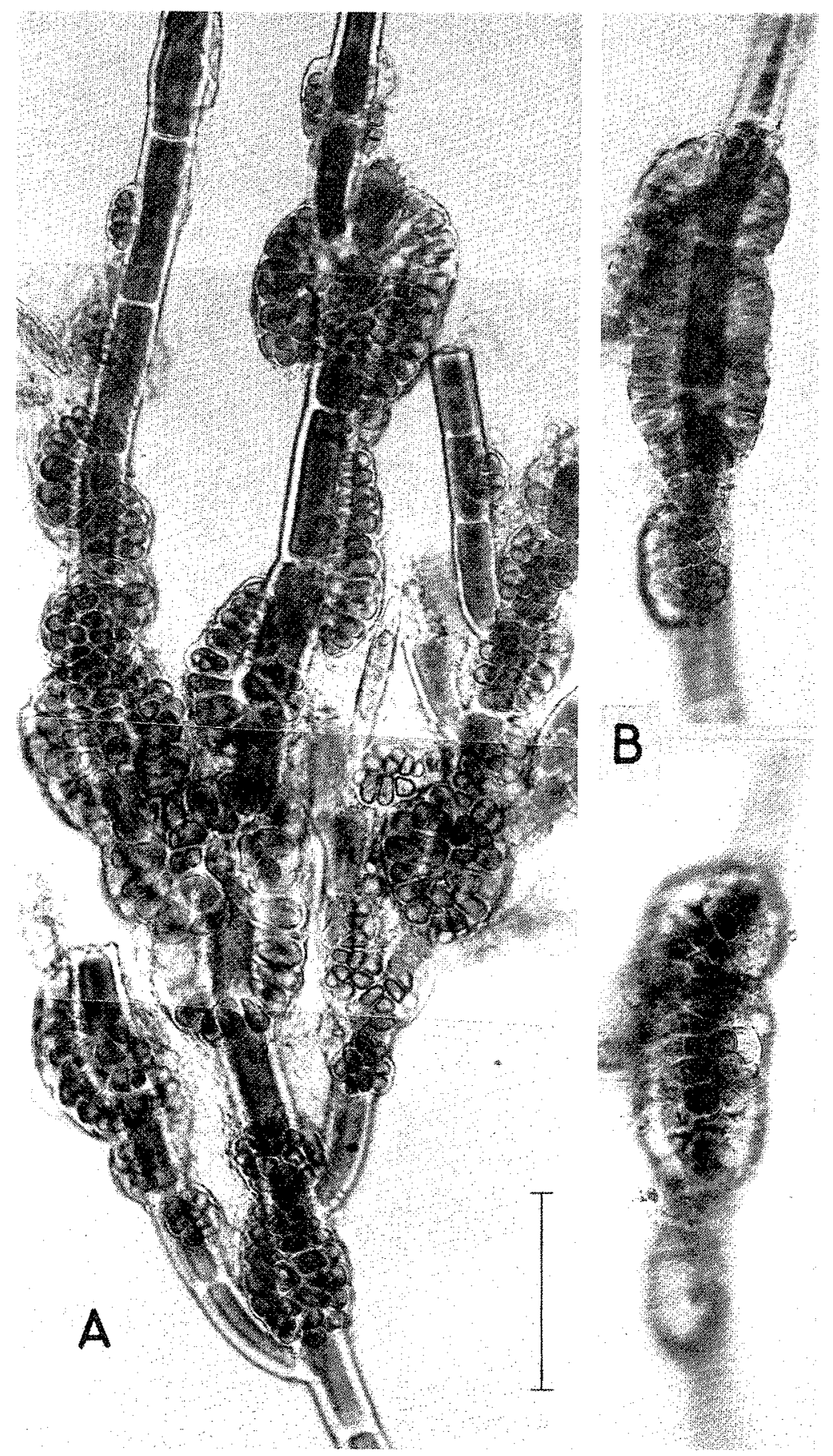

Abb. 11. Syncoryne reinkei auf Rhodochorton purpureum. A Kurze Zeit nach der Fixierung. B In der Aufsicht und im optischen Schnitt, lebend. Maßstrecke $=50 \mu \mathrm{m}$ 
teilweise ausgeschwärmten Gametophyten schon die junge Sporophytengeneration. Thre ontogenetische Entwicklung entspricht dem Muster von Ulvella lens (Abb. 9). Die Gametophyten sind monözisch, die ziemlich kugeligen männlichen Gameten im Durchschnitt 3,5 $\mathrm{m}$, die weiblichen Gameten wie auch die Zoosporen 5-6 $\mu \mathrm{m}$ lang.

\section{Syncoryne reinkei Nielsen et Pedersen}

Die Gattung Syncoryne wurde von Nielsen \& Pedersen (1977) von Pringsheimia scutata Reinke abgetrennt (p. 19). Außerhalb der Ostsee ist Syncoryne reinkei als Epiphyt auf Rhodochorton purpureum bei der Isle of Man und auf Halosaccion ramentaceum bei Godthăb, Grönland, gefunden worden (Nielsen \& Pedersen 1977). Bei Helgoland ist die Alge während des ganzen Jahres anzutreffen; sie wächst epiphytisch auf Sphacelaria radicans und Rhodochorton purpureum, siedelt sich aber auch auf Sertularia an.

Die zu einer einschichtigen Scheibe zusammengeschlossenen Zellen bilden kissenförmige oder kugelige Polster, dünnfädige Wirtspflanzen werden mantelförmig umhüllt (Abb. 11). Die Aufsicht auf ein Polster zeigt eckig gegeneinander abgeplattete, im optischen Schnitt ovale Zellen (B). Die reifenden Sporangien vergrößern ihr Volumen stark; in ihnen entstehen viele viergeißelige Zoosporen, die einzigen bekannten Fortpflanzungszellen.

Die gerade zur Ruhe gekommenen Schwärmer sind meist vierzählig gelappt, eine Eigenart, die auch noch am nächsten Tage bei einzelnen Keimlingen zu erkennen ist (Abb. 12). Nach zwei Tagen haben sich die meisten Keimlinge geteilt, drei Tage alt sind sie vierzellig. Der Phaenotypus der sich entwickelnden Pflanzen wird von der Beschaffenheit des Substrats beeinflußt. Auf Glas haften die Keimlinge nicht, sondern bilden Haufen aus großen Zellen (Abb. 12, linke Seite). Auf dem Boden von Kunststoffschalen dagegen breiten sich die kurzzelligen Fäden bei geringer Verzweigung zu kleinen Scheiben aus, bevor sich die zentralen Zellen keulenförmig aufwärts wölben (rechte Seite). Diese durch das Substrat bedingten Unterschiede bleiben bis zur Fertilisierung deutlich erkennbar.

Die Entstehungsgeschichte weist die Syncoryne-Scheibe dem bilateral-symmetrischen Organisationstyp von Stromatella zu. Vielleicht können vergleichende Entwicklungsstudien für die Systematik der scheibenförmigen Chaetophorales von Bedeutung sein.

\section{CODIOLOPHYCEAE}

\section{Einleitende Bemerkungen zur Systematik}

Chlorocystis und Halochlorococcum, ihrer Einzelligkeit wegen bisher bei den Chlorococcales eingeordnet, schließen sich durch ihre Erscheinungsform und neue Erkenntnisse über thre Entwicklung aus dieser Gruppe aus, in der sie ohnehin als Fremdkörper empfunden wurden. Sind schon ihr differenzierter Chromatophor sowie die in großer Zahl gebildeten nackten Zoosporen Merkmale, die sie von den Chlorococcales als Ordnung der Chlamydophyceae trennen, so bedingt der jetzt aufgedeckte heteromorphe Generationswechsel von Chlorocystis cohnii mit einem ausgeprägten Codiolum-Stadium (Abb. 15) die Eingliederung bei den Codiolophyceae. Ebenso bildet 

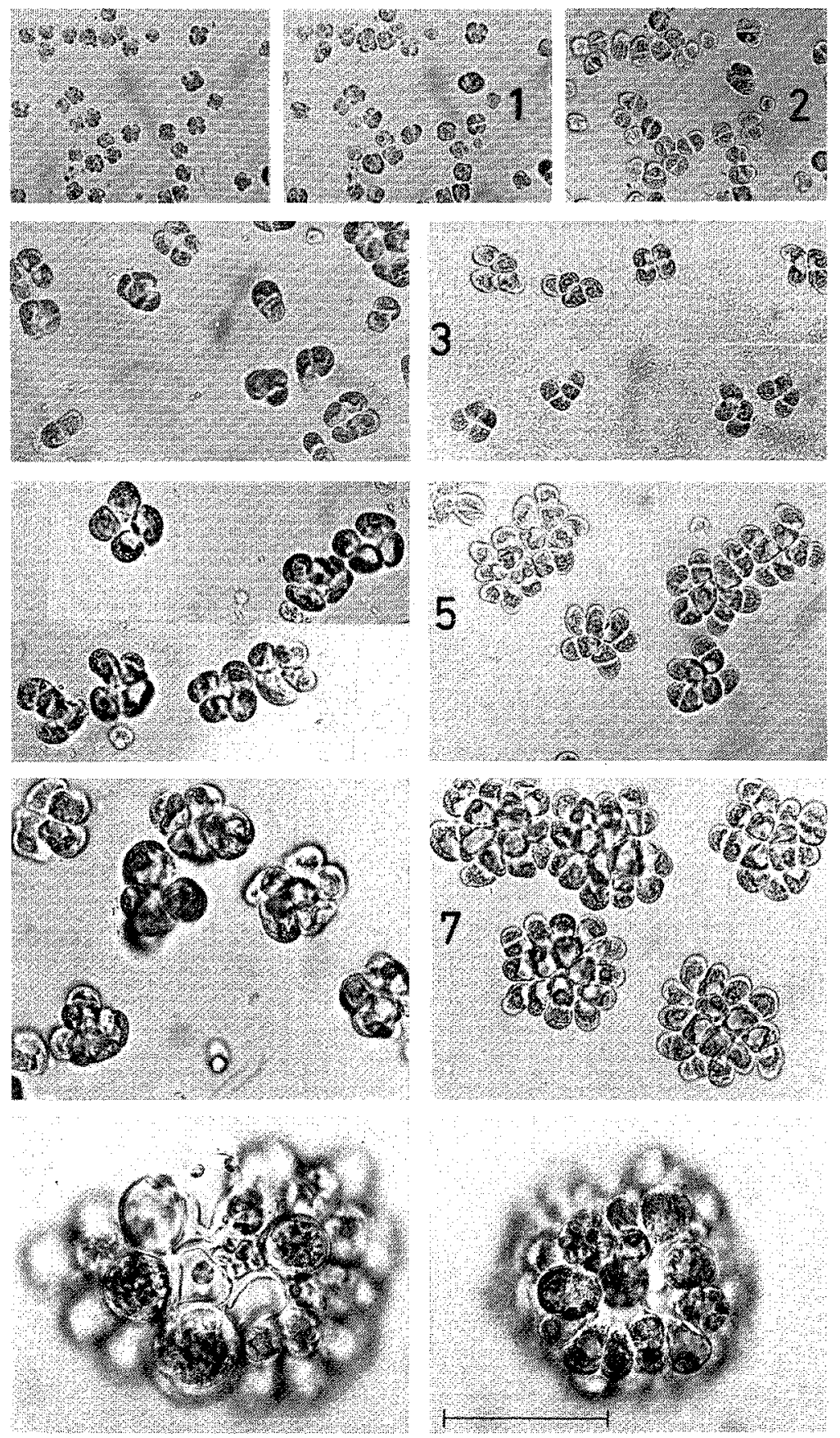

Abb. 12. Syncoryne reinkei, Entwicklung des Thallus auf Glas (linke Seite) und auf Plastikschalenboden (rechte Seite). Die Ziffern geben das Alter der Kultur in Tagen an. Die fertilen Thalli sind etwa 4 Wochen alt. Maßstrecke $=50 \mu \mathrm{m}$ 
eine der fünf untersuchten Halochlorococcum-Arten neben viergeißeligen auch zweigeißelige Zoosporen, von denen sich ein. Teil zu gestielten Keimlingen entwickelt, die ganz dem Codiolum von Chlorocystis entsprechen (Abb. 17); ein obligater Wechsel von Generationen mit zwei- und viergeißeligen Zoosporen liegt aber nicht vor. Auf der Grundlage ihrer Entwicklungsgeschichte werden die genannten Gattungen der neuen Ordnung Chlorocystidales der Codiolophyceen zugeführt.

Chlorocystidales, ordo novus Codiolophycearum:

Chlorophyta unicellularia. Codiolum-status ex zygotis, gametis aut zoosporis biflagellatis evolvens.

Chlorocystidaceae, familia nova ordinis Chlorocystidales:

Familia definita proprietatibus ordinis.

Genus typicum: Chlorocystis Reinhard 1885.

\section{Chlorocystis Reinhard 1885}

Den Anlaß, Chlorocystis in unsere Untersuchungen einzubeziehen, gaben die Abbildungen von Dangeards Halochloris marinum (1965c), die zweifellos Chlorocystis darstellen. $\mathrm{Ob}$ es sich dabei um eine eigene Art oder um Chlorocystis cohnii handelt, kann nicht entschieden werden.

Die Klärung ihrer Entwicklungsgeschichte verleiht Chlorocystis cohnil endilich eine sichere taxonomische Grundlage. Auf eine Wiederholung der Angaben in der Literatur kann verzichtet werden, zumal nach der Zusammenstellung von Bristol (1920) nichts Wesentliches mehr erschienen ist. Es ist nicht möglich, aus den unvollständigen Angaben der älteren Autoren und ihren nomenklatorischen Manipulationen ein objektives Bild zu gewinnen. Wie wenig gesicherte Befunde noch 1976 vorlagen, zeigen die Anmerkungen zur Gattung Chlorochytrium in der Liste von Parke \& Dixon (1976). Von den vier dort aufgeführten Arten bleibt nur noch die taxonomische Stellung von Chlorochytrium dermatocolax ungeklärt, einer besonders in arktischen Gewässern auf Sphacelariaceen weitverbreiteten Art (Lund, 1959; Pedersen, 1976).

\section{Chlorocystis cohnii (Wright) Reinhard \\ Synonym: Chlorochytrium cohnii. Wright}

Unser Untersuchungsmaterial entspricht in der kugeligen bis abgeplatteten Gestalt seiner Zellen der von Wright (1877) abgebildeten, endophytisch in "Schizonema"Schläuchen lebenden Alge. Trotz vieler Bemühungen konnte nur zweimal - am 6 . Juni und am 13. Juli 1981 - spärliches Material dieser Art gesammelt werden; der taxonomische Status der Form mit ovalen Zellen (vgl. Kornmann \& Sahling, 1977, Abb. 23 und 24) bleibt daher vorläufig ungeklärt.

Zimmermann (1925), dem im Sommer 1921 bei Helgoland sehr viel Chlorocystis zur Verfügung stand, beobachtete nur viergeißelige Schwärmer. Unsere beiden Aufsammlungen enthielten außer diesen auch Gameten und vereinzelte Kopulanten. Es gelang zunächst nicht, die Entwicklung der Zygoten zu verfolgen, weil die Kulturen sehr schnell durch Labyrinthula- oder Pilzinfektionen zerstört wurden. Auch schlugen alle Versuche fehl, in freier Kultur Gametophyten zu erhalten; es wiederholten sich nur Generationen mit viergeißeligen ungeschlechtlichen Schwärmem. Erst endophytisch in "Schizonema" kultiviert, traten auch Gametangien auf, und der vollständige Entwick- 

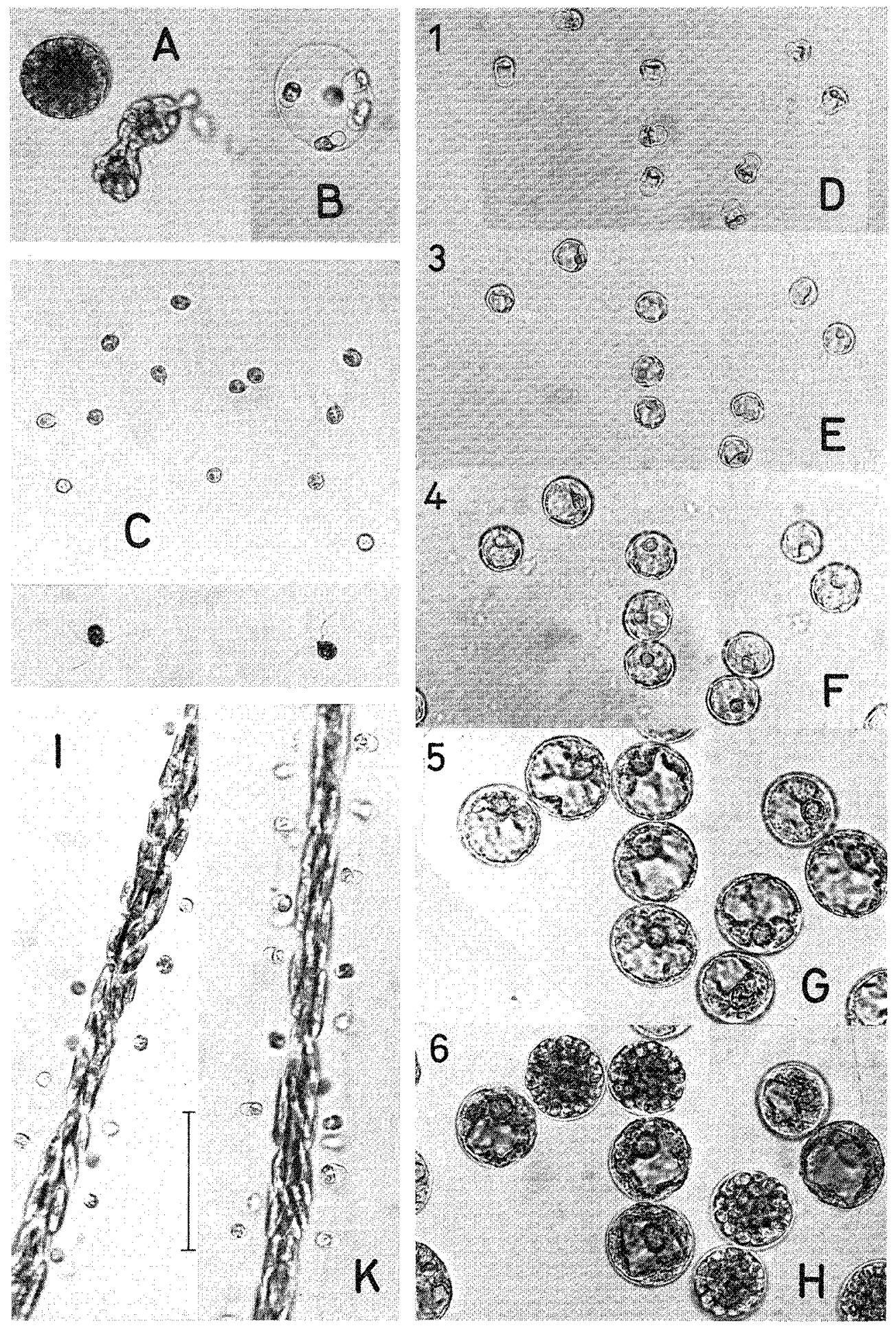

Abb. 13. Chlorocystis cohnii, ungeschlechtliche Entwicklung. A Fertile und sich entleerende Zelle. B In der Hülle gekeimte Zoosporen. C Zoosporen, lebend und gefärbt. D-H Jeweils dieselbe Gruppe von Zellen in freier Kultur im Alter von 1 bis 6 Tagen. I, K Zoosporen kurz nach dem Festsetzen auf einem ,'Schizonema" "Schlauch und 4 Stunden später. Maßstrecke: A-K $=50 \mu \mathrm{m}$ 
lungszyklus konnte geklärt werden. Die Entwicklung ungeschlechtlicher Schwärmer und die Sporophytenentwicklung werden in getrennten Abschnitten behandelt, denen zusammenfassende Bemerkungen zur Systematik folgen.

\section{Freie Entwicklung aus ungeschlechtlichen Schwärmern}

Entwicklung und Wachstum der Chlorocystis-Kugeln in freier Kultur sind in Abbildung $13 \mathrm{~A}-\mathrm{H}$ dargestellt. Die reife Zelle bei A entleert viergeißelige, rundlich-ovale Schwärmer von durchschnittlich 6 bis $7 \mu \mathrm{m}$ Länge (C). Einige in der Kugel bei $B$ verbliebene Schwärmer sind gerade gekeint. Die freie Entwicklung auf einem Deckglas während sechs Tagen ist in einer Serie von Aufnahmen veranschaulicht (D-H). Die Zellen vergrößern ihr Volumen außerordentlich schnell; sie erreichen ihre volle Größe nach 5 bis 6 Tagen und werden fertil.

\section{Die Entwicklung in der Wirtsalge}

In einem Tropfen Nährlösung bleiben die Schwärmer trotz ihres Augenflecks mehrere Stunden lang ohne ausgeprägte Phototaxis beweglich, bevor dann die meisten am Lichtrand zur Ruhe kommen. Enthält der Tropfen jedoch einige "Schizonema"Schläuche, so setzen sich die Schwärmer innerhalb weniger Minuten auf deren Oberfläche fest, ganz offensichtlich chemotaktisch angelockt (Abb. 13 I). Nur vier Stunden später ist das Stadium bel $\mathrm{K}$ erreicht: die Schwärmer haben sich umhäutet und ihren Inhalt in die Wirtspflanze eingesenkt. Die leere Sporenhülle überragt die Oberfläche des Diatomeenschlauches und krönt auch noch die ausgewachsene Zelle als helle Papille. Die weitere Entwicklung enfolgt wie bei den aus Sporophyten entleerten Zoosporen, die in Abbildung 16 dargestellt ist.

Die "Schizonema" -Schläuche werden so lange besiedelt, bis sie den Zoosporen keinen Platz mehr bieten. Das Ergebnis sind grüne Ketten von dicht aneinandergedrängten Chlorocystis-Zellen. Ihre Schwärmer setzen sich auf dem Schalenboden und an der Oberfläche der Nährlösung fest.

\section{Die Entwicklung des Sporophyten}

In zwei mit Chlorocystis-Schwärmern infizierten "Schizonema"-Kulturen traten nach etwa 6 Wochen geschlechtliche Fortpflanzungszellen auf. Die eine Kultur enthielt nur Gameten einen Geschlechts (Abb. 14 A). Sie geht auf zwei Chlorocystis-Zellen zurück, die auf einem isolierten "Schizonema"-Faden zunächst unbemerkt geblieben waren und - größer geworden - bei einer Kontrolle nach einigen Tagen gefunden wurden. Die andere "Schizonema"-Kultur war mit vielen Chlorocystis-Schwärmern infiziert worden; ihr Schwärmersaum enthielt reichlich Gameten und Kopulanten (Abb. $14 \mathrm{~B}, \mathrm{C}$ ). Diese Beobachtungen lassen auf Diözie der Gametophyten schließen. Die Kopulanten sind deutlich anisogam, die schlanken Gameten zwischen 5 und 6 um lang. Die Zygoten setzen sich überwiegend am hinteren Rand eines Tropfens fest, kommen aber auch auf seiner ganzen Fläche zur Ruhe. Sie zeigen überhaupt keine Affinität zu "Schizonema"-Schläuchen, an denen sich die meisten der stets auch im Schwärmersaum vorhandenen ungeschlechtlichen Schwärmer sofort ansetzen. Auf diese Weise gelingt eine weitgehende Trennung von Zygoten und Zoosporen.

Die Sporophytenentwicklung ist in einer Serie von Aufnahmen dargestellt, es ist jeweils derselbe Ausschnitt aus einer Kultur (Abb. 15 A-E). Schon am Tage nach dem 


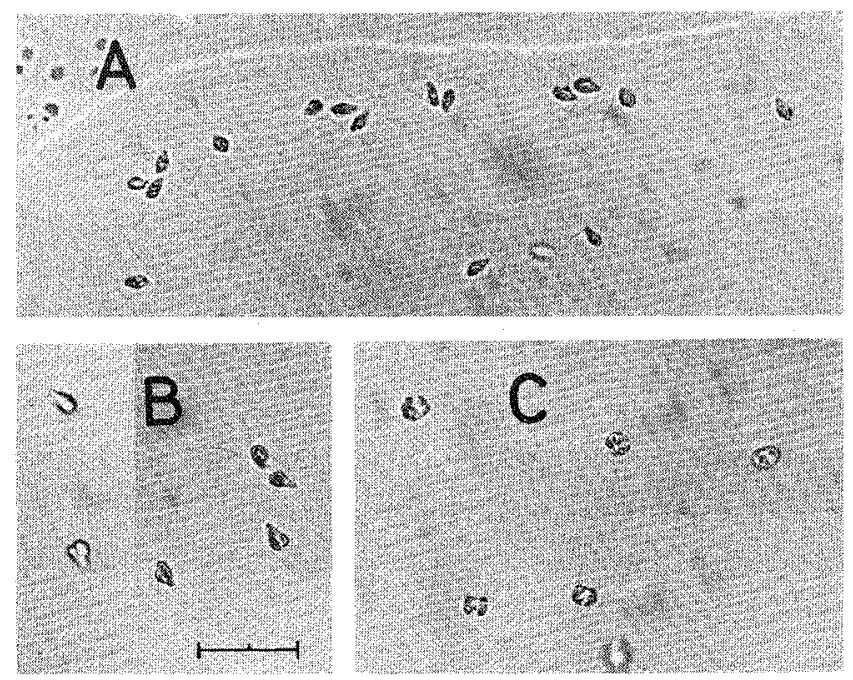

Abb. 14. Chlorocystis cohnii. A Gameten eines Geschlechts. B Anisogame Kopulanten. C Zygoten, nach Fixierung über Osmiumdampf. MaBstrecke: $A-C=20 \mu \mathrm{m}$

Festsetzen sind die Zygoten zu langgestielten Keimlingen ausgewachsen (A). Das äußerst zarte, mehrfach eingeschnürte und dadurch gegliedert erscheinende Stielchen trägt die langgestreckte Kopfzelle mit dem gefärbten Inhalt. Die beiden Augenflecke sind in diesem Stadium noch deutlich zu erkennen. Bei den zwei Tage alten Keimlingen hat sich das Köpfchen abgekugelt, der Stiel ist länger geworden und besteht jetzt aus einem unteren hyalinen und einem oberen derberen, schwach bräunlich gefärbten Abschnitt (B). Wie ein Vergleich mit Abbildung A zeigt, geht der bräunlich gefärbte Abschnitt allein auf die Differenzierung der bei A noch langgestreckten Kopfzelle zurück; die Pfeile in den Abbildungen A, B und C weisen jeweils auf dieselbe Stelle der jungen Sporophyten hin. Bis zum vierten Tage tritt keine wesentliche Veränderung mehr ein (C), danach vergrößern sich die Kopfzellen rasch. Der becherförmige Chromatophor mit Pyrenoid ist nicht in auffallende fingerförmige Lappen aufgeteilt wie bei den Kugeln aus ungeschlechtlichen Schwärmern, auch ist die Zellmembran derber $(D, 8$ Tage alt). Am 11. Tage ihrer Entwicklung werden schon die ersten Sporophyten fertil, und die Augenflecke ihrer Schwärmer sind deutlich zu erkennen (E). Mit diesem Bild endet die Serie der Aufnahmen, weil die Sporophyten am nächsten Tage von freien Diatomeen der Wirtsalge überwachsen waren. Die in der Abbildung bei F dargestellten Stadien entstammen einer anderen, 13 Tage alten Kultur.

Die derbe Membran des reifen Sporangiums öffnet sich mit einem breiten RiB. Die Schwärmermasse quillt ganz langsam, in eine hyaline Blase eingeschlossen, aus dem Sporangium heraus; bis zum Freiwerden der Zoosporen vergehen meist etwa $15 \mathrm{Minu}-$ ten. Daher war es möglich, den bei dem Buchstaben $F$ abgebildeten, sich gerade entleerenden Sporophyten in einen Tropfen Nährlösung zu übertragen und Zoosporen zu erhalten. Ein Teil von ihnen wurde einem 'Tropfen mit wenigen "Schizonema"Schläuchen zugesetzt, die übrigen verblieben in dem Tropfen. Sowohl in freier Kultur (Abb. 16 A) als auch endophytisch (B) entwickelten sie sich in gleicher Weise wie die 


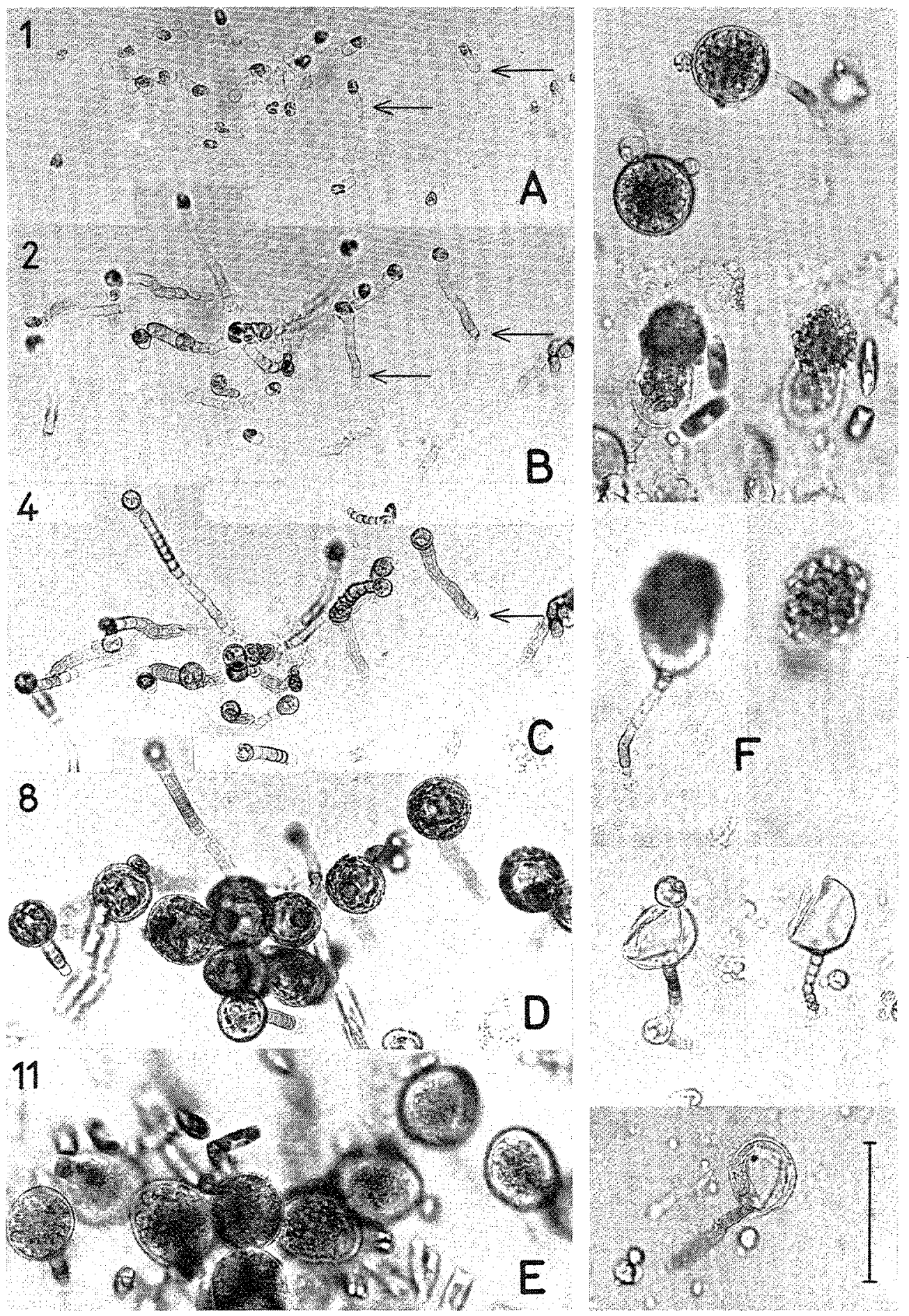

Abb. 15. Chlorocystis cohnii, Sporophytenentwicklung. A-E Jeweils derselbe Ausschnitt einer Kultur; die Ziffern geben das Alter an. Ausfuhrliche Erlauterung im Text. F Reife und entleerte Sporophyten aus einer 13 Tage alten Kultur. Maßstrecke: $A-F=50 \mu \mathrm{m}$ 


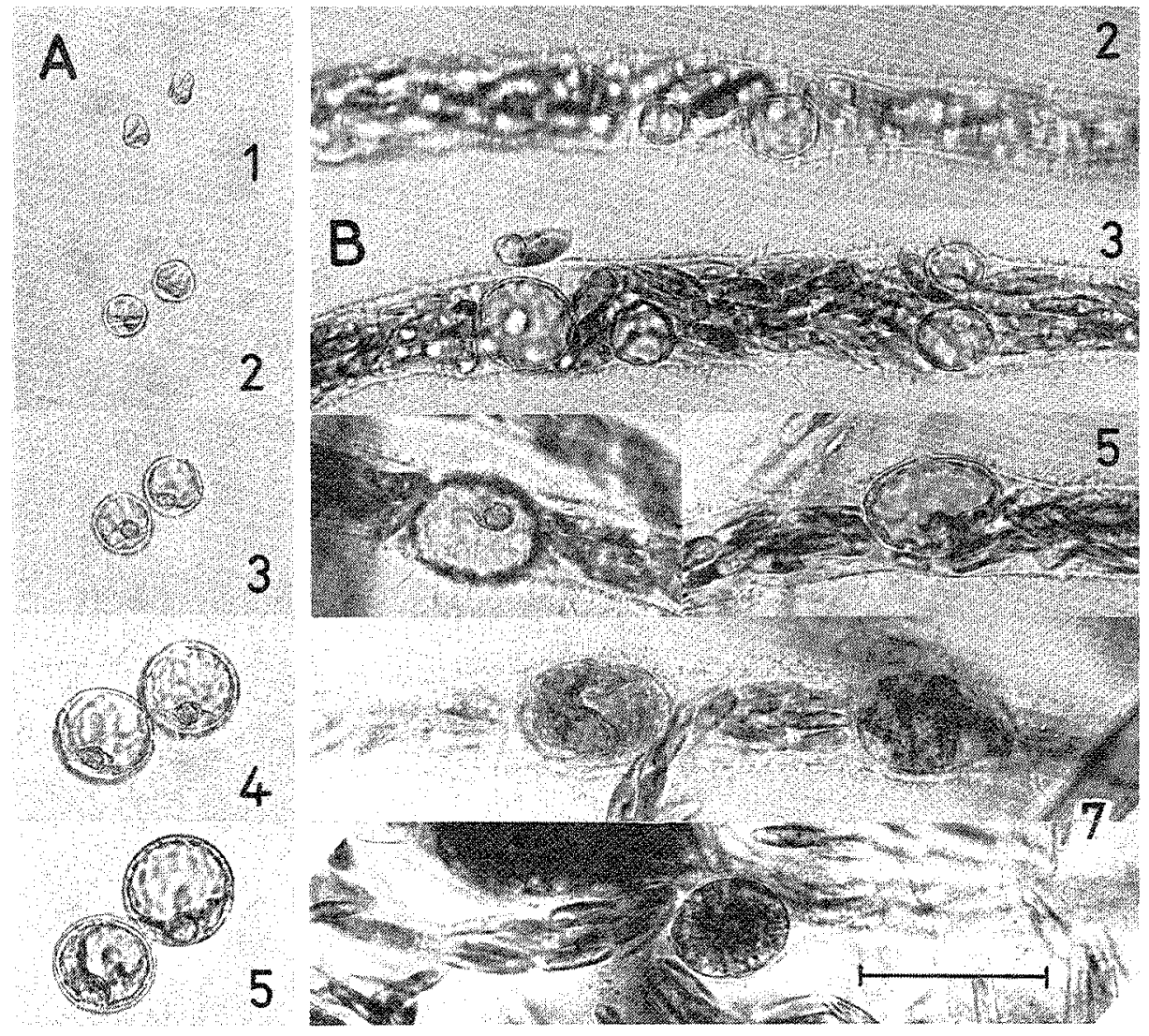

Abb. 16. Chlorocystis cohnii. Entwicklung der Zoosporen eines Sporophyten in freier Kultur (A) und endophytisch (B). Die Ziffern geben das Aiter der Kulturen in Tagen an. Maßstrecke $=50 \mu \mathrm{m}$

ungeschlechtlichen Schwärmer der Gametophyten. Schon nach 7 Tagen waren einige Kugeln fertil oder ausgeschwärmt, wie die frische Infektion der Wirtsalge mit kleinen Kugeln anzeigte.

\section{Parthenogenetische Entwicklung}

Ein geringer Bruchteil der Gameten keimt in ähnlicher Weise wie die Zygoten, jedoch erfolgt ihre Entwicklung wesentlich langsamer. Die meisten Kopfzellen bleiben klein, nur wenige wachsen zu grünen Kugeln heran. Es konnte nicht festgestellt werden, ob sie fertil werden, weil die nicht auszuschaltenden, nach jeweils 6 Tagen fertil werdenden Generationen aus ungeschlechtlichen Schwärmern die Kulturen überwucherten. Vermutlich sind die Keimlinge in Abbildung $15 \mathrm{C}$ und D, deren Köpfchen nicht anschwollen, parthenogenetischen Ursprungs.

\section{Zusammenfassende Bemerkungen}

Chlorocystis cohnii ist eine einzellige Grünalge mit heteromorphem Generationswechsel. Nicht nur morphologisch, sondern auch in ihrer Lebensweise sind die Genera- 
tionen verschieden: der kugelige diözische Gametophyt lebt endophytisch; der gestielte Sporophyt ist frei und nur aus Kulturen bekannt. Neben ungeschlechtlichen viergeißeligen Schwärmern werden unter besonderen, nicht näher bekannten Umständen in der Natur und im endophytisch wachsenden Kulturmaterial Gametangien gebildet. Die Zygoten zeigen keine Affinität zu der Wirtspflanze.

Durch diese Befunde erhält die von Reinhard (1885) vorgenommene Abtrennung der Art von der typischen, im Süßwasser vertretenen Gattung Chlorochytrium eine gediegene Grundlage. Der heteromorphe Generationswechsel mit einem gestielten, Codiolum-artigen Sporophyten weist der Gattung Chlorocystis ihren Platz bei den Codiolophyceae zu. Unterschiede in der Lebensweise der heteromorphen Generationen kommen auch in anderen Gruppen dieser Klasse vor; bei den Acrosiphoniales und Monostromatales sind die Sporophyten die endophytische oder in Kalkschalen eingesenkt lebende Generation.

\section{Halochlorococcum Dangeard}

Die Gattung Halochlorococcum wurde von Dangeard (1965c) für eine einzellige kugelförmige Grünalge geschaffen, deren für eine Chlorococcale ungewöhnlicher Lebensraum durch das Epithet marinum gekennzeichnet ist. Der netzförmige Chromatophor schließt die Alge aus der Gattung Chlorococcum aus.

Uber die Herkunft von Halochlorococcum marinum liegen keine anderen Angaben vor, als daß sie in Kulturen verschiedenen Ursprungs aufgetreten und daher wohl nicht selten sei. Wir konnten aus Schwärmern, die sich phototaktisch in Kulturschalen mit ausgelegten Muschelschalen und Steinen ansammelten, zunächst zwei verschiedene Formen isolieren, die zweifellos zur Gattung Halochlorococcum gehören, aber nicht mit der typischen Art identisch waren. Dagegen entsprach eine dritte, in einer Rohkultur mit Kleinalgen aus dem obersten Litoral gefundene Art ganz dem Typus von Dangeard. Halochlorococcum marinum Dangeard aus der Kulturensammlung der Universität Texas (Starr, 1978) stimmt nicht mit der Beschreibung des Typus überein und wird hier als neue Art, Halochlorococcum tenuis, beschrieben (p. 37).

Symbiosphaera marina L. Moewus (1950) gehört sehr wahrscheinlich auch in diesen Formenkreis, doch reichen ihre Angaben nicht aus, um die Identität mit einer der im folgenden ausführlich dargestellten Arten zu sichern. Eine Art aus brackigem Milieu von der Küste Floridas, Halochlorococcum saccatum, wurde von Guillard, Bold \& MacEntee (1975) beschrieben. Schließlich führen wir der Gattung Halochlorococcum noch Chlorochytrium moorei zu, einen Epiphyten auf Blidingia (p. 42).

\section{Halochlorococcum marinum Dangeard non Halochlorococcum marinum Dangeard (Utex 1490)}

Als einzige der fünf untersuchten Arten weist diese in einer Rohkultur mit Kleinalgen aus dem obersten Litoral von Helgoland gefundene Form das wesentliche Merkmal der typischen Art auf: das Vorkommen von ungeschlechtlichen zweigeißeligen neben viergeißeligen Zoosporen. Uber entwicklungsgeschichtliche Zusammenhänge machte Dangeard keine Angaben.

Die während mehreren Wochen nicht kontrollierte Ausgangskultur enthielt eine negativ phototaktische Ansammlung meist zweigeißeliger neben wenigen viergeißeligen Zoosporen. Ihre Keimlinge waren kugelig, aber etwa $10 \%$ hatten einen gegliedert 


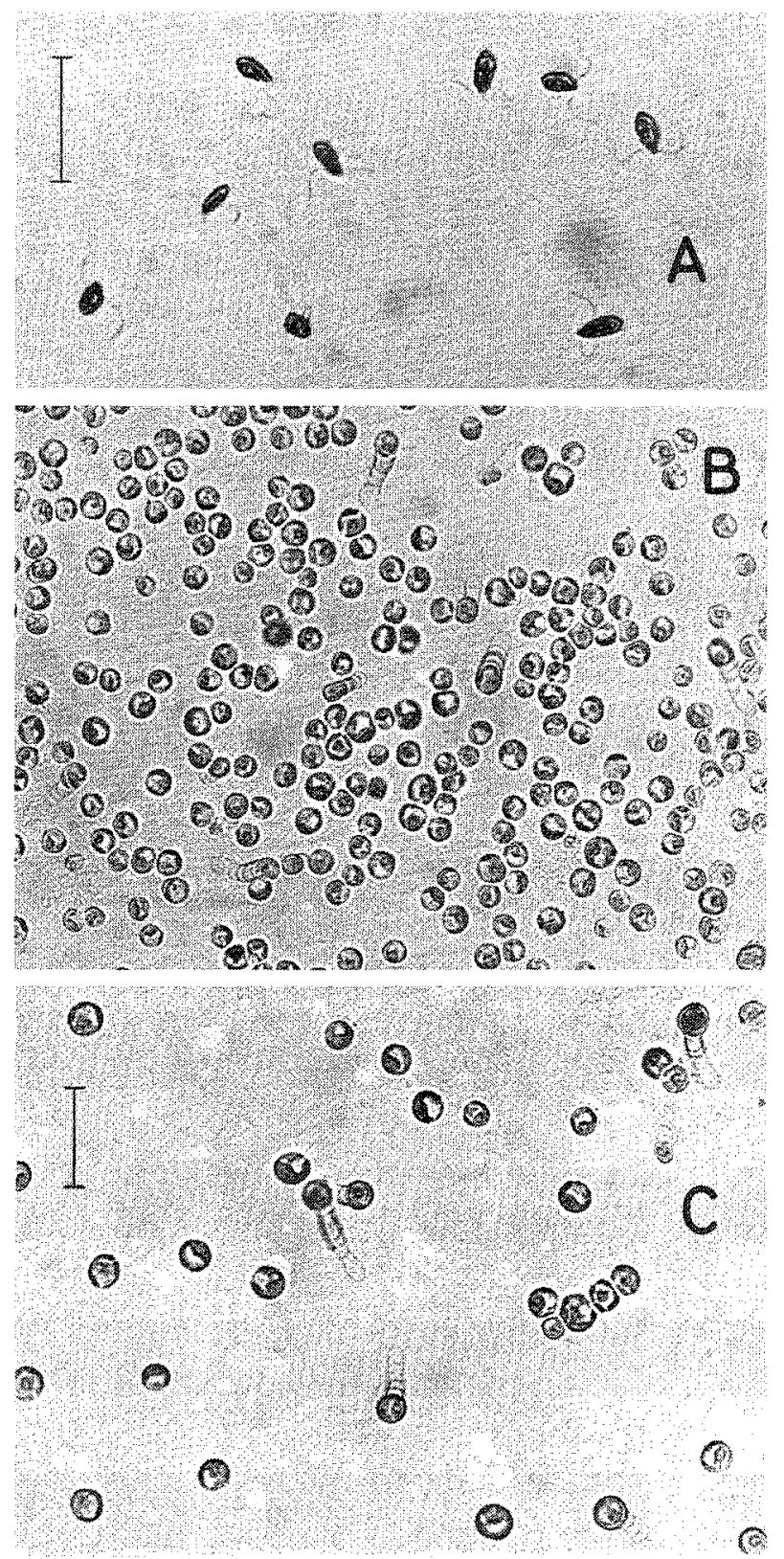

Abb. 17. Halochlorococcum marinum. A Zweigeißelige Zoosporen. B, C Zwei bzw. drei Tage alte Kulturen mit einem geringen Anteil von gestielten Zellen. Maßstrecken: $A=20 \mu m ; B, C=20 \mu m$

erscheinenden Stiel (Abb. 17). Nach 10 Tagen fruktifizierte diese Kultur ganz unerwar tet mit überwiegend viergeißeligen Schwärmern, nur wenige, etwas kleinere, waren zweigeißelig. Bei subjektiver Beobachtung ließen sich ohne weiteres bräunlich-orange 


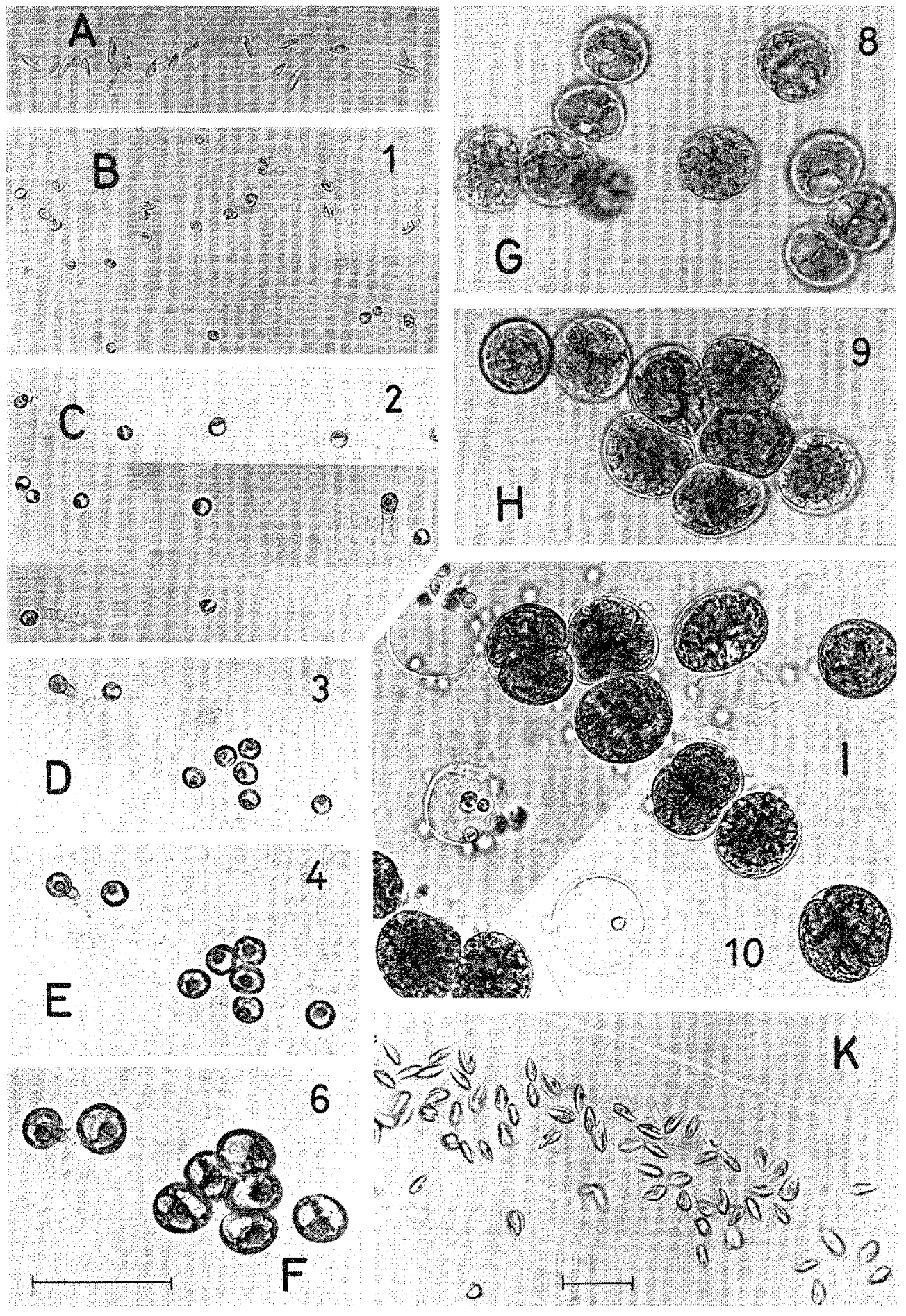

Abb. 18. Halochlorococcum marinum. Entwicklung aus zweigeißeligen Zoosporen, die mit Ausnahme von $A$ und $B$ einem Einzelsporangium entstammen. $D$ bis $F$ und $H$ zeigen jeweils dieselbe Gruppe von Zellen; die Ziffern geben das Alter der Kultur an. $K$ ViergeiBelige Zoosporen aus Sporangien bei $\mathrm{I}$. Maßstrecken: $\mathrm{A}$ und $\mathrm{K}=20 \mu \mathrm{m}_{\mathrm{i}} \mathrm{B}-\mathrm{I}=50 \mu \mathrm{m}$ 

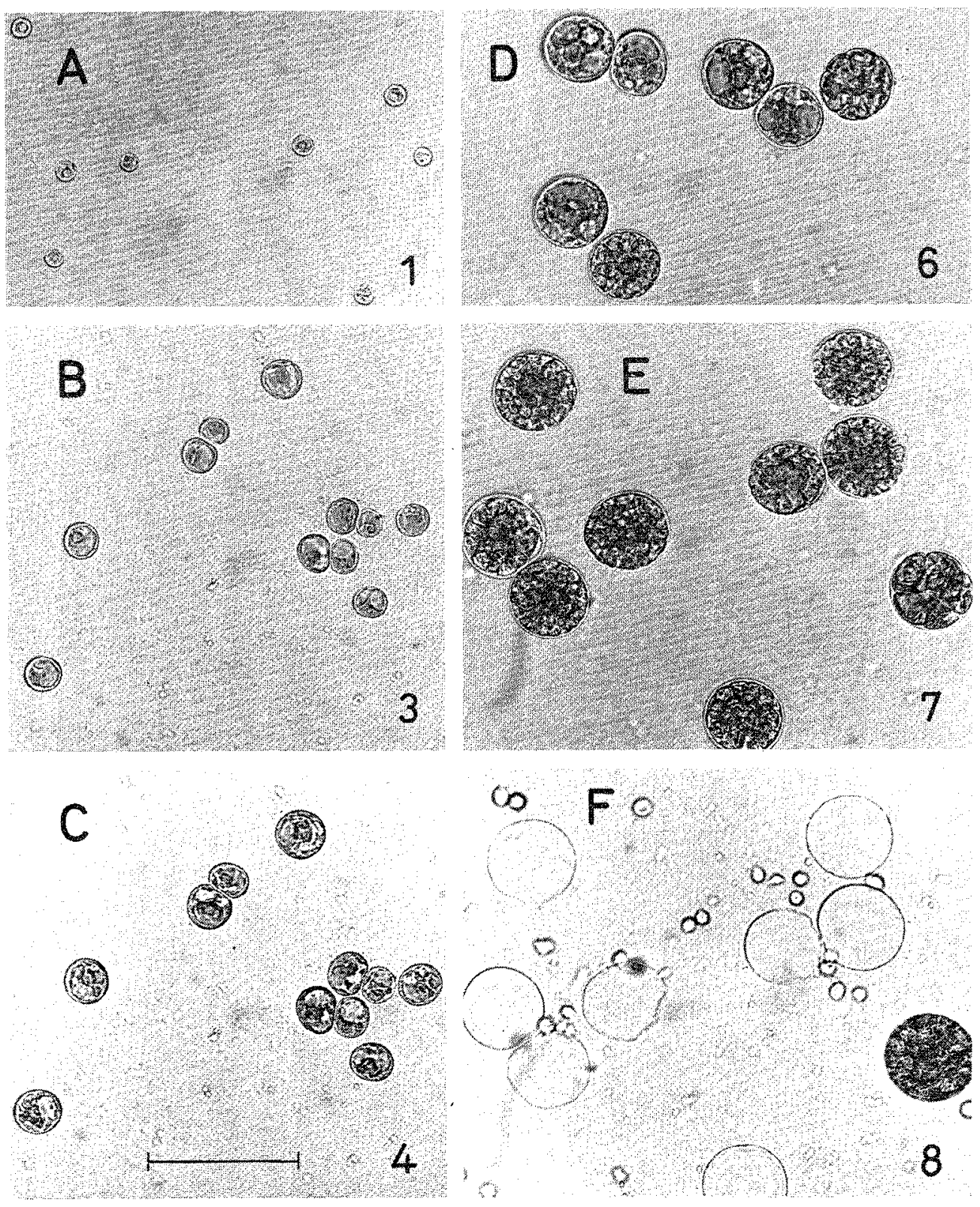

Abb. 19. Halochlorococcum marimum. Aus den in $\mathrm{Abb} .18 \mathrm{~K}$ dargestellten viergeiBeligen Zoosporen entstandene Generation. Bei $B$ und $C$ sowie bei $E$ und $F$ jeweils dieselben Gruppen; die Ziffern geben das Alter der Kultur an. Maßstrecke $=50 \mu \mathrm{m}$

gefärbte Sporangien mit kleineren und grüne mit größeren Schwärmern erkennen. Es lag daher nahe, die Versuche mit Einzelsporangien fortzusetzen.

In Abbildung $18 \mathrm{C}-1$ ist die Entwicklung zweigeißeliger Zoosporen aus einer Einzelkugel dargestellt, die Figuren bei A und B stammen aus einer Kultur mit vielen Zellen. Alle Zoosporen keimen, aber nur ein geringer Anteil entwickelt sich zu gestiel- 


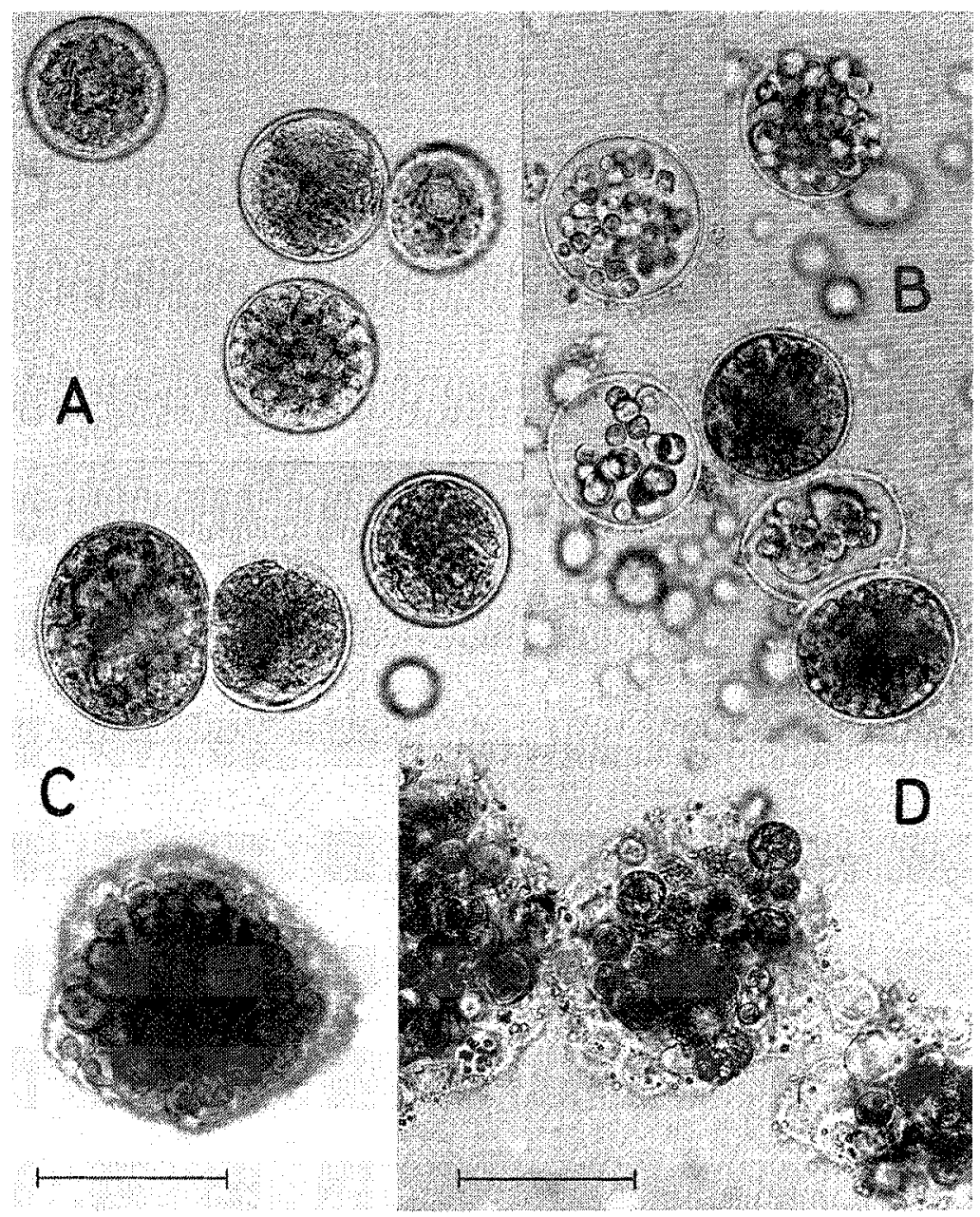

Abb. 20. Halochlorococcum marinum. Zellen des Typus B nach Dangeard. A Aus einer 19 Tage alten Kultur: Beginn der Schwärmerbildung. B Aus derselben Kultur, 8 Tage älter: unvollständig entleerte Sporangien. C Morula-artiger Zellhaufen. D Zellhaufen mit reifen und leeren Sporangien. MaBstrecken: $\mathrm{A}-\mathrm{C}=50 \mu \mathrm{m} ; \mathrm{D}=100 \mu \mathrm{m}$

ten Keimlingen. Die Stielchen erscheinen schon bei den nur ein Tag alten Keimlingen gegliedert (B). Diese Struktur wird an den folgenden Tagen deutlicher, zugleich nehmen die Stielchen in ihrem oberen Teil eine leicht bräunliche Färbung an. Sie bleiben erheblich kürzer als die Stielchen der Chlorocystis-Sporophyten, denen sie morphologisch ähnlich sind. Nach anfänglich nur langsamem Wachstum vergrößern sich die Kugeln vom 4. Tage an rasch. Die Stiele aufrecht wachsender Pflänzchen werden im allgemeinen von den größer werdenden Köpfchen verdeckt ( $F$ und $H$ ). Nach 8 Tagen beginnt der Protoplast sich aufzuteilen, und in der 10 Tage alten Kultur (I) sind schon einige Zellen ausgeschwärmt. Die Entleerung der Sporangien erfolgt in wenigen Sekunden. Durch eine große runde Offnung ergießt sich die Masse der Zoosporen in 
eine hyaline Blase, aus der sie sich schnell befreien. Die Sporangienhülle behält ihre scharfe Kontur und schrumpft nach dem Schwärmeraustritt nicht. Die in diesen Sporangien gebildeten Schwärmer waren viergeißelig $(\mathrm{K})$ und erheblich größer als die zweigeißeligen. Wie schon von Dangeard angegeben, sind sie abgeflacht; sie erscheinen daher, von der Fläche oder von der Seite gesehen, verschieden breit. Viele Schwärmer haben ein mehr oder weniger stark ausgebuchtetes Hinterende und können wie Doppelbildungen aussehen; sie haben aber nur einen Augenfleck. Häufig ist eine mehr oder weniger scharfe Längsfurche zu beobachten, die auch an dem unregelmäßigen Umriß vieler gerade sich festsetzender Zoosporen zu bemerken ist.

Die in Abbildung 19 dargestellte Generation stammt aus den viergeißeligen Zoosporen bei $18 \mathrm{~K}$. Am Tage nach dem Festsetzen waren die Keimlinge schon so groß wie die drei Tage alten aus zweigeißeligen Zoosporen. Vom 6 . Tage an wurden die Zellen fertil, und nach 7 und 8 Tagen entleerten sich die Sporangien. Es waren wiederum viergeißelige Zoosporen; erst die folgende Generation schwärmte überwiegend mit zweigeiBeligen Zoosporen.

Der von uns isolierte Stamm enthielt auch die von Dangeard (1965c) beschriebenen Zellen des Typus B. In allen Kulturen wurde ein mehr oder weniger großer Teil der Zellen nicht nach 10 bis 12 Tagen fertil. Sie wuchsen weiter und erreichten Durchmesser von 40 bis $50 \mu \mathrm{m}$; ihr Inhalt wurde dunkelgrün und erschien fein granuliert. Nach Erneuerung der Nährlösung wurden die etwa 3 Wochen alten Zellen fertil und schwärmten ganz normal aus. Häufig blieb aber ein Teil der Zoosporen in der Hülle zurück, sie keimten und entwickelten sich innerhalb des Sporangiums (Abb. 20 B). So entstanden die bei $\mathrm{C}$ abgebildeten Morula-ähnlichen Zellhaufen, deren einzelne Kugeln bei einer Größe von etwa 25-30 $\mu \mathrm{m}$ ausschwärmten. Wahrscheinlich gehen auch die von Dangeard beschriebenen, als Aplanosporen gedeuteten Zellhaufen auf solche im Sporangium zur Entwicklung gekommenen Schwärmer zurück; eine echte Aplanosporenbildung haben wir nicht beobachtet. Es sei noch erwähnt, daß in älteren Kulturen einzelne Kugeln bis zu $60 \mu \mathrm{m}$ dick werden konnten. Sie wurden auch nach dem Umsetzen in frische Nährlösung nicht fertil, sondern gingen nach einiger Zeit zugrunde.

\section{Zusammenfassende Schlußbemerkung}

Das eingehende Studium des bei Helgoland isolierten Stammes von Halochlorococcum marinum läßt keinen Zweifel an seiner Ubereinstimmung mit dem Typus Dangeards. Halochlorococcum marinum hat keinen obligaten Wechsel von Generationen mit zwei- und viergeißeligen Zoosporen. Auf ein Einzelsporangium mit zweigeißeligen Schwärmern können zwei Generationen mit Viergeißlern folgen. Andererseits schwärmte eine mit vielen zweigeißeligen Schwärmern angelegte, sehr dichte Kultur (Abb. 17 B) wiederum ganz überraschend mit Zweigeißlern, nur einige der zuerst reif gewordenen Sporangien enthielten viergeißelige Zoosporen. Ganz allgemein wurde in älteren Kulturen ein Überwiegen der zweigeißeligen Schwärmer beobachtet.

Ebenso ungeklärt wie die unregelmäßige Aufeinanderfolge der Generationen sind die Ursachen für die in allen Kulturen beobachtete unterschiedliche Entwicklung der zweigeißeligen Zoosporen teils zu ungestielten, teils zu gestielten Zellen. Dies gilt selbst für die einem einzigen Sporangium entstammenden, unter völlig gleichen Kulturbedingungen wachsenden Keimlinge (Abb, 18),

Parthenogenetisch sich zu Codiolum-Stadien entwickelnde Gameten sind bei allen 


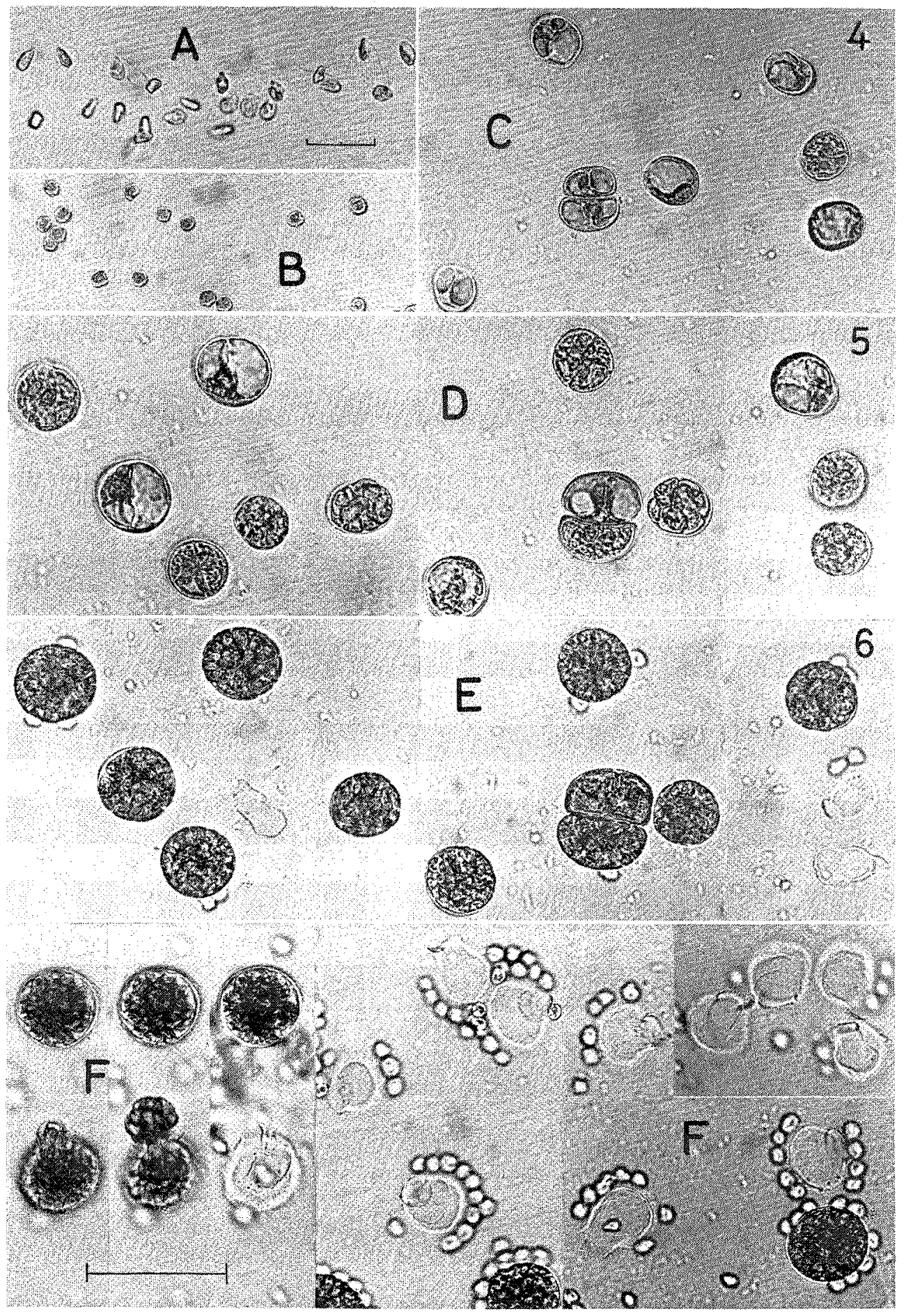

Abb. 21. Halochlorococcum tenuis. A Schwärmer am Tropfenrand. B Schwärmer nach dem Festsetzen. C-E Dieselbe Zellengruppe 4,5 und 6 Tage alt; die kleinsten Zellen werden zuerst reif. F Aus der 7 Tage alten Kultur, links unten Entleerung eines Sporangiums. Maßsstrecken: $A=20 \mu m$; $B-F$ $=50 \mu \mathrm{m}$ 
Gattungen der Codiolophyceen bekannt. Kürzlich machte Berger-Perrot (1980) bei Urospora gracilis (= Ulotrichella gracilis Berger-Perrot, 1981) eine Beobachtung, die zu den Befunden bei Halochlorococcum überleitet. ZweigeiBelige Zoosporen, als parthenogenetische Gameten interpretiert, ergaben eine Codiolum-Generation, aus deren viergeißeligen Schwärmern wieder Fäden hervorgingen. Wie bei Halochlorococcum wurde auch bei Ulotrichella gracilis keine Sexualität festgestellt, das Codiolum-Stadium entstand aus ungeschlechtlichen zweigeißeligen Zoosporen.

\section{Halochlorococcum tenuis spec. nov.}

Die in der Kulturensammlung der Universität Texas (Starr, 1978) als Halochlorococcum marinum bezeichnete Alge (Utex 1490) stimmt nicht mit den Merkmalen des von Dangeard (1965c) beschriebenen Typus überein. Bei wiederholten Prüfungen verschieden alter Kulturen wurden immer nur viergeißelige Schwärmer beobachtet, während die typische Art vier- und zweigeiBelige Zoosporen hat. Guillard et al. (1975) haben das Material mit ihrer neuen Art, Halochlorococcum saccatum, verglichen und offenbar auch keine zweigeißeligen Zoosporen beobachtet (p. 19: "H. marinum is said to form both quadri- and biflagellate ones"). Die Kugeln erreichen auch nicht die von Dangeard angegebene Größe von 30-40 $\mu \mathrm{m}$; reife Sporangien sind nur $20-32 \mu \mathrm{m}$ dick. Sie sind sehr zartwandig und schrumpfen daher deutlich nach der Entleerung, während Dangeards einzige Zeichnung eines leeren Sporangiums eine glatte Membran mit scharfem Umriß zeigt (Tafel I, Fig. 9). In ihrer kurzen Entwicklungszeit weicht "Utex 1490" sowohl von unserer mit Halochlorococcum marinum identifizierten Form als auch von den übrigen Arten der Gattung $a b$; sie muß daher als bisher nicht beschriebenes Taxon erkannt werden. Offenbar hat Izard, der die Alge 1965 der Kulturensammlung übermittelte, sie ohne nähere Prüfung als identisch mit Halochlorococcum marinum angesehen.

Die viergeißeligen Schwärmer (Abb. 21 A) sind abgeflacht, mitunter an ihrem hinteren Ende etwas ausgebuchtet. Sie sind 6-7 $\mu \mathrm{m}$ lang, in Flächenansicht bis $5 \mu \mathrm{m}$, auf der Kante liegend etwa $3 \mu \mathrm{m}$ breit. Morphologisch sind sie den viergeißeligen Schwärmern von $H$. marinum ähnlich, erreichen jedoch nicht deren Größe. Nur während der ersten vier Tage bleiben die sich entwickelnden kugeligen Zellen vegetativ und zeigen den lockeren netzförmigen Chromatophor mit großem Pyrenoid. Vereinzelte Zellen beginnen sogar schon am vierten Tage mit der Aufteilung des Protoplasten, und zwar sind es - wie auch bei den anderen Arten - die kleineren Kugeln, bei denen die Fertilisierung zuerst beginnt (Abb. $21 \mathrm{C}$ ). In der 5 Tage alten Kultur (D) sind die meisten Zellen in Umwandlung, sie sind deutlich größer geworden und erreichen ihre endgïltige Größe vor der vollständigen Aufteilung in Schwärmer am 6. Tage, an dem sich schon einzelne Sporangien entleeren (E). In der 7 Tage alten Kultur sind viele Zellen ausgeschwärmt (F).

Die Entleerung konnte mehrfach beobachtet werden, sicherlich durch die stärkere Beleuchtung ausgelöst ( $F$, links unten). Das Sporangium öffnet sich an einer vorher nicht erkennbaren Stelle; durch eine weite und oft schlundartig vorgezogene Mündung strömen die Schwärmer rasch in eine ausgestülpte Blase, aus der sie sich nach wenigen Sekunden befreien. Die Sporangienwandung ist auBerordentlich zart; sie schrumpft und deformiert sich nach dem Ausschwärmen mehr oder weniger stark, wie ein Vergleich von reifen und leeren Sporangien erkennen läßt (Abb. 21 D, E). Ausschnitte aus der 7 Tage alten Kultur zeigen die Zartheit der urnenförmigen Hüllen mit ihrer oft recht 




Abb. 22. Halochlorococcum operculatum. A Schwärmer, lebend am Tropfenrand und gefärbt mit Hämatoxylin nach Ehrlich. B, C Vegetative Zellen nach 3 bzw. 6 Tagen. D Beginnende Fertilisierung am 7. Tage. $E_{1} E^{\prime} 9$ Tage alte Kultur; die reifen Sporangien schwärmten während der Beobachtung aus. F Leere Sporangien; rechts: Entleerung eines Sporangiums. Die eingetragenen Ziffern geben das Alter der Kultur an. Maßstrecken: $A=10 \mu \mathrm{m} ; \mathrm{B}-\mathrm{F}=50 \mu \mathrm{m}$ 
großen Mündung, an der mitunter ein deckelartig abstehendes Membranfragment haftet.

\section{Diagnose}

Halochlorococcum tenuis spec. nov.

Zellen kugelig, Chromatophor netzförmig mit Pyrenoid. Sporangien 20-32 $\mu \mathrm{m}$ dick. Die viergeißeligen Zoosporen sind abgeplattet, oftmals mit leicht ausgebuchtetem Hinterende, 6-7 $\mu \mathrm{m}$ lang, in Flächenansicht bis $5 \mu \mathrm{m}$, auf der Seite liegend etwa $3 \mu \mathrm{m}$ breit, Geißeln etwa doppelt so lang wie der Körper. Die zarte Membran der Sporangien fällt bei der Schwärmerentleerung zusammen, die leeren Hüllen sind schlauch- oder urnenförmig.

Typus: Abbildung 21 (p. 36)

Herkunft: Utex 1490, fälschlich als Halochlorococcum marinum Dangeard bezeichnet.

Halochlorococcum tenuis spec. nov.

Cellulae globosae. Chromatophorum reticulatum, pyrenoideo praediturn. Diametrus sporangii $20-32 \mu \mathrm{m}$. Propagatio zoosporis quadriflagellatis planis effecta quarum posterior pars saepe paulum sinuosa est; $6-7 \mu \mathrm{m}$ longis, ad $5 \mu \mathrm{m}$ latis, $3 \mu \mathrm{m}$ altis. Flagellum circiter duplum cellulae. Membrana tenuis zoosporangiorum post liberationem zoosporarum collapsa et formam utris vel umae assumens.

Typus: Figura 21 (p. 36).

Origo: Utex 1490, falso nominatum Halochlorococcum marinum Dangeard.

Halochlorococcum operculatum spec. nov.

Ausgangsmaterial der nur einmal in unseren Kulturen aufgetretenen Art war eine am 28. Juli 1978 in einem Tümpel nahe der Niedrigwasserlinie gesammelte alte Austernschale. Aus den viergeißeligen, recht einheitlich $7-8 \mu \mathrm{m}$ langen und $5 \mu \mathrm{m}$ breiten Zoosporen (Abb. 22 A) entwickeln sich die rundlich-elliptischen, bei dichter Lagerung gegeneinander abgeplatteten Zellen mit netzförmigem Chromatophor und großem Pyrenoid. Bis zum 6. Tage bleiben sie vegetativ (C); am 7. Tage beginnt in einzelnen Kugeln die Schwärmerbildung (D). Dieser Vorgang spielt sich nicht gleichzeitig in allen Zellen ab, auch am 9. Tage waren noch einzelne Zellen in Umwandlung. Die reifen Sporangien schwärmten während der mikroskopischen Beobachtung aus ( $E$, E'). Die Sporangienöffnung ist recht klein, und die Zoosporen ergießen sich ziemlich langsam in eine ausgestülpte Blase, bevor sie frei werden ( $F$, ganz rechts). Die leere Hülle ist gegenüber dem reifen Sporangium nur unwesentlich deformiert, ihre Membran ist deutlich gestreift. An der scharf umrissenen Sporangienöffnung haftet in den meisten Fällen der aus der Wandung gelöste Membranausschnitt als Deckel. Dieses Merkmal teilt Halochlorococcum operculatum mit dem Epiphyten auf Blidingia, $H$. moorei (Abb. 24 F).

\section{Diagnose}

Halochlorococcum operculatum spec, nov.

Zellen rundlich-elliptisch, der größere Durchmesser länglicher Sporangien erreicht $42 \mu \mathrm{m}$. Chromatophor netzartig mit Pyrenoid. Vermehrung durch viergeißelige Zoospo- 
ren, 7-8 $\mu \mathrm{m}$ lang und 5-6 $\mu \mathrm{m}$ breit, Geißeln etwa doppelt so lang wie der Körper. Das leere Sporangium verändert seine Form mur wenig, es öffnet sich mit einem runden, 10-14 $\mu \mathrm{m}$ großen Loch, an dem häufig der Membranausschnitt als Deckel haftet.

Typus: Abbildung 22 (p. 38). Aus einer Kultur mit einer alten Austernschale aus einem Gezeitentümpel an der Niedrigwasserlinie isoliert.

\section{Halochlorococcum operculatum spec. nov.}

Cellulae subglobosae vel ellipsoidales. Major diametrus oblongorum sporangiorum ad $42 \mu \mathrm{m}$. Chromatophorum reticulatum pyrenoideo praeditum. Propagatio zoosporis quadriflagellatis effecta, $7-8 \mu \mathrm{m}$ longis, 5-6 $\mu \mathrm{m}$ latis. Flagellum circiter duplum cellulae. Sporangium exhaustum commutat formam minime. Zoosporae per foraminem praeformatum liberatae, 10-14 $\mu \mathrm{m}$ latum; pars membranae excisa format operculum adhaerentem.

Typus: Figura 22 (p. 38).

Origo: Cultura isolata de testa Ostreae edulis collecta in parvo lacu litoris insulae Helgolandiae.

Halochlorococcum dilatatum spec. nov.

Diese Art wurde mehrfach isoliert, sowohl aus Rohkulturen mit Muschelschalen und Steinen aus Tümpeln nahe der Niedrigwasserlinie als auch aus dem Sublitoral. Die kugeligen Sporangien sind 30-38 $\mu \mathrm{m}$ dick, ihre Zoosporen etwas kleiner als die von $H$. operculatum, ziemlich einheitlich 6-7 $\mu \mathrm{m}$ lang und $5 \mu \mathrm{m}$ breit (Abb. $23 \mathrm{~A}$ ). Die vier Tage alte Kultur (B) zeigt kugelige Zellen, deren Chloroplast dichter ist und die netzartige Struktur nicht so ausgeprägt erkennen läßt wie bei den vorher beschriebenen Arten. Die fortschreitende Fertilisierung derselben Gruppe von Zellen vom 6. bis zum 8. Tage ist. bei C-E dargestellt. Auch hier läuft dieser Vorgang nicht gleichzeitig in allen Zellen ab, sie wachsen bis zur Aufteilung ihres Protoplasten und werden daher unterschiedlich groß. Die Zoosporen entleeren sich durch eine breite Offnung der verquellenden Membran zunächst in eine hyaline Blase, bevor sie frei werden $\left(F, F^{\prime}\right)$. Die leeren Hüllen zeigen in der Aufsicht und in Seitenansicht ein großes Loch (G). Ein charakteristisches Merkmal dieser Art ist die polare Struktur ihrer Zellen: der Sporangienöffnung gegenüberliegend ist die Wandung verdickt, was besonders deutlich an den seitlich liegenden leeren Hüllen zu erkennen ist (G). Auch bei vielen in Umwandlung befindlichen Zellen ist eine im optischen Schnitt sichelförmig erscheinende basale Wandverstärkung wahrzunehmen $(\mathrm{H})$.

\section{Diagnose}

Halochlorococcum dilatatum spec. nov.

Zellen kugelig. Chromatophor dicht netzförmig mit Pyrenoid. Vermehrung durch viergeißelige Zoosporen, $6-7 \mu \mathrm{m}$ lang, $5 \mu \mathrm{m}$ breit. Geißeln etwa doppelt so lang wie der Körper. Sporangien 30-38 $\mu \mathrm{m}$ dick. Entleerung der Schwärmer durch ein rundes, breites Loch, der ihm gegenüberliegende Teil der Membran ist verdickt und erscheint in Seitenansicht sichelförmig.

Typus: Abbildung 23 (p. 41). Vorkommen: Helgoland. Aus Kulturen mit Steinen und Muschelschalen aus Gezeitentiümpeln und dem Sublitoral isoliert. 




Abb. 23. Halochlorococcum dilatatum. A Schwärmer am Tropfenrand, lebend. B 4 Tage alte Kultur. C-E Dieselbe Zellengruppe vom Beginn der Fertilisienung bis zur Reife; die eingetragenen Ziffern geben das Alter an. F, F' Entleerung eines Sporangiums. G Leere Sporangien in der Aufsicht und in Seitenansicht. H Sichelförmige Wandverstärkung an der Basis junger Sporangien, vgl. auch $G$. Maßstrecken: $A=10 \mu \mathrm{m} ; B-H=50 \mu \mathrm{m}$ 


\section{Halochlorococcum dilatatum spec. nov.}

Cellulae globosae. Chromatophorum confertim reticulatum, pyrenoideo praeditum. Diametrus sporangii $30-38 \mu \mathrm{m}$. Propagatio zoosporis quadriflagellatis effecta, $6-7 \mu \mathrm{m}$ longis, $5 \mu \mathrm{m}$ latis. Flagellum circiter duplum cellulae. Zoosporae per foramen rotundum et valde latum liberatae. Membrana sporangii foramini opposita incrassata efficiens aspectum a latere falcatum.

Typus: Figura 23 (p. 41). Origo: Habitant lapides et testas Molluscorum in zonis litoralibus et sublitoralibus insulae Helgolandiae.

Halochlorococcum moorei (Gardner) comb. nov.

Basionym: Chlorochytrium moorei Gardner 1917

Synonym: Chlorocystis cohnii (Wright) Reinhard bei Moore, 1900; ?Chlorochytrium willei Printz 1926

Nach dem eingehenden Studium von vier ihrer Arten mit der Gattung Halochlorococcum vertraut, konnte ihr noch eine weitere, längst bekannte Alge zugeführt werden. Als Chlorocystis cohnii (Wright) Reinhard veröffentlichte Moore (1900) seine Beobachtungen über einen auf Blidingia wachsenden Epiphyten. Seine Abbildungen kennzeichnen diese Alge ganz eindeutig: die auf der Wirtspflanze aufsitzenden oder leicht eingesenkten KugeIn, den netzartigen Chromatophor mit dem stets an der Außenwand liegenden, großen Pyrenoid, die charakteristische schizogone Aufteilung des Zellinhaltes bei der Bildung der viergeißeligen Schwärmer und die sich mit einem Deckel öfnenden Sporangien. Selbst die von Moore beobachteten kleineren Zoosporen lassen sich vielleicht deuten: es könnten Blidingia-Schwärmer sein, die bei der Keimung einen hyalinen Schlauch bilden (Tafel X, Abb. 13 und 8). Gardner (1917) hat Moores irrtümliche taxonomische Auffassung berichtigt und diese Alge Chlorochytrium moorei genannt. Mit der neuen Kombination Halochlorococcum moorei (Gardner) wird der Blidingia-Epiphyt aus der Verflechtung mit der Süßwasser-Gattung Chlorochytrium gelöst und erhält einen wohlbegründeten Namen.

In freier Kultur entwickeln sich die viergeißeligen Zoosporen von Halochlorococcum moorei in gleicher Weise wie die der übrigen Arten (Abb. 24). Dicht aneinandergelagert platten sich die Zellen jedoch nicht $a b$, sondern bilden Haufen von kugeligen Zellen. Die Membran bleibt auch nach dem Ausschwärmen kugelig. An der kreisrunden, scharf herausgeschnittenen Sporangienöffnung haftet im allgemeinen der deckelförmige Membranausschnitt ( $E, F)$.

Auf ihrer Wirtspflanze Blidingia kultiviert, entsprechen die Epiphyten ganz der Darstellung bei Moore (Abb. 25). Proben des Naturmaterials stimmen völlig mit den Beobachtungen an den Kulturen überein (Abb. 26).

Halochlorococcum moorei ist bei Helgoland ein auf Blidingia-Arten oft anzutreffender Epiphyt. Zur Beobachtung eignen sich besonders die ausgeschwärmten Partien der Wirtsalge (Abb. 26 A, D). Der Einfluß der Epiphyten auf Blidingia ist unterschiedlich stark; im allgemeinen sitzen sie auf der Oberfläche oder bewirken nur eine Umwallung durch die angrenzenden Wirtszellen. Sie können aber auch ganz in die Zellschicht von Blidingia eingesenkt sein, so daß nach dem Ausschwärmen der Epiphyten Löcher in dem Gewebe entstehen, das gelegentlich netzartig durchbrochen wird (E). Auch in den Kulturen ließen die ausgeschwärmten Kugeln manchmal Löcher in der Wirtsalge zurück 


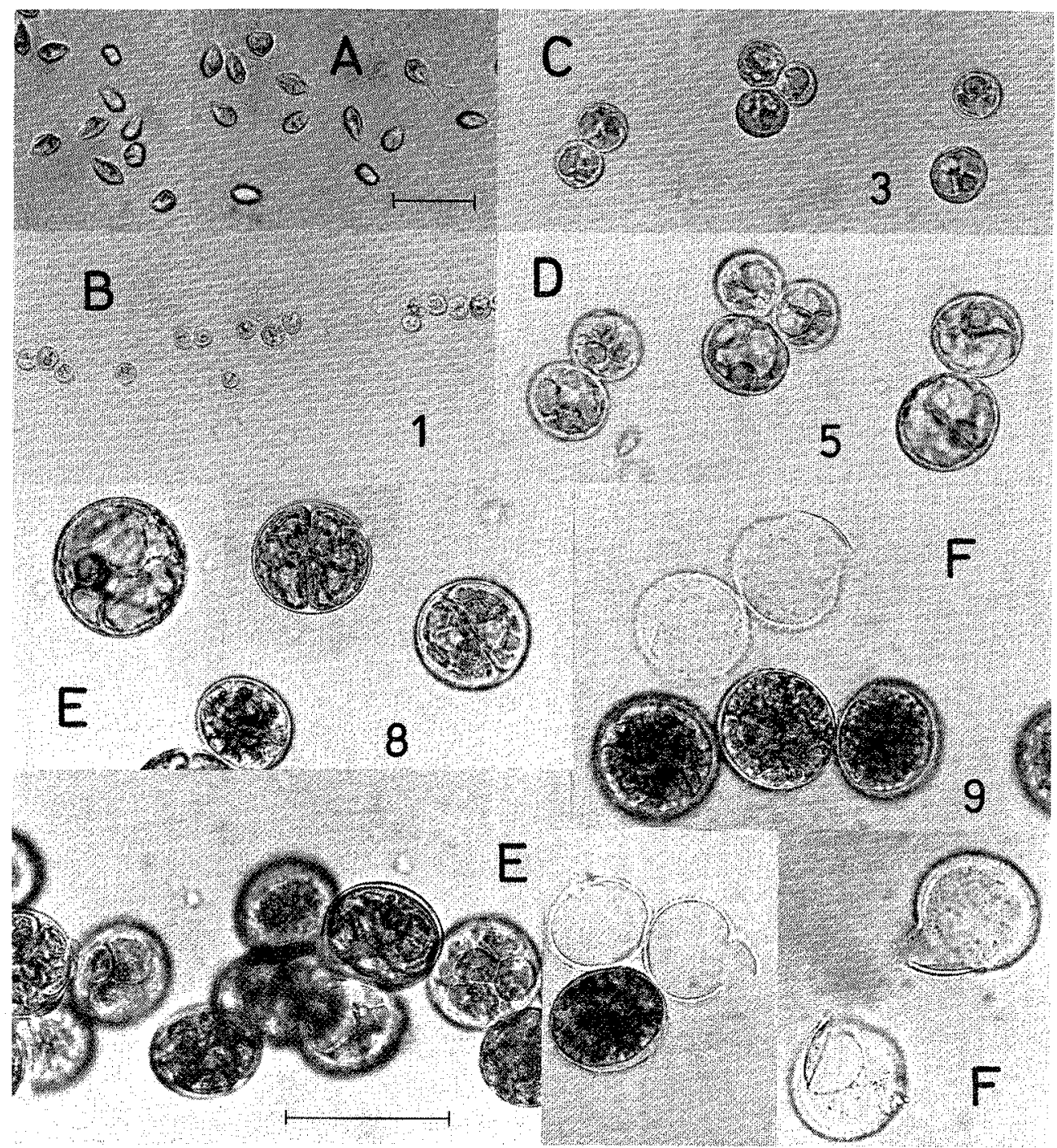

Abb. 24. Halochlorococcum moorei. A Zoosporen. B-F Entwicklung in freier Kultur; die eingetragenen Ziffern geben das Alter in Tagen an. Maßstrecken: $A=20 \mu \mathrm{m} ; \mathrm{B}-\mathrm{F}=50 \mu \mathrm{m}$

(Abb. 25 E). Bei sehr starkem Befall kann Blidingia ganz unnatürlich kraus und dunkelgrün erscheinen, wie in zwei im Juni 1978 gesammelten Proben.

In unserer Arbeit von 1977 ist Halochlorococcum moorei als Chlorochytrium (?) willei aufgeführt. Nach Printz' eigenen Angaben (1926) steht die Alge aus dem Trondhjemsfjord sicherlich Chlorochytrium moorei recht nahe, unterscheidet sich aber von dieser Art durch eine warzen- bis schnabelförmige Verdickung der Sporangienwand. Solche Membranpapillen konnten wir an dern Helgoländer Material nicht beobachten, so daß die Ubereinstimmung mit der von Printz beschriebenen Art nicht ganz gesichert erscheint. 


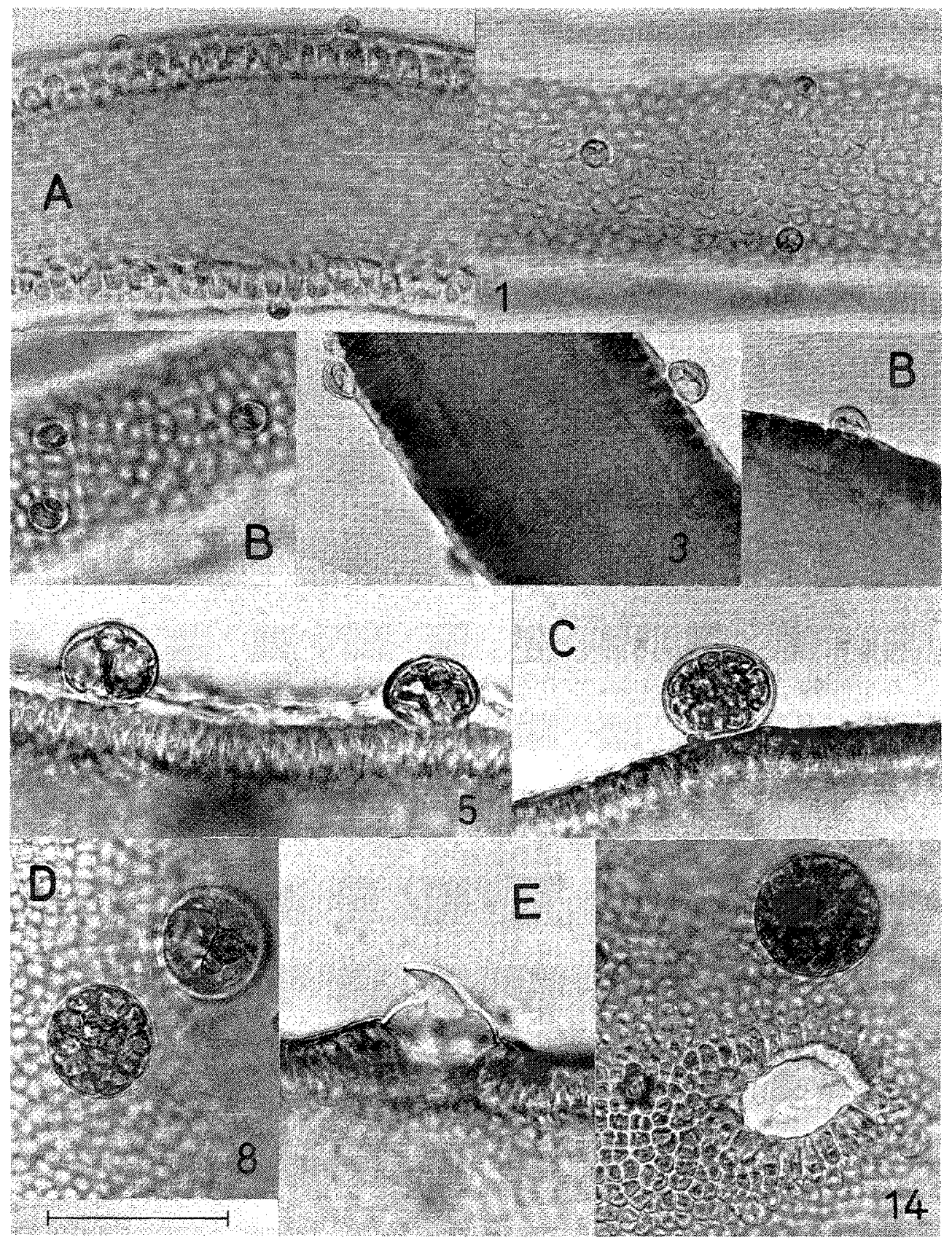

Abb. 25. Halochlorococcum moorei. A-E Als Epiphyten auf Blidingia minima kultiviert. Die eingetragenen Ziffern geben das Alter der Epiphyten an. Maßstrecken: $A-E=50 \mu \mathrm{m}$ 

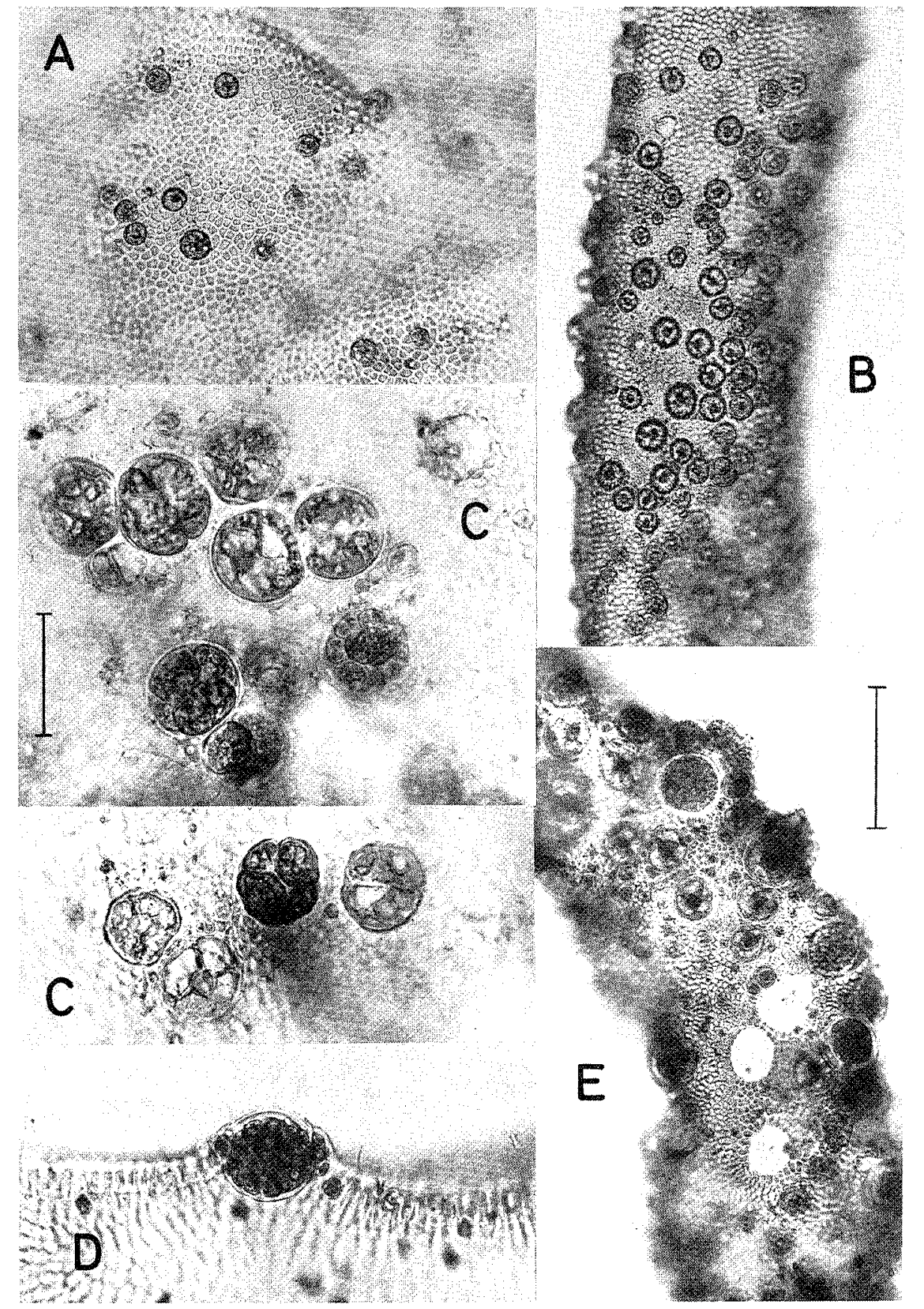

Abb. 26. Halochlorococcum moorei, Naturmaterial auf Blidingia minima. A, D Auf dem ausgeschwärmten Thallus der Wirtspflanze. B, C Vegetative und in Umwandlung befindliche Zellen. E Der Blidingia-Thallus ist nach dem Ausschwärmen der eingesenkten Epiphyten netzartig durchbrochen. Maßstrecken: A, B, E $=100 \mu \mathrm{m} ; \mathrm{C}, \mathrm{D}=50 \mu \mathrm{m}$ 
Der folgende Schlüssel enthält die wesentlichen Merkmale zur Unterscheidung der fünf Halochlorococcum-Arten:

A. Epiphytisch auf Blidingia-Arten ... . . . . . . . . . H. moorei

A. Aus Rohkulturen von Steinen, Muschelschalen oder Algen isoliert . B

B. Mit vier- und zweigeißeligen Zoosporen . . . . . . . . . . . . H. marinum

B. Nur viergeißelige Zoosporen . . . . . . . . . . . . . . . . C

C. Sporangien 20-32 $\mu \mathrm{m} \varnothing$, kugelig, zartwandig, leere Hülle

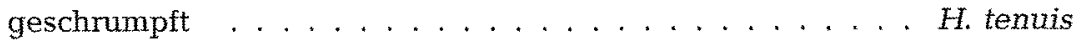

C. Sporangien $30-40 \mu \mathrm{m}$, kugelig oder elliptisch . . . . . . D

D. Sporangienöffnung klein, mit Deckel .......... H. operculatum

D. Sporangien verquellen mit weiter Offnung, ihr gegenüber-

liegend ist die Wandung verdickt .......... . H. dilatatum

\section{BRYOPSIDOPHYCEAE}

"Characium hagmeierianum O. C. Schmidt" = Chaetomorpha-Keimlinge

Um es vorwegzunehmen: die Existenz mariner Characium-Arten ist zweifelhaft, und eine taxonomische Uberprüfung wird als notwendig erachtet (Parke \& Dixon, 1976). Nach Levring (1937, p. 16, Fußnote) handelt es sich bei Characium marinum Kjellman um Keimlinge von Cladophora. Dieser Ansicht schließen wir uns für eine andere "Art", Characium hagmeierianum, an. O. C. Schmidt (1938) beschrieb diesen im Litoral von Helgoland auf Cladophora vorkommenden Epiphyten. Das nur bis $23 \mu \mathrm{m}$ lange Objekt ist kleiner als $C h$. marinum (bis $40 \mu \mathrm{m}$ ) und meist gestielt, die Zellen sollten ca. 16 Schwärmer von 4 bis $4,5 \mu \mathrm{m}$ Länge enthalten, deren Natur nicht festgestellt werden konnte.

Wir haben am 13. Juni 1978 eine dieser Beschreibung genau entsprechende Form beobachtet. Eine Probe von Chaetomorpha aerea aus einem Wasserloch war neben anderen Epiphyten mit "Schizonema"-Schläuchen besetzt. Sie beherbergten reichlich Chlorocystis cohnii und trugen epiphytisch die in Abbildung 27 A-E dargestellten Zellen, teils gestielt mit scheibenartigem FuB, teils auch in eine längere schlauchartige Basis mit einem roten Körperchen (Augenfleck?) verlängert. Viele Zellen zeigten die von O. C. Schmidt beobachtete Aufteilung des Inhalts, jedoch ohne Augenpunkte. Rohkulturen mit diesem Material wurden nicht fertil, vielmehr waren die Epiphyten 4 Wochen später zu mehrzelligen Fäden, wahrscheinlich Chaetomorpha aerea, ausgewachsen (F).

\section{PHAEOPHYCEAE}

\section{Myrionema strangulans}

Die häufig auf Ulva und Enteromorpha anzutreffenden runden, scheibenförmigen braunen Epiphyten werden im allgemeinen ohne nähere Prüfung als Myrionema strangulans angesehen. Wir haben im Laufe der Jahre viele Proben untersucht, doch nur in einem Falle traf diese Vermutung zu. Im allgemeinen fruktifizieren solche Epiphyten reichlich mit plurilokulären Sporangien, so daß es leicht möglich ist, Kulturen zu erhalten. Dabei stellt sich schnell heraus, ob sich die Zoosporen in der von Kylin (1934) 

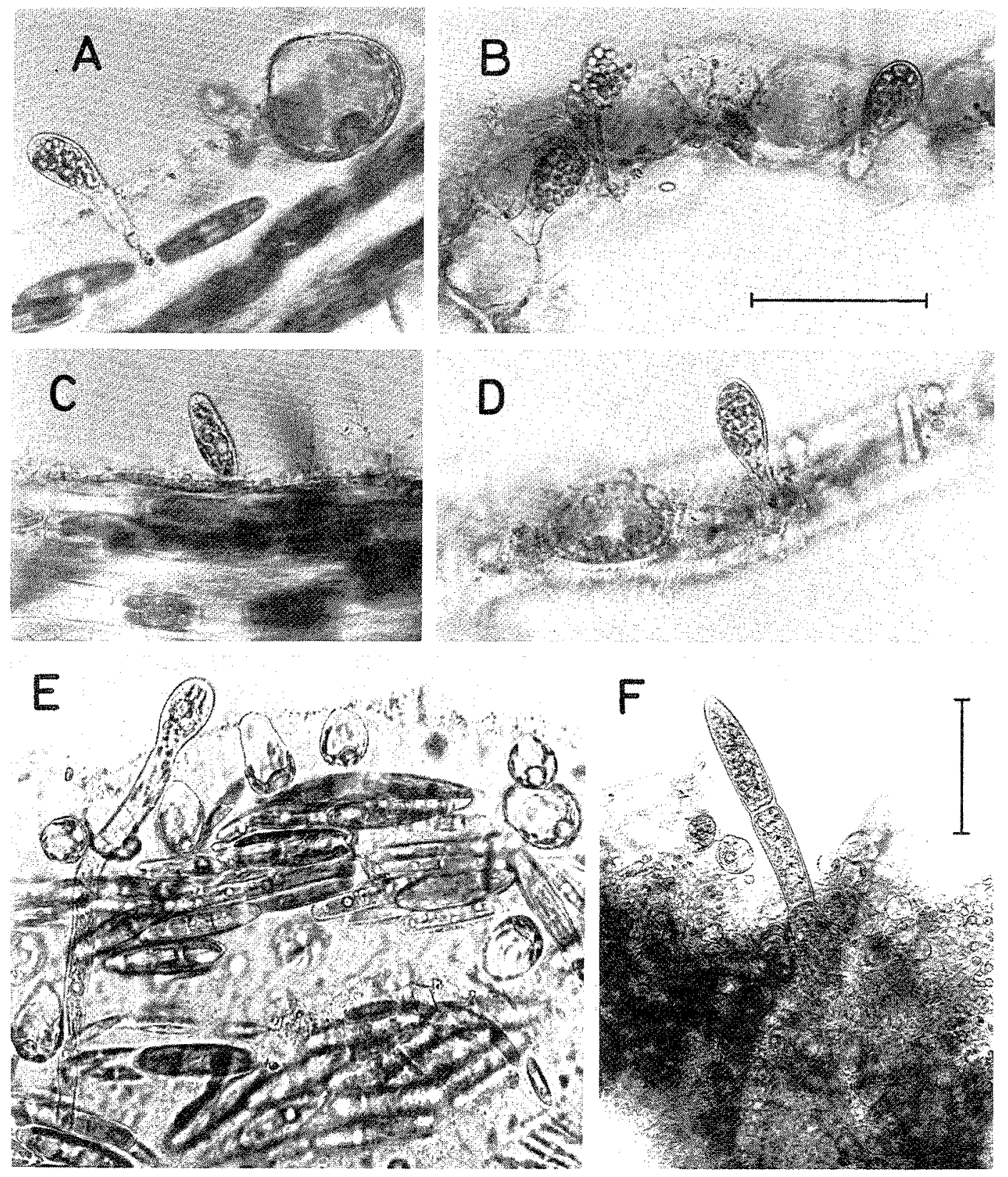

Abb. 27, "Characium hagmeierianum". A-E ,Schizonema" -Schläuche mit Chlorocystis cohnii und epiphytischen Chaetomorpha-Keimlingen, 13. 6. 1978. F In der Rohkultur entstandene Chaetomorpha-Fädchen. Maßstrecken: $A-E=50 \mu \mathrm{m} ; \mathrm{F}=100 \mu \mathrm{m}$ 

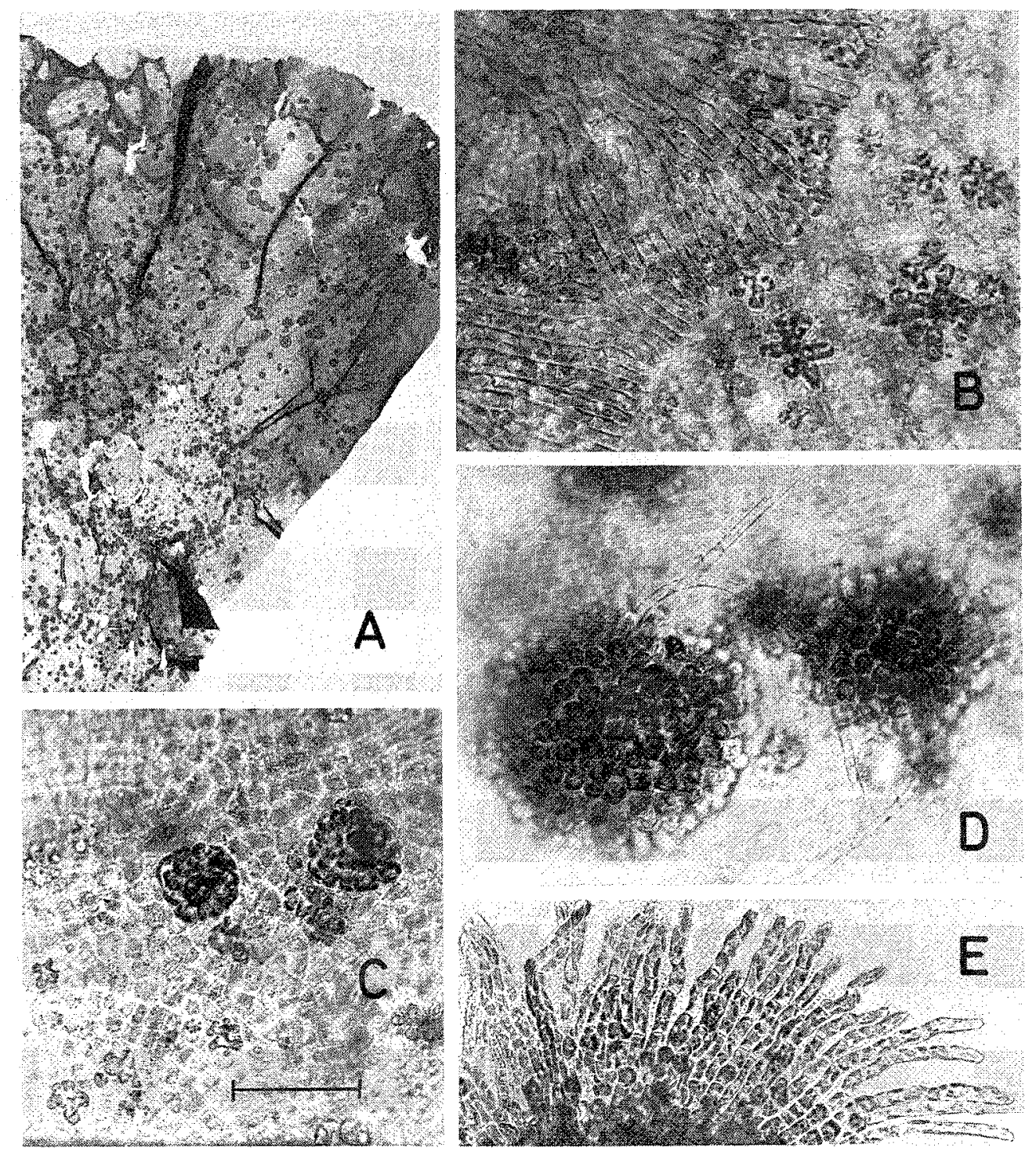

Abb. 28. Myrionema strangulans. A-D Naturmaterial. A Auf Ulva lactuca in natürlicher Gröbe, 19. 4. 1979. B-C Auf ausgeschwärmter U7va, Keimlinge gut erkennbar. D Fertiler Thallus mit Haaren. E Randteil einer auf einer Ulva-Membran in Kultur gewachsenen Pflanze. Maßstrecke: $B-E=50 \mu \mathrm{m}$

beschriebenen Weise gleich nach dem Festsetzen sternförmig auf der Unterlage ausbreiten und zu den für Myrionema strangulans charakteristischen Keimlingen entwikkeln (Abb. 29 A, B). Mitunter kann man solche Stadien auch im Naturmaterial finden (Abb. 28 B, C).

Im April und Mai 1979 wurde die Alge mehrfach auf Ulva lactuca von der untersten Stufe der Ostmole gesammelt (Abb. 28). Die Epiphyten waren in allen Entwicklungssta- 

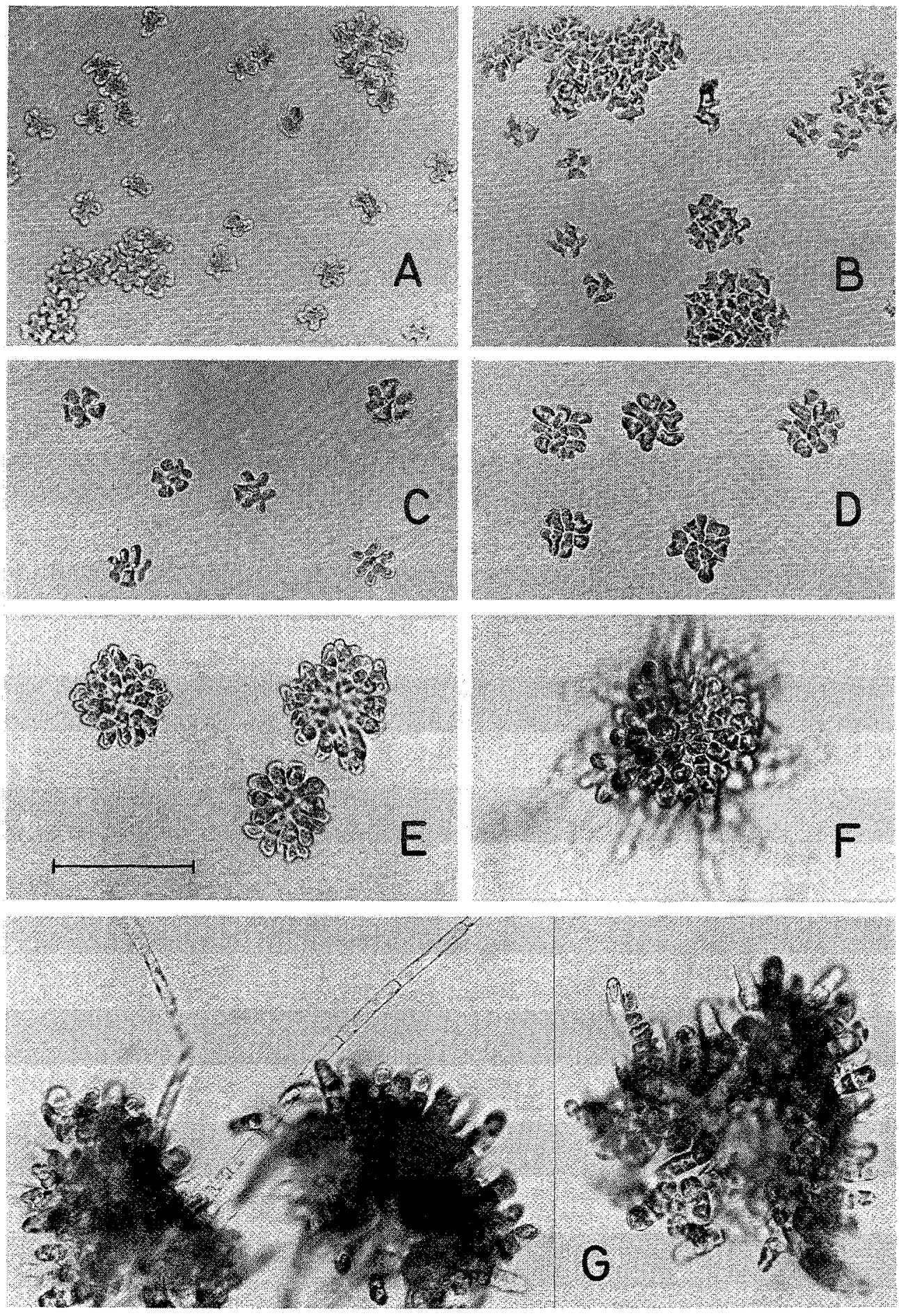

Abb. 29. Myrionema strangulans, Kulturen. A Zoosporen 11/2 Stunden nach dem Festsetzen, B nach 19 Stunden. C-E 2,3 und 5 Tage alte Scheiben. F 8 Tage alt, beginnende Sporangienbildung. G Fertile, 11 Tage alte Thalli. Maßstrecke: $A-G=50 \mu \mathrm{m}$ 
dien vertreten. Jüngere Thalli sind kompakte, in der Mitte gewölbte Scheiben; bei älteren Thalli bilden die Randpartien ein radial wachsendes, fest auf der Unterlage haftendes einschichtiges Lager. Auf dem mittleren Teil des Thallus erheben sich die aufrechten Fäden, Sporangien und Haare (Abb. 28 D).

Die Helgoländer Pflanzen trugen nur plurilokuläre Sporangien. Schon nach $1 \frac{1}{2}$ Stunden nehmen die zur Ruhe gekommenen Schwärmer eine charakteristische sternförmige Gestalt an (Abb. 29 A). Die Scheiben entstehen in ähnlicher Weise wie die von Uivella lens (B-D). Auf ausgeschwärmten UIva-Thalli als Substrat konnten Pflänzchen von natürlichem Habitus kultiviert werden, während sie sïch vom Boden der Kulturschalen im allgemeinen frühzeitig ablösen. 11 Tage alte Thalli fruktifizierten reichlich mit plurilokulären Sporangien (Abb. 29 G).

\section{Microspongium globosum Reinke}

Im April 1979 wurde diese Alge zum ersten Male bei Helgoland gefunden. Ihre kugeligen 1 bis $2 \mathrm{~mm}$ großen Polster besiedelten dicht die obere Hälfte der Fäden von Chaetomorpha melagonium, zusammen mit jungen Laminaria-Sporophyten, Säckchen von Monostroma, Ectocarpus und Schlauchdiatomeen (Abb. 30). Jüngere Polster sind flach; ihre einschichtige Basalscheibe trägt einreihige plurilokuläre Sporangien zwischen etwa gleichhohen aufrechten Fäden und Haaren (Abb. 31 A, B). In den älteren Büscheln sitzen die Sporangien meist endständig auf den nur scheinbar dichotom verzweigten Fäden; an die Stelle eines Zweiges kann auch ein Haar treten (C, D).

Die entwicklungsgeschichtliche Untersuchung ergab keine Besonderheiten; ältere verworren fädig wachsende Büschel fruktifizierten nach einem Wechsel der Nährlösung mit plurilokulären Sporangien (Abb. 31 F).

Microspongium globosum, von Reinke aus der Kieler Föhrde beschrieben, kommt reichlich an der schwedischen Westküste vor $(K y l i n, 1947)$ und ist in nördlichen Gewässern verbreitet (Island, Nordnorwegen, Ostgrönland); an den britischen Küsten wird die Alge nur für Schottland, Isle of Cumbrae, angegeben (Newton, 1931, als Hecatonema globosum Batt.).

\section{FLORIDEOPHYCEAE}

\section{Melobesia membranacea (Esper) Lamour.}

Melobesia membranacea gilt allgemein als epiphytische Corallinaceen-Kruste; als solche wird sie auch in einer entsprechenden Studie von Chamberlain (1978) behandelt und fehlt in der Bearbeitung der epilithischen Krusten von Adey \& Adey (1973). Thre epiphytische Lebensweise ist jedoch nicht obligat; Suneson (1943) fand sie zwar überwiegend auf anderen Algen, aber auch auf Hydroiden, Bryozoen, Muschelschalen und Steinen. Als bevorzugte Wirtspflanze wird Furcellaria angegeben, und diese bei Helgoland nicht häufige Rotalge beherbergt auch Melobesia. Regelmäßig und reichlich aber ist sie auf den Haftkrallen von Laminaria hyperborea zu finden, ebenso auf den dort häufig abgelegten Agonus-Eiern (Kommann \& Sahling, 1977).

Glasstïcke aus $6 \mathrm{~m}$ Tiefe waren reichlich mit Melobesia-, Lithophyllum- und Rhodophysema-Krusten besiedelt. Solche Thalli können ohne jede Präparation mikroskopisch untersucht werden. Gegenüber anderen Substraten - Algen oder Steinen - 


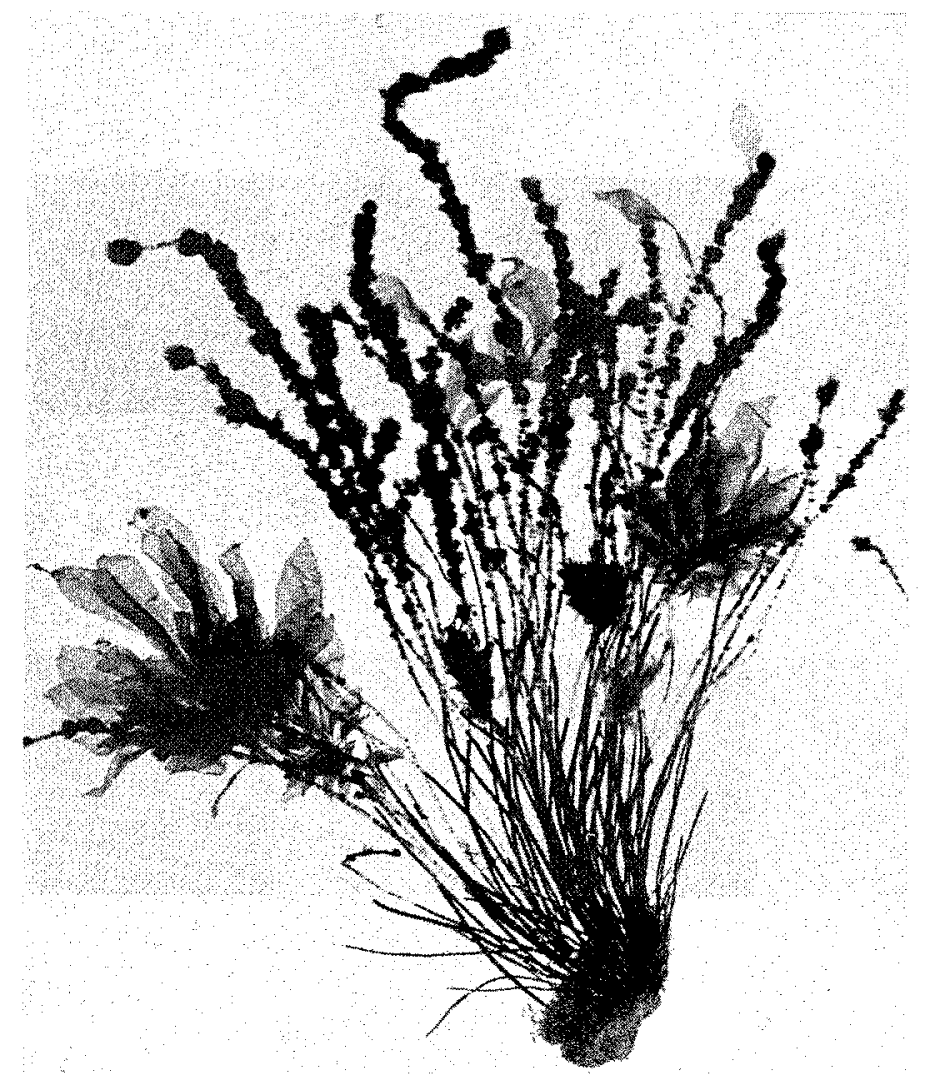

Abb. 30. Microspongium globosum. Auf Chaetomorpha melagonium. 14. 4. 1979. Natürliche Größe

breiten sich die Krusten auf der glatten, ebenen Glasfläche unbehindert zu kreisförmigen Thalli aus (Abb. 32, 34, 35). Geringfügige Hindernisse wie Cocconeis-Kolonien werden von der harten Kante des Randmeristems von Melobesia membranacea weggeschoben oder überwachsen (Abb, $32 \mathrm{C}$ ). Sehr anschaulich zeigt dieses Bild den weißen Saum der plastidenlosen Randinitialzellen. Die nur 1,5 mm große, schon fertile Kruste (Abb. $32 \mathrm{~A}$ ) ist auBerordentlich dünn und in einer breiten Randzone einschichtig, von den wenig auffallenden Epithalliumzellen abgesehen. Diese können aber an älteren und dickeren Thalli deutlich in Erscheinung treten (D). Die Mitte des Thallus zeigt den bei der Sporenkeimung zuerst gebildeten Zellkomplex, dessen Randzellen meristematisch werden (E).

Die Hypothalliumzellen teilen sich periodisch in konzentrischen Zonen. In ihnen leitet ein lokal verstärktes Perithalliumwachstum die Ausbildung der Konzeptakel ein, die daher ringförmig angeordnet sind. Drei aufeinanderfolgende Stadien der Konzeptakelentwicklung aus der Kruste Abbildung $32 \mathrm{~A}$ sind in Abbildung $33 \mathrm{~A}, \mathrm{~B}, \mathrm{~B}$ ' nach Fixierung und Färbung dargestellt.

Das Dach der reifen ungeschlechtlichen Konzeptakeln zeigt schon bei schwacher Vergrößerung die zahlreichen Porenöffnungen (Abb. $33 \mathrm{C}$ ). Die Sporangialkanäle sind 

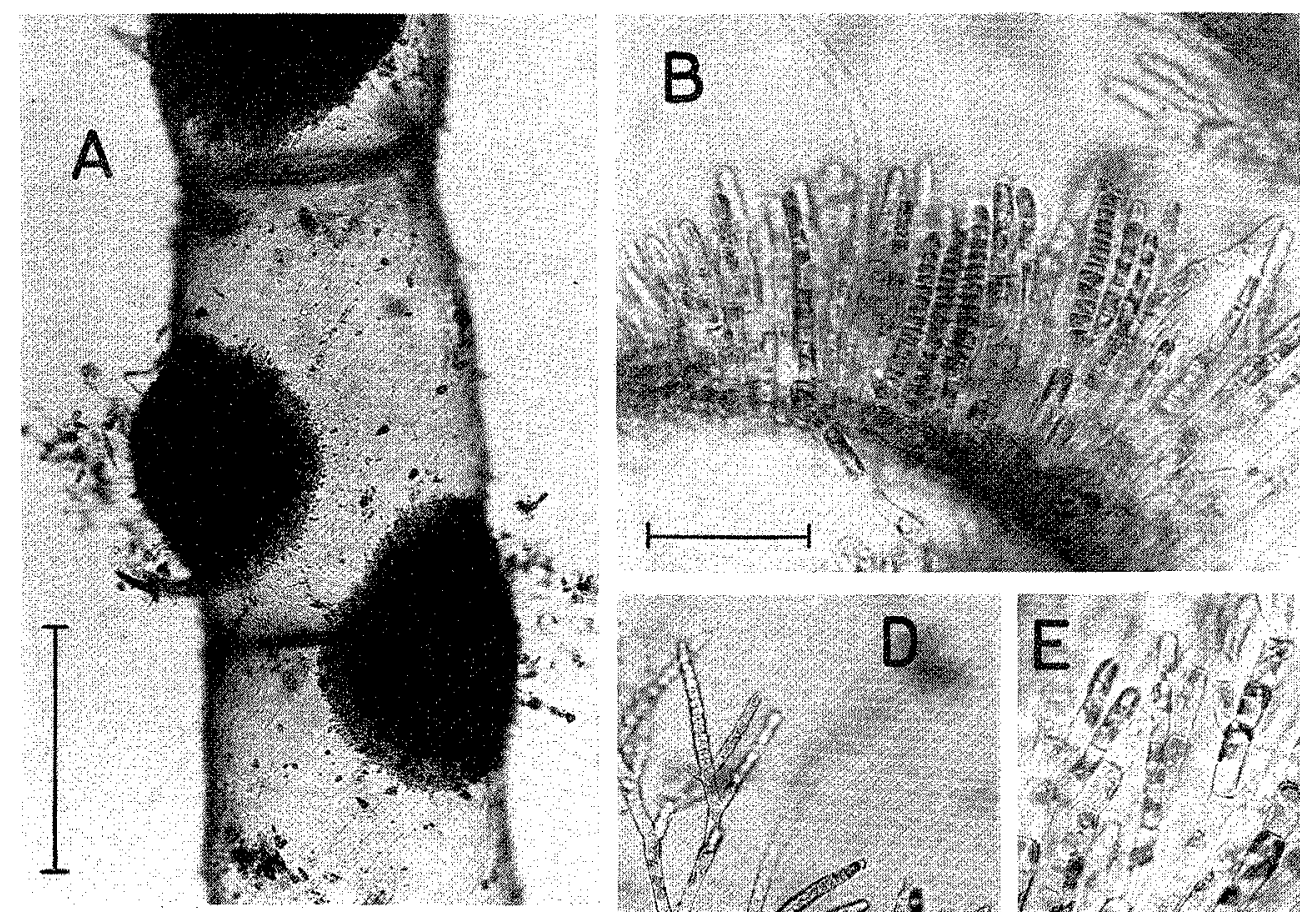

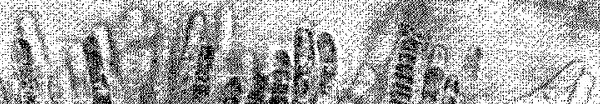
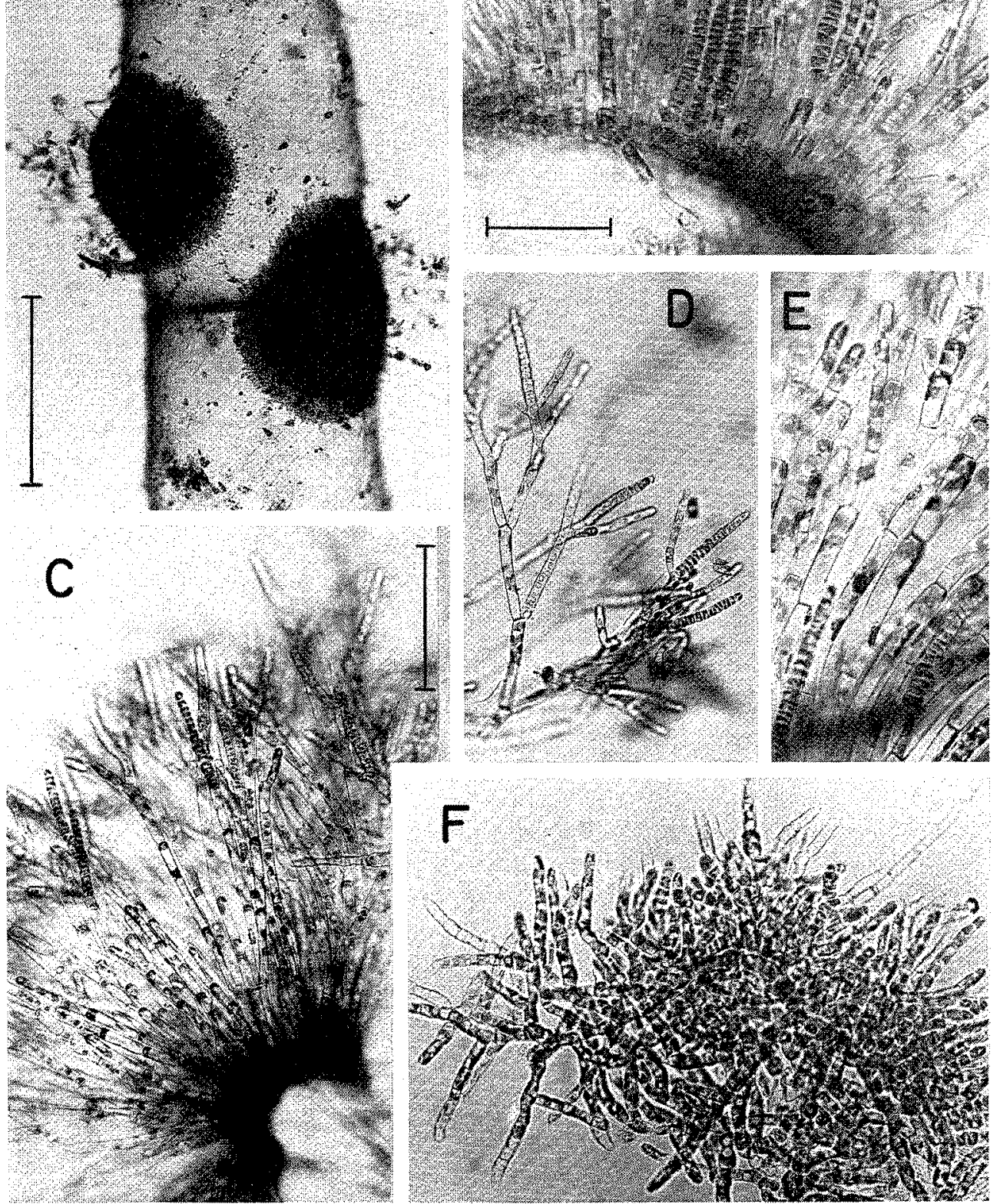

Abb. 31. Microspongium globosum. A-E auf Chaetomorpha melagonium, lebend. A Jüngere Polster, Haare mit Diatomeen besetzt. B Querschnitt durch ein jüngeres, C durch ein älteres Polster. D Verzweigte Fäden mit Sporangien und einem Haar. E Zellen meist mit zwei scheibenförmigen Chromatophoren. F In Kultur fertil gewordener Thallus. MaBstrecken: $A=500 \mu \mathrm{m}_{i} B, E, F=50 \mu \mathrm{m}_{\text {; }}$ 


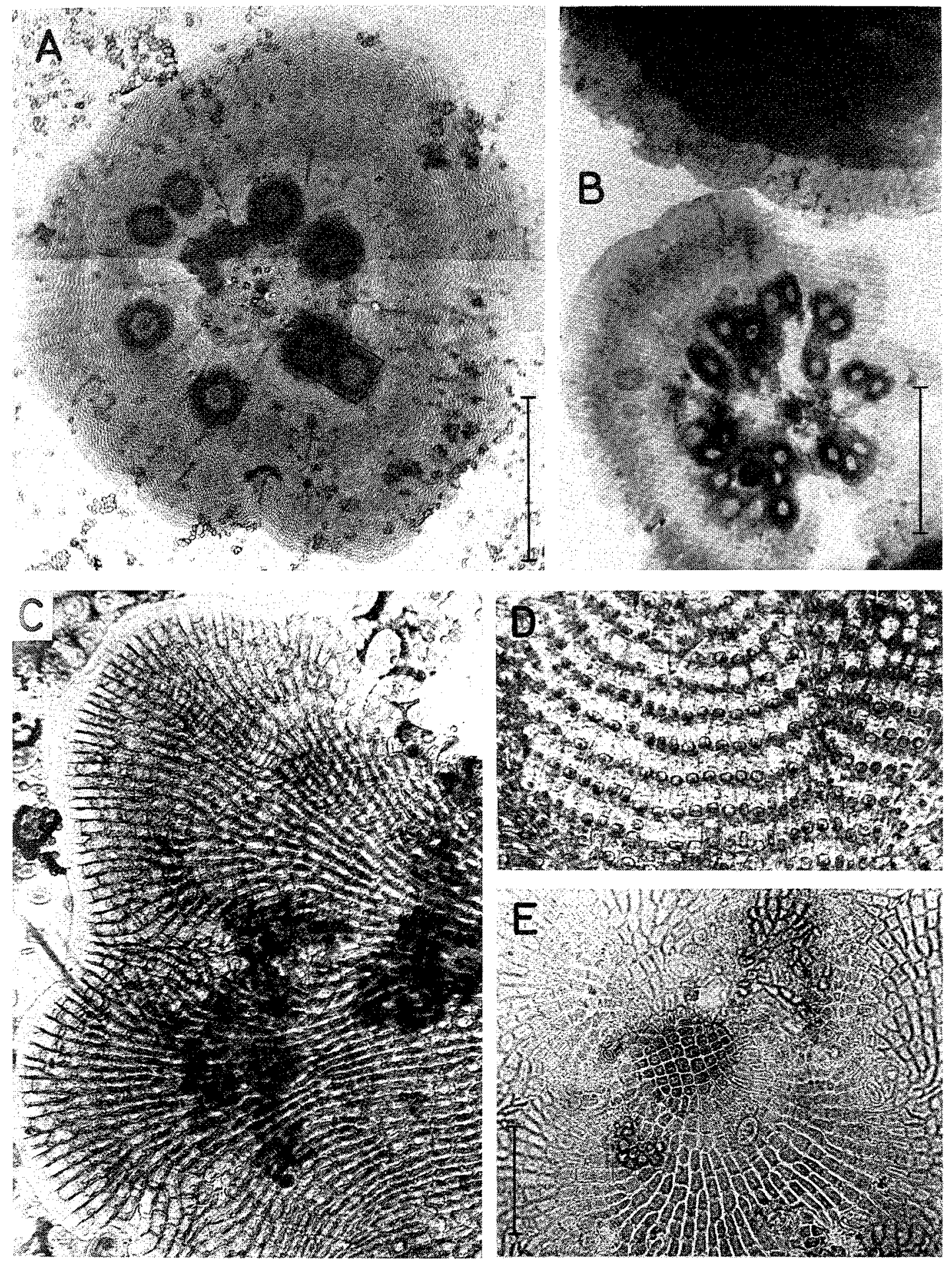

Abb. 32. Melobesia membranacea, lebend auf Glasplatten. A, B Thalli mit ungeschlechtlichen Konzeptakeln, oben rechts Lithophyllum orbiculatum. Die beiden umrahmten Konzeptakeln sind in $\mathrm{Abb}, 33 \mathrm{~B}, \mathrm{~B}$ ' vergrößert dargestellt. C 'Thallusrand, D Aufsicht auf eine dickere Kruste mit gut erkennbaren Epithalliumzellen. E Thallusmitte von A mit dem aus der aufgeteilten Spore gebildeten Zellkomplex, nach Fixierung. Maßstrecken: $A=500 \mu \mathrm{m}_{i} \mathrm{~B}=1 \mathrm{~mm} ; \mathrm{C}-\mathrm{E}=50 \mu \mathrm{m}$ 


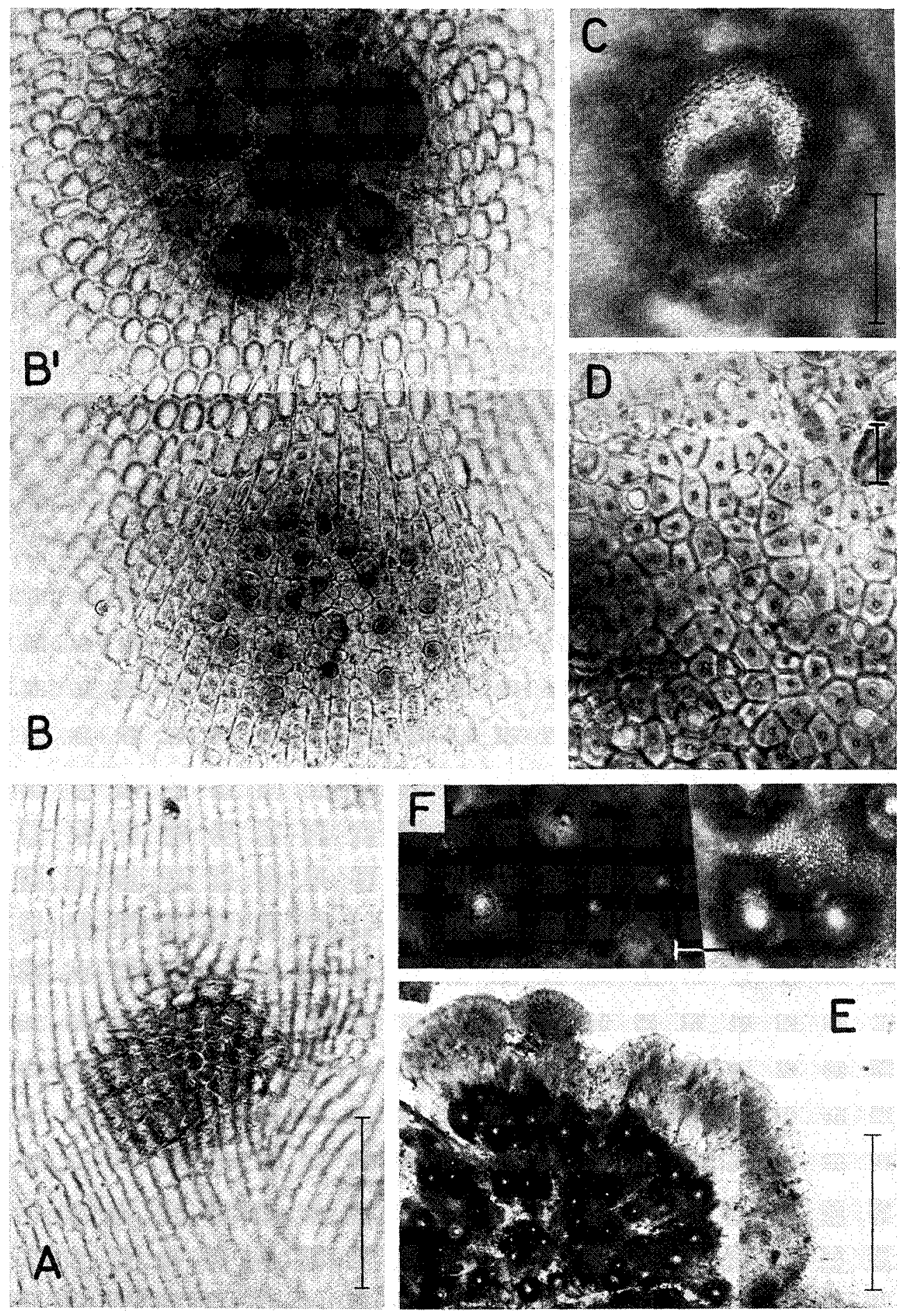

Abb. 33. Melobesia membranacea. A, B, B' Entwicklung der ungeschlechtlichen Konzeptakeln: Ausschnitte aus der Kruste Abb. 32 A nach Fixierung und Färbung mit Alizarinviridin. A Junge Anlage, ein Sporangialpfropf in der Mitte, B Mit fertigem Sporangialdach, B' mit den im lebenden Präparat nicht sichtbaren jungen Sporangien; die beiden Konzeptakeln sind in Abb. 32 A umrahmt. C, D Reifes Konzeptakel und Ausschnitt aus dem Dach mit Entleerungsporen, lebendes Material. E, F Weiblicher Thallus, lebend. Maßstrecken: $A, B, B^{\prime}=50 \mu \mathrm{m} ; C=100 \mu \mathrm{m} ; \mathrm{D}=10 \mu \mathrm{m} ; \mathrm{E}=1 \mathrm{~mm}$; 

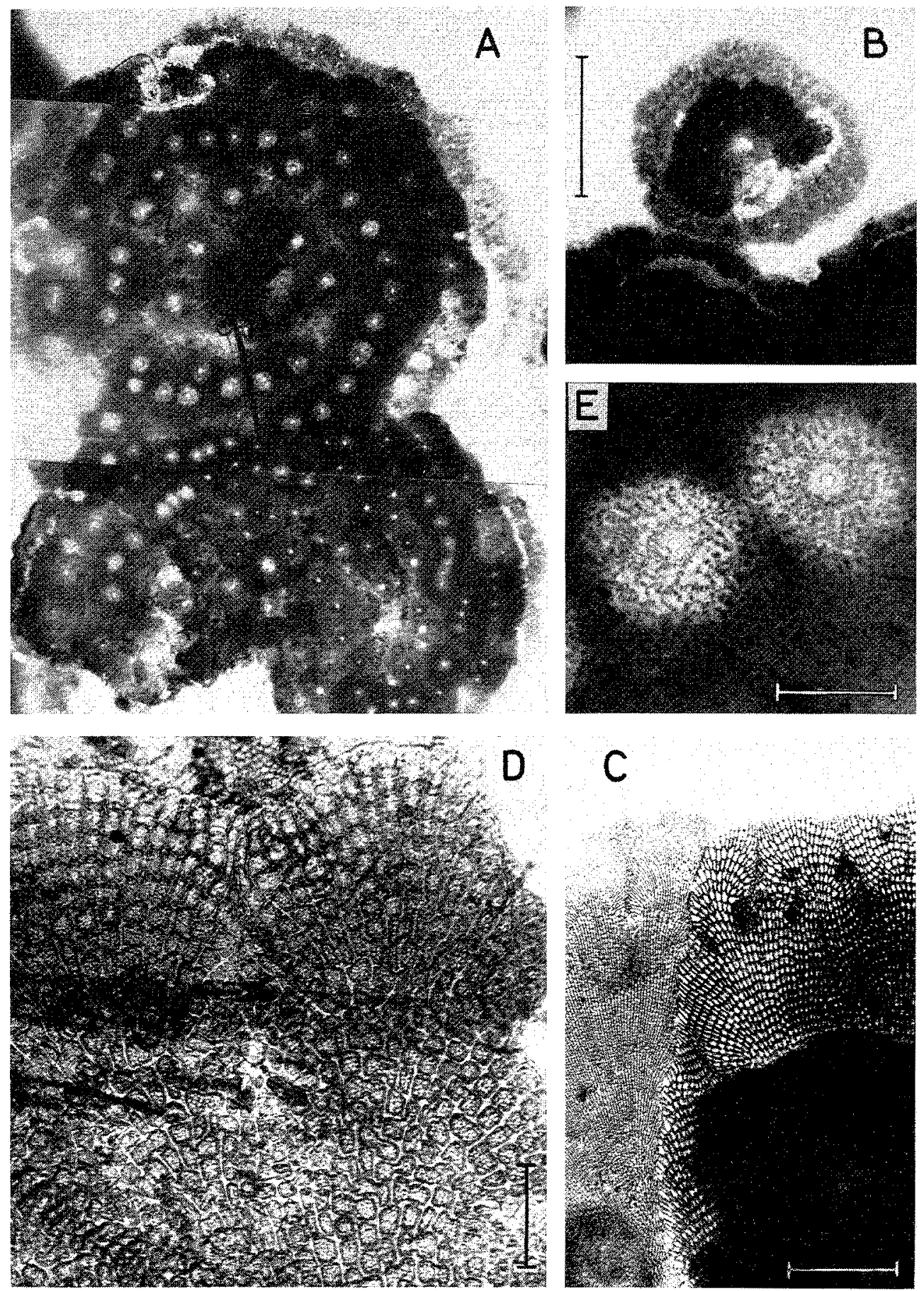

Abb. 34. Lithophyllum orbiculatum, lebend auf einer Glasplatte. A, B Habitus verschieden alter Krusten mit ungeschlechtlichen Konzeptakeln. C Thallusrand, links Melobesia membranacea. D Aufsicht auf den Hypothallus. E Ungeschlechtliche Konzeptakeln. MaBstrecken: $\mathrm{A}, \mathrm{B}=1 \mathrm{~mm}$; $C=200 \mu \mathrm{m} ; \mathrm{D}=50 \mu \mathrm{m} ; \mathrm{E}=100 \mu \mathrm{m}$ 
von eckigen, oft rosettenartig zusammenschließenden Zellen umgeben, die in ihrer Mitte sehr deutlich eine kleine Vertiefung erkennen lassen (D). Offenbar entsprechen diese den epithallialen Hôhlungen, die Garbary (1978) mit rasterelektronenmikroskopischen Aufnahmen in den Oberflächenzellen von Corallinaceen abbildet. Die Aufsicht auf eine vegetative Kruste von Melobesia membranacea zeigt ein eigenes, bei den übrigen 15 von Garbary untersuchten Arten nicht wiederkehrendes Muster; das Bild ist unserer Abbildung $32 \mathrm{D}$ ähnlich.

\section{Lithophyllum orbiculatum (Fosl.) Fosl.}

Ebenso wie Melobesia wachsen auch die Krusten von Lithophyllum orbiculatum auf der Oberfläche von Glasplatten nahezu kreisförmig und zeigen in der Aufsicht bei schwacher Vergrößenung konzentrische "Ringwälle" (Abb. $34 \mathrm{~A}$ ). In diesen liegen dicht nebeneinander eingesenkt die ungeschlechtlichen Konzeptakeln, deren Höhlung und Offnung hell durchscheint. Selbst eine Scheibe von nur 1,5 mm Durchmesser zeigt schon einen Ring von Konzeptakelanlagen (B). Ebenso wie bei Melobesia ist auch hier die Kruste von einer ziemlich breiten einschichtigen Hypothalliumzone gesäumt, bevor sich das Perithallium erhebt, in dem nur noch die Konzeptakelhöhlungen durchleuchtet werden $(C, E)$. Durch dichotome Verzweigung der Hypothalliumzellen verbreitert sich der Thallus; Zellen benachbarter Reihen verschmelzen häufig miteinander (D). Die Kruste bleibt in ihrer ganzen Fläche ziemlich dünn; der Thallus ist am dicksten in den Wällen, in denen die Konzeptakeln eingesenkt sind; in den Furchen zwischen diesen wird er wieder etwas durchscheinender.

Lithophyllum orbiculatum ist bei Helgoland nicht so selten, wie nach unseren früheren Beobachtungen angenommen wurde; sie stützten sich auf einen einzelnen Fund auf Steinen aus $2 \mathrm{~m}$ Tiefe. Im Nordhafen kommt die Alge in $6 \mathrm{~m}$ Tiefe reichlich vor.

\section{Rhodophysema elegans (Crouan frat. ex J. Ag.) Dixon}

Durch zwei Beobachtungen werden unsere früheren Angaben über Rhodophysema elegans (Kornman \& Sahling, 1977) wesentlich ergänzt: das Vorkommen von Thalli mit Tetrasporangien und die in Kulturen aufgetretenen Pflanzen mit Tetrasporangien und Spermatangien. Die damals im obersten Sublitoral gesammelten Krusten trugen nur Bisporangien, während sie in 6-8 m Tiefe mit Tetrasporangien fruktifizieren. Auch Kuckuck (1897) beschreibt Tetrasporangien bei der von ihm als Rhododermis parasitica Batters bezeichneten, auf den Stielen von Laminaria hyperborea, also in tieferem Wasser wachsenden Pflanze.

Auf Glasplatten in etwa $6 \mathrm{~m}$. Tiefe bildet Rhodophysema ziemlich runde, dïnne Krusten mit scharf ausgeprägten konzentrischen Ringen von Perithallusfäden (Abb. 35 $A, B)$, auch die Sporangiensori sind häufig ringförmig angeordnet (C, D). In ihnen sind die kreuzgeteilten Tetrasporangien von gebogenen Paraphysen umgeben. Ganz der Abbildung $35 \mathrm{C}$ entsprechende fertile Krusten entstanden auch in den Kulturen. Die Ränder älterer beschädigter Krusten regenerieren durch Auswachsen des Hypothallus (E).

Unbeabsichtigt erhielten wir Kulturen von Rhodophysema. Von dem. Bewuchs einer Muschelschale aus 6-8 m Tiefe vom 6. August 1980 lösten sich besonders dicke Rotalgensporen $a b$, deren Herkunft sich zunächst nicht feststellen ließ. Einige der isolierten Sporen bildeten auf dem Boden einer Plastikschale haftende Scheiben mit hyalinen 

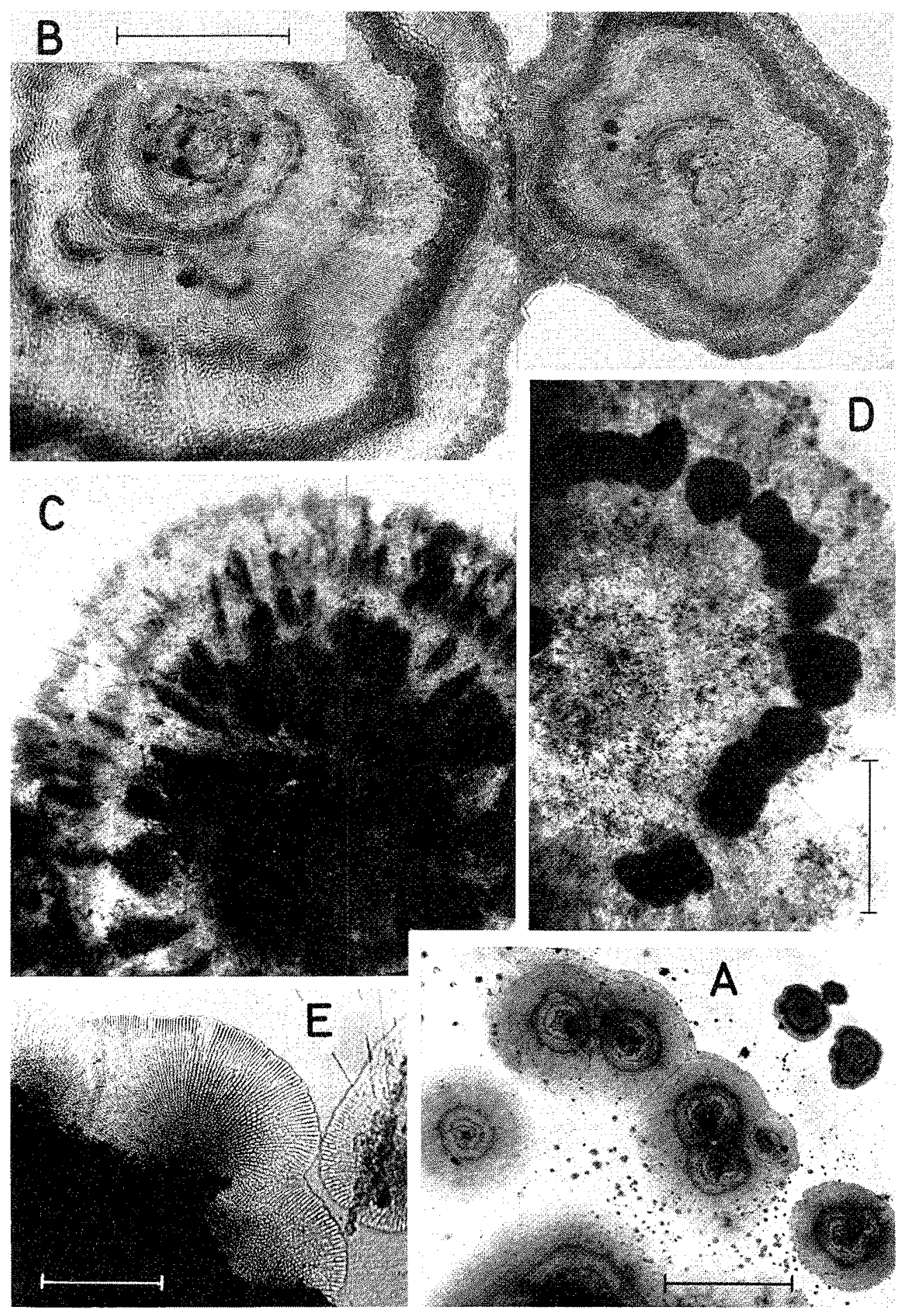

Abb. 35. Rhodophysema elegans, Naturmaterial auf Glasscheiben. A, B Krusten mit Konzentrischen Ringen von Perithallusfäden. C Kruste mit radial-ringförmig gewachsenen Sori. D Kruste mit einem Ring von reifen Tetrasporangiensori. E Alte Kruste mit regenerierendem Hypothallus. Maßstrecken: $A=5 \mathrm{~mm} ; \mathrm{B}=500 \mu \mathrm{m} ; \mathrm{C}, \mathrm{D}=1 \mathrm{~mm} ; \mathrm{E}=200 \mu \mathrm{m}$ 
Haaren, die meisten aber entwickelten sich zu unregelmäßigen, freitreibenden Bällchen aus lockeren Fäden. Diese Pflänzchen entleerten schon nach 4 Wochen reichliche Mengen von Spermatien, eine Woche später auch Tetrasporen. Abbildung 36 B-E zeigt Teile solcher unter einem Deckglas zerdrückten Bällchen. An freien, durchaus dorsiventral organisierten Fäden entspringen paarweise die ovalen, blassen Spermatangien. Ihrer Natur als freie Hypothallium-Fäden entsprechend, können sich diese Fäden auf dem Substrat zu einer monostromatischen Kruste verbreitern (F). Die kreuzgeteilten Tetrasporangien entstehen einzeln oder seltener dicht knäuelig und von Paraphysen begleitet auf denselben Pflanzen. Sie sind im Durchschnitt 35-40 $\mu \mathrm{m}$ lang und $20 \mu \mathrm{m}$ breit, der Durchmesser der meisten Tetrasporen liegt zwischen 18 und $20 \mu \mathrm{m}$. Aus den vielen entleerten Tetrasporen gehen gleichartige Generationen hervor, die sich auf Deckgläsern im allgemeinen scheibenförmig ausbilden. Dicht nebeneinanderliegende junge Scheiben verschmelzen zu einem einheitlich Thallus (Abb. 36 A). Die Thalli wachsen an ihrem Rand stetig weiter und vergrößern sich rasch; die bei A abgebildete, drei Wochen alte Kruste von 1,2 mm Durchmesser hatte 12 Wochen später an der Deckglaskante eine Breite von $10 \mathrm{~mm}$ erreicht und fruktifizierte reichlich mit Spermatangien und Tetrasporangien. Wenn ältere, $2-3 \mathrm{~mm}$ große Thalli miteinander verwachsen, so bilden ihre Berührungslinien ein polygonales Netz, ganz entsprechend den geraden Linien zwischen den miteinander verwachsenen Krusten des Naturmaterials (Abb. 35 A).

Bemerkenswert ist das Vorkommen von Spermatangien. Sehr wahrscheinlich waren sie schon in dem Naturmaterial auf der Muschelschale vorhanden; zu dieser Vermutung berechtigt ihr Auftreten in mehreren aufeinanderfolgenden Generationen. Thalli mit männlichen Organen sind bei Rhodophysema elegans bisher nur selten beobachtet worden, von Rosenvinge (1910) an Material aus Nordostgrönland, von den Alëuten (Masuda, 1978) und von Hokkaido (Masuda \& Ohta, 1981). Rhodophysemopsis laminariae und Rhodophysema georgii sind nur in Japan mit Spermatangien gefunden worden (Masuda, 1976; Masuda \& Ohta, 1975), bei drei weiteren Arten sind nur Tetrasporangien bekannt.

Mitte der siebziger Jahre erschienen mehrere entwicklungsgeschichtliche Arbeiten über Rhodophysema-Arten, war es doch nicht auszuschließen, daß die tetrasporangientragende Kruste eine Phase im Lebenszyklus einer Floridee darstellen könnte. Ein solcher Zusammenhang konnte nicht nachgewiesen werden.

Kulturversuche mit Pflanzen von verschiedenen Küsten hatten kein einheitliches Ergebnis. Wie unsere Helgoländer Art verhielt sich Rhodophysema georgii aus japanischen Gewässern (Masuda \& Ohta, 1975), während Fletcher (1975) mit Material von der englischen Kanalküste nur Generationen mit Tetrasporangien erhielt. Rhodophysema elegans von Neufundland produzierte in der Natur und in Kultur neben Tetrasporangien auch Mono- und Bisporangien (South \& Whittick, 1976). Fletcher (1977) kultivierte Rhodophysema elegans aus Gezeitentümpeln von der englischen Südküste. Ahnlich wie unsere bei extrem niedrigem Wasser trockenfallenden Krusten trugen sie überwiegend Bisporangien, während kreuzgeteilte Tetrasporangien nur sehr selten waren. Auf den recht langsam wachsenden Thalli wurden erstmals nach 14 Monaten Sporangien gebildet, die sich jedoch nicht entleerten.

Nach einer kürzlich erschienenen Arbeit von DeCrew \& West (1982) über den Lebenszyklus von Rhodophysema elegans aus Kalifornien müssen frühere entwick- 


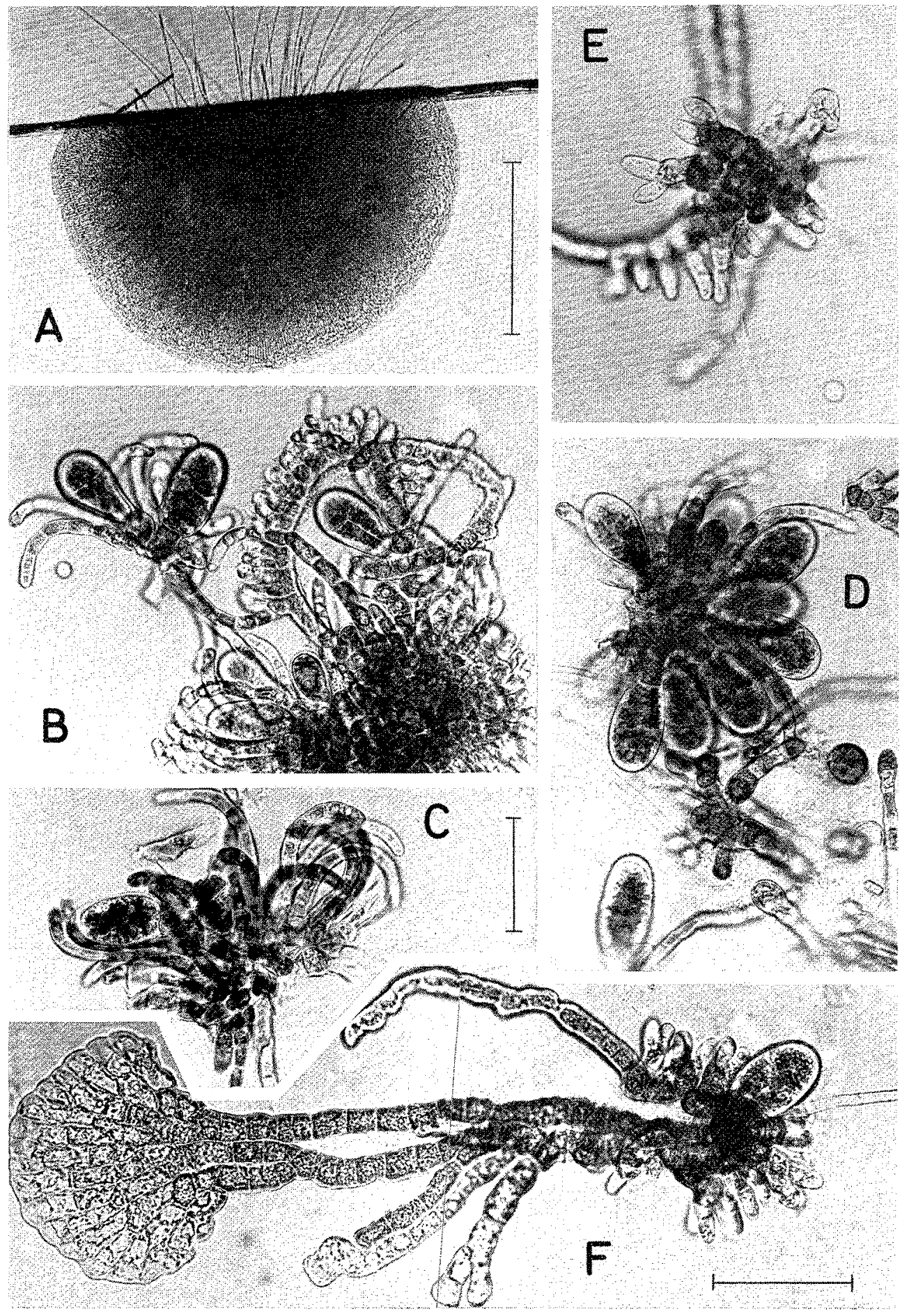

Abb. 36. Rhodophysema elegans, in Kultur gewachsen. A Aus mehreren jungen Scheiben verschmolzener Thallus, 3 Wochen alt. B-E Teile von zerdrückten lockeren Bällchen mit Spermatangien, Tetrasporangien und gekrümmten Paraphysen. F Breite fruktifizierende Fäden gehen auf dem Substrat zu krustenförmigem Wachstum über. Maßstrecken: $A=500 \mu m_{;} B-D=50 \mu m_{i} E, F$ 
lungsgeschichtliche Beobachtungen sehr zurückhaltend beurteilt werden. Sie untersuchten dasselbe Kulturmaterial, an dem vorher Ganesan \& West (1975) nur Generationen mit Tetrasporangien gefunden hatten: es erwies sich in der Nachuntersuchung als monözischer Gametophyt. Der Lebenszyklus ist äußerst reduziert; ein Karposporophyt fehlt, die Zygote teilt sich in eine Tetrasporenmutterzelle und eine Stielzelle. Aufgrund dieser Merkmale wird die bisher bei den Cryptonemiales geführte Gattung den Palmariales zugeordnet.

Wie sind nach diesen überraschenden Erkenntnissen unsere Beobachtungen zu deuten? Eine Nachprüfung an Hand der Präparate und lebender Kulturen gab keinen Anlaß, an der Richtigkeit unserer Darstellung zu zweifeln. Trichogynen wären bei der Ubersichtlichkeit des Materials wohl nicht zu übersehen gewesen, man hätte bei den Massen freier Spermatien, die die Bällchen wie eine Wolke einhüllten, einzelne anhaftende Spermatien erwarten dürfen. Haare sind zahlreich, selten kommen auch gegabelte vor. Schließlich können Tetrasporangien auch an Krusten ohne Spermatangien entstehen. Die Folgerung ist daher berechtigt, daß in dem Helgoländer Material funktionslose Spermatien vorliegen und die Tetrasporangien sich direkt entwickeln. $\mathrm{Zu}$ diesem Ergebnis sind auch Masuda \& Ohta (1975) bei Rhodophysema georgii in japanischen Gewässern gekommen.

Die taxonomische Bewertung der regional und lokal so unterschiedlich mit Fortpflanzungsorganen ausgestatteten Formen von Rhodophysema elegans ist eine offene Frage. Einen verheißungsvollen Schritt zu ihrer Lösung machen Masuda \& Ohta (1981) in einer variationsstatistischen Analyse anatomischer und entwicklungsgeschichtlicher Merkmale. Vier Populationen von Rhodophysema elegans von Hokkaido ließen sich in zwei klar voneinander unterscheidbare Gruppen trennen. Die sowohl an Naturmaterial als auch an Kulturen festgestellten Unterschiede lassen auf ihre genetische Fixierung schließen.

Callithamnion byssoides Arnott ex Harv. in Hook.

Callithamnion byssoides kommt vielleicht ständig bei Helgoland vor, doch trifft man die Alge nur gelegentlich an. In ihrem Habitus sind die 1-3 cm hohen, lockeren, rosafarbenen Büschel von dem häufigeren Callithamnion hookeri sehr verschieden (vgl. Kornmann \& Sahling, 1977, Abb. 131). Die geraden einreihigen, langzelligen Achsen sind unberindet; sie tragen wie ihre Seitenäste spiralig angeordnete Verzweigungen (Abb. 37 A). Die Endzellen der Zweige sind im allgemeinen abgerundet; können aber auch ein langes hyalines Haar tragen, wie die am 21. 7. 1960 gesammelten männlichen Pflanzen (Abb. 37 B). Die Haare sind kein signifikantes Merkmal; nur eine von mehreren in derselben Kultur wachsenden weiblichen Pflanzen trug Haare (Abb. $38 \mathrm{C}$ ). Die in Kultur reif gewordenen Karposporophyten - weibliche Pflanzen wurden in dem spärlichen Naturmaterial noch nicht beobachtet - stehen paarweise, sie sind kugelig (Abb. 38 D).

Die sichere Identifizierung der vorher meist nur in vegetativem Zustand gefundenen Alge wurde möglich, nachdem am 15. Oktober 1980 an der Lichtseite eines Pontons im Südhafen reife Tetrasporophyten gesammelt wurden. Die ovalen Sporangien sitzen ungestielt im unteren Teil der Endzweige (Abb. $37 \mathrm{C})$. Aus den in großer Zahl entleerten Tetrasporen entstanden am Nordfenster eines ungeheizten Laboratoriums bei etwa $15^{\circ} \mathrm{C}$ nach 4 Wochen fertile getrenntgeschlechtliche Gametophyten (Abb. $38 \mathrm{~A}-\mathrm{C}$ ) und nach 7 Wochen reife Karposporophyten (D). Das Tageslicht erreichte im November nur 


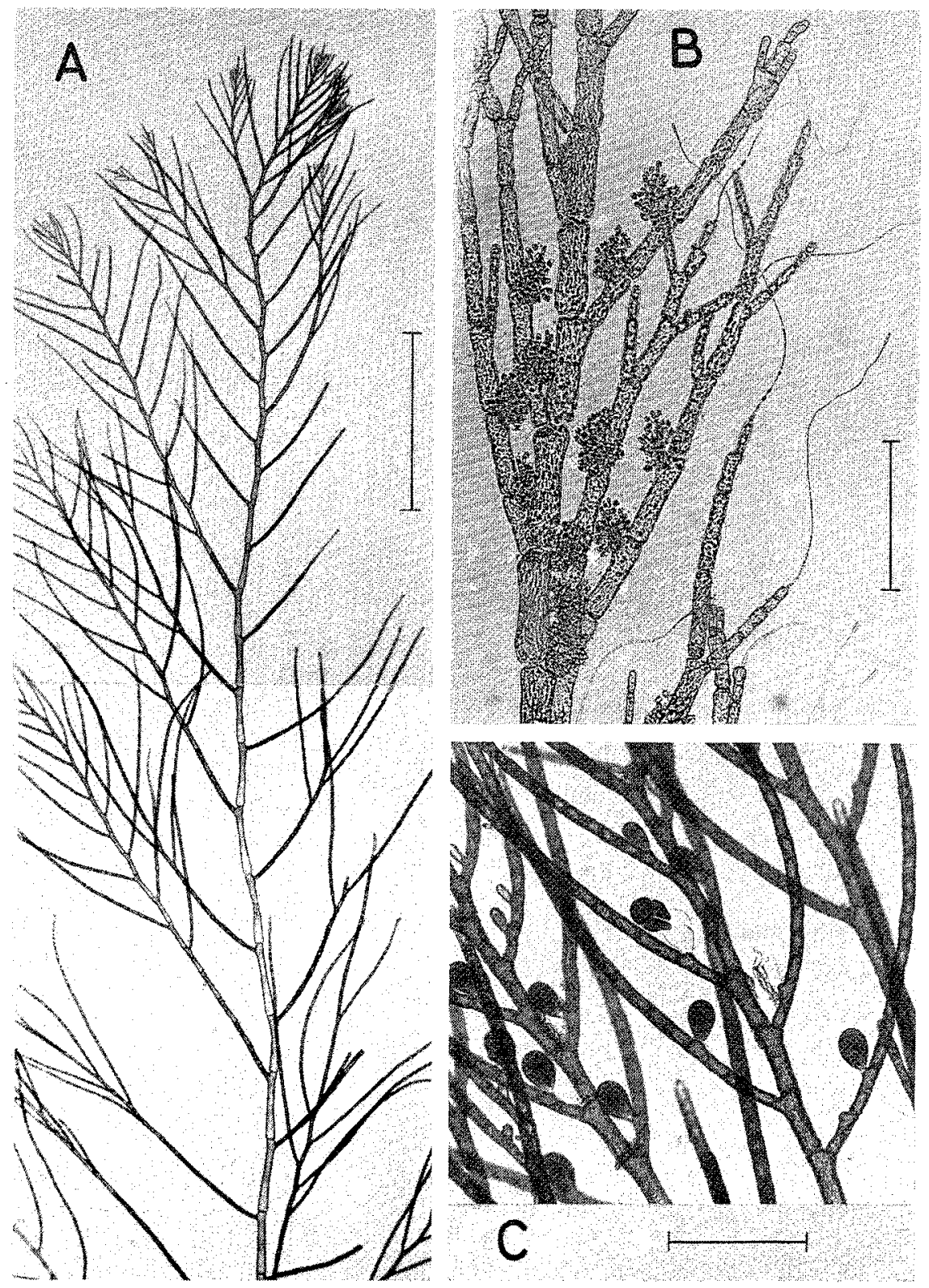

Abb. 37. Callithamnion byssoides. A Teil einer sterilen Pflanze, lebend, 28. 9. 1972. B Männliche Pflanze mit Haaren, Präparat vom 21. 7. 1960. C Tetrasporophyt, lebend, ein Sporangium entleert sich gerade, 15. 10. 1980. Maßstrecken: $A=1 \mathrm{~mm} ; B=100 \mu \mathrm{m} ; C=200 \mu \mathrm{m}$

kurzfristig den Wert von 1200 Lux. Die bei $15^{\circ} \mathrm{C}$ und 14 stündiger Beleuchtung mit 1400 Lux aus den Karposporen kultivierten Tetrasporophyten brauchten 5 Wochen bis zur Reife. 

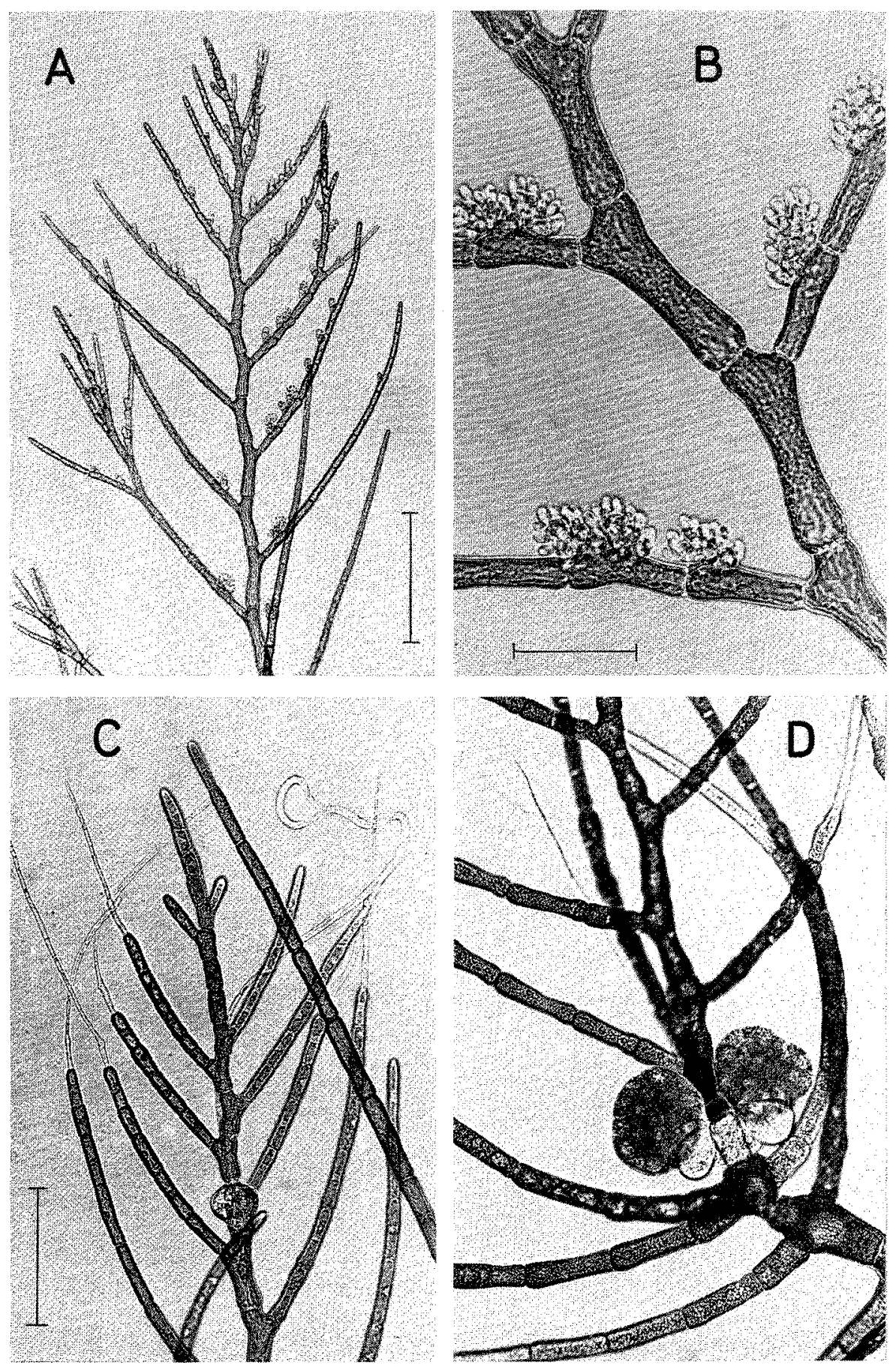

Abb. 38. Callithamnion byssoides, in Kultur gewachsen. A, B Junger und reifer männlicher Gametophyt. C Weiblicher Gametophyt mit Haaren; Karpogon mit langer Trichogyne. D Reifer Karposporophyt, Rest der Trichogyne noch erkennbar. Maßstrecken: $A=200 \mu \mathrm{m} ; \mathrm{B}=50 \mu \mathrm{m} ; \mathrm{C}, \mathrm{D}$ 
In der regelmäßigen Generationenfolge nach dem Polysiphonia-Schema stimmt dieser Befund mit den Ergebnissen von Edwards (1969) und Kapraun (1978) überein. Beide Autoren untersuchten Populationen von der nordamerikanischen Atlantikküste, wo Callithamnion byssoides vom Golf von Mexiko bis zum südlichen Neuengland vorkommt. Wesentlicher Gegenstand ihrer Arbeiten, auf die hier nicht näher eingegangen werden soll, war die Phänologie der Alge und ihre Entwicklung unter variierten Kulturbedingungen. Dabei erhielt Edwards (1969) mit Material aus Texas bei $23{ }^{\circ} \mathrm{C}$ und 16stündiger Belichtung mit 2260 Lux reife Gametophyten nach 13 Tagen und reife Karposporophyten nach 18 Tagen. Karposporen von Material aus North Carolina ergaben bei $20^{\circ} \mathrm{C}$ und 14 stündiger Belichtung mit 963 Lux nach 20 Tagen reife Tetrasporophyten, deren Sporen wiederum 20 Tage bis zur fertilen Gametophytengeneration brauchten (Kapraun, 1978). Das Gedeihen bei so unterschiedlichen Bedingungen zeigt die breite Anpassungsfähigkeit von Callithamnion byssoides an die gänzlich verschiedenen ökologischen Verhältnisse. Cape Cod (Massachusetts) begrenzt das reichliche Vorkommen der Alge in dem warmen Wasser des Südens scharf gegen ihr spärliches Auftreten in dem Gebiet kälteren Wassers im Norden. Für Portsmouth (New Hampshire) wird die Höchsttemperatur mit $16,2^{\circ} \mathrm{C}$ angegeben (Edwards, 1971). Ganz entsprechend dürfte das seltene Vorkommen bei Helgoland in den Monaten Juli bis Oktober durch die Wassertemperatur bedingt sein, die im August ihren Höchstwert von $17^{\circ} \mathrm{C}$ erreicht und Ende Oktober auf $12,5^{\circ} \mathrm{C}$ absinkt.

Rueness \& Rueness (1980) kultivierten Callithamnion byssoides von der norwegischen Küste und stellten morphologische Unterschiede zwischen ihrem und dem amerikanischen Material fest, die auf verschiedene Arten schließen lassen. Mit ihren gelappten Gonimoblasten entspricht die norwegische Pflanze eher Callithamnion furcellariae. Die Helgoländer Pflanze gleicht in der Morphologie ihrer Gonimoblasten und Spermatangien den Abbildungen amerikanischen Materials (Spencer et al., 1981). Kreuzungsversuche dieser Autoren der norwegischen Pflanze mit vier amerikanischen C. byssoides-Stämmen waren negativ.

Danksagungen. Für wertvolle Hinweise zur Beurteilung der ungewöhnlichen marinen Chlamydomonas-Art danken wir Herrn Dr. H. Ettl, Brno (ČSSR); Herm Dr. Werner, Hamburg, danken wir für seine Hilfe bei der Übersetzung der Diagnosen ins Lateinische.

\section{ZITIERTE LITERATUR}

Adey, W. H. \& Adey, P. J., 1973. Studies on the biosystematics and ecology of the epilithic crustose Corallinaceae of the British Isles. - Br. phycol. J. 8, 343-407.

Berger-Perrot, Y., 1980. Trois nouvelles espèces d' Urospora à cellules uninucléés sur les côtes de Bretagne. - Cryptogamie 1, 141-160.

Berger-Perrot, Y., 1981. Création du genre Ulotrichella nov. gen. (Chlorophycées, Ulotrichales).-Rev. gén. Bot. 88, 83-86.

Bourrelly, P., 1966. Les algues d' eau douce. Initiation à la systématique. I. Les algues vertes. Boubée, Paris, 511 pp.

Bristol, B. M., 1920. A review of the genus Chlorochytrium, Cohn. - J. Linn, Soc. Bot. 45, 1-28.

Chamberlain, Y. M., 1978. Investigation of taxonomic relationships amongst epiphytic, crustose Corallinaceae. - In: Modern approaches to the taxonomy of red and brown algae. Ed. by D. E. G. Irvine \& J. H. Price. Acad. Press, London, 223-246.

Dangeard, P., 1965a. Sur un nouveau genre de Phéophycées: Giraudyopsis nov. gen. (G. stellifer nov. sp.). - C. r. hebd. Séanc. Acad. Sci., Paris (D) 261, 2699-2701. 
Dangeard, P., 1965b. Sur cinq espèces d' "Ulvella". - Botaniste 48, 45-64.

Dangeard, P., 1965c. Sur deux Chlorococcales marines. - Botaniste 48, 65-74.

Dangeard, P., 1965d. Sur le nouveau genre "Giraudyopsis" P. D. - Botaniste 49, 99-108.

Dangeard, P., 1969. Quelques Chlorophycées rares ou nouvelles. - Botaniste 52, 29-58.

DeCrew, T. C. \& West, J. A., 1982. A sexual life history in Rhodophysema (Rhodophyceae): a reinterpretation. - Phycologia 21, 67-74.

Edwards, P., 1969. The life history of Callithamnion byssoides in culture. - J. Phycol. 5, 266-268.

Edwards, P., 1971. The effects of light intensity, daylength and temperature on the growth and reproduction of Callithamnion byssoides. - In: Selected papers in phycology. Ed. by B. Parker \& M. Brown. Allen Press, Lawrence, Kansas, 163-173.

Ettl, H., 1981. Die neue Klasse Chlamydophyceae, eine natürliche Gruppe der Grünalgen (Chlorophyta). - Pl. Syst. Evol. 137, 107-126.

Fletcher, R. L., 1975. The life history of Rhodophysema georgii in laboratory culture.-Mar. Biol. 31, 299-304.

Fletcher, R. L., 1977. Studies on the life history of Rhodophysema elegans in laboratory culture. Mar. Biol. 40, 291-297.

Ganesan, E. K. \& West, J. A., 1975. Culture studies on the marine red alga Rhodophysema elegans (Cryptonemiales, Peysonneliaceae). - Phycologia 14, 161-166.

Garbary, D. J., 1978. An introduction to the scanning electron microscopy of red algae. - In: Modern approaches to the taxonomy of red and brown algae. Ed. by D. E. G. Irvine \& J. H. Price. Acad. Press, London, 205-222.

Gardner, N. L., 1917. New Pacific coast marine algae. I. - Univ. Calif. Publs Bot. 6, 377-416.

Gayral, P. \& Billard, C., 1977. Synopsis du nouvel ordre des Sarcinochrysidales (Chrysophyceae). Taxon 26, 241-245.

Gerneck, R, 1907. Zur Kenntnis der niederen Chlorophyceen. - Beih. bot. Zbl. 21, II, 221-290.

Guillard, R. R. L., Bold, H. C. \& MacEntee, F. J., 1975. Four new unicellular chlorophycean algae from mixohaline habitats. - Phycologia 14, 13-24.

Huber, J., 1893. Contribution à la connaissance des Chaetophoracées épiphytes et endophytes et de leurs affinités. - Annls Sci. nat. Bot. (Sér. 7), 16, 265-359.

Kapraun, D. F., 1978. Field and culture studies on growth and reproduction of Callithamnion byssoides (Rhodophyta, Ceramiales) in North Carolina. - J. Phycol. 14, 21-24.

Kornmann, P. \& Sahling, P.-H., 1977. Meeresalgen von Helgoland. Benthische Grün-, Braun- und Rotalgen. - Helgoländer wiss. Meeresunters. 29, 1-289.

Kornmann, P. \& Sahling, P.-H., 1978. Die Blidingia-Arten von Helgoland (Ulvales, Chlorophyta). Helgoländer wiss. Meeresunters. 31, 391-413.

Kornmann, P. \& Sahling, P.-H., 1980a. Kalkbohrende Mikrothalli bei Helminthocladia and Scinaia (Nemaliales, Rhodophyta). - Helgoländer Meeresunters. 34, 31-40.

Kornmann, P. \& Sahling, P.-H., 1980b. Ostreobium quekettii (Codiales, Chlorophyta). - Helgoländer Meeresunters. 34, 115-122.

Korshikov, A. A., 1932. Studies in the Vacuolatae. I. - Arch. Protistenk. 78, 557-612.

Kuckuck, P., 1897. Beiträge zur Kenntnis der Meeresalgen.

1. Über Rhododermis parasitica Batters. - 2. Uber Rhodochorton membranaceum Magnus, eine chitinbewohnende Alge. - 3. Die Gattung Mikrosyphar Kuckuck. - 4. Über zwei höhlenbewohnende Phaeosporeen. - Wiss. Meeresunters. (Helgoland) 2, 329-370.

Kylin, H., 1934. Zur Kenntnis der Entwicklungsgeschichte einiger Phaeophyceen. - Lunds Univ. Årsskr. (Avd. 2) 30 (9), 1-19.

Kylin, H., 1947. Die Phaeophyceen der schwedischen Westküste. - Lunds Univ. Årsskr. (Avd. 2) 43 (4), 1-99.

Levring, T., 1937. Zur Kenntnis der Algenflora der norwegischen Westküste. - Lunds Univ. Årsskr. (Avd. 2) 33 (8), 1-148.

Loiseaux, S., 1967. Sur la position systématique du genre Giraudyopsis P. Dangeard. - Rev. gén. Bot. 74, 389-395.

Lund, S., 1959. The marine algae of East Greenland I. Taxonomical part. - Meddr Gronland 156(1), $1-247$.

Masuda, M., 1976. Taxonomic notes on Rhodophysemopsis gen. nov. (Rhodophyta), -J. Jap. Bot. 51, $175-187$. 
Masuda, M., 1978. Two species of Rhodophysema (Rhodophyta) from the Aleutian Islands. - Acta phytotax. geobot. 29, 149-156.

Masuda, M. \& Ohta, M., 1975. The life history of Rhodophysema georgii Batters (Rhodophyta, Cryptonemiales). - J. Jap. Bot. 50, 1-10.

Masuda, M. \& Ohta, M., 1981. A taxonomic study of Rhodophysema elegans (Rhodophyta) from Japan. - Acta phytotax. geobot. 32, 75-89.

Moewus, L., 1950. Entwicklungsgeschichtliche Studien über einige mikroskopisch kleine Aufwuchsalgen. - Schweiz. Z. Hydrol. 12, 47-66.

Moore, G. Th, 1900. New or little known unicellular algae. I. Chlorocystis Cohnii. - Bot. Gaz. 30, $100-112$.

Newton, L., 1931. A handbook of the British seaweeds. British Museum, London, $478 \mathrm{pp}$.

Nielsen, R., 1977. Culture studies on Ulvella lens and Ulvella setchelli. - Br. phycol. J. 12, 1-5.

Nielsen, R. \& Pedersen, P. M., 1977. Separation of Syncoryne reinkei nov, gen., nov, spec. from Pringsheimiella scutata (Chlorophyceae, Chaetophoraceae). - Phycologia 16, 411-416.

Oltmanns, F., 1922. Morphologie und Biologie der Algen. I. Chrysophyceae - Chlorophyceae. Fischer, Jena, 459 pp.

Parke, M. \& Dixon, P. S., 1976. Check-list of British marine algae-third revision. -J. mar. biol. Ass. U. K. $56,527-594$.

Pedersen, P. M., 1976. Marine, benthic algae from southernmost Greenland.-Meddr Grønland 199 (3), 1-80.

Pedersen, P. M., 1980. Giraudyopsis stellifer (Chrysophyceae) and Streblonema immersum (Phaeophyceae), additions to the British marine algae. - Br. phycol. J. 15, 247-248.

Printz, H., 1926. Die Algenvegetation des Trondhjemsfjordes. - Skr. norske Vidensk.Akad. (Mat.nat. K1.) 1926 (5) 1-274.

Reinhard, L., 1885. Algologische Untersuchungen. 1. Materialien zur Morphologie und Systematik der Algen des Schwarzen Meeres. Diss. Odessa. (Russ.; dt Zsfsg. von G. Woltke. In: Scripta Botanica. T. 2. P. 1889, 25-49.)

Reinke, J., 1888. Einige neue braune und grüne Algen der Kieler Bucht. - Ber. dt. bot. Ges. 6 , $240-241$.

Reinke, J., 1889. Atlas deutscher Meeresalgen, Parey, Berlin, 1, 1-34 (Taf. 1-25).

Rosenvinge, L. K., 1910. On the marine algae from North-East Greenland collected by the "Danmark Expedition", - Meddr Grønland 43, 93-133.

Rueness, J. \& Rueness, M., 1980. Culture and field observations on Callithamnion bipinnatum and C. byssoides (Rhodophyta, Ceramiales) from Norway, - Sarsia 65, 29-34.

Schmidt, O. C., 1938. Zwei neue Helgoländer Grünalgen. - Hedwigia 77, 231-232.

South, G. R. \& Whittick, A., 1976. Aspects of the life history of Rhodophysema elegans (Rhodophyta, Peyssonneliaceae). - Br. phycol. J. 11, 349-354.

Spencer, K. G., Yu, M.-H., West, J. A. \& Glazer, A. N., 1981. Phycoerythrin and interfertility patterns in Callithamnion (Rhodophyta) isolates. - Br. phycol. J. 16, 331-343.

Starr, R., 1978. The culture collection of algae at the University of Texas at Austin. - J. Phycol. 14 (Suppl.) 47-100.

Suneson, S., 1943. The structure, life-history and taxonomy of the Swedish Corallinaceae. - Lunds Univ. Årsskr. (Avd. 2) 39, 1-66.

Wright, E. P., 1877. On a new species of parasitic green algae belonging to the genus Chlorochytrium of Cohn. - Trans. R. Ir. Acad. 26, 355-368.

Zimmermann, W., 1925. Helgoländer Meeresalgen. I - VI. - Wiss. Meeresunters. (Helgoland) 16, $1-25$. 